\title{
Die Ei- und Embryonalentwicklung von Corydendrium parasiticum mit besonderer Berücksichtigung der Oocyten-Feinstruktur während der Vitellogenese
}

\author{
K. H. GLÄTZER \\ I. Zoologisches Institut der Justus-Liebig-Universität Gießen; \\ Gießen/Labn, Bundesrepublik Deutschland
}

\begin{abstract}
Egg and embryo development of Corydendrium parasiticum with special reference to fine structure of the oocytes during vitellogenesis. Egg and embryo development of Corydendrium parasiticum (L.) (Hydroida, Athecata) has been examined with special regard to ultrastructural changes of the oocytes during vitellogenesis. It has been established that ectodermal interstitial cells migrate through the mesolamella into the endoderm and differentiate there to germ cells. Despite differences in the origin of the interstitial cells during early development there is still justification to speak of ectodermal descent of hydroid germ cells. The gonophores are equivalent to hydranth buds. By early immigration, oocytes determine the development of buds into gonophores. After completion of vitellogenesis and rupture of the follicle epithelium eggs undergo meiosis. The total and equal segmentation starts already during spawning. After forming a solid morula, gastrulation takes place as moruladelamination. Interstitial cells and cnidoblasts are formed in the prospective endoderm and migrate early into the ectoderm. A polar differentiation becomes evident shortly before hatching of the planula. The planulae keep their solid endoderm untill their transformation into primary polyps. Metamorphosis can occur after one day. The delayed beginning of metamorphosis up to 12 days under lab conditions is probably due to the absence of certain bacteria. According to developmental stages of the oocytes ultrastructural changes during vitellogenesis are described. The endproducts of vitellogenesis are heterogeneous yolk ("Komplexdotter"), lipid droplets and glycogen. The "Komplexdotter" represents the bulk of reserve material which is formed by several components of different origin. Of special interest in this respect are the cytosomes resembling the microbodies of liver and kidney because of their paracristalline core and close relationship to the rough endoplasmic reticulum. Comparable cores exist in the "Komplexdotter" which may correspond to enzymes histochemically identified in the yolk of other species.
\end{abstract}

\section{EINLEITUNG}

Embryologische Studien an Hydroiden, die gegen Ende des vergangenen Jahrhunderts mit dem bedeutenden Werk von Metschnikoff (1886) einen Höhepunkt erreichten, sind erst in neuerer Zeit in verstärktem Umfang wiederaufgenommen worden (BÉnard-Botrard 1962, Nagao 1965, van de Vyver 1964, 1967, 1968 a, b, Bodo \& Bourlion 1968). Als Beginn dieser Untersuchungen kann man die mit den klassischen 
Mitteln der Lichtmikroskopie durchgeführte, umfassende Arbeit von MERGNER (1957) über die Ei- und Embryonalentwicklung von Eudendrium racemosum CAvoliNI ansehen.

Eine zusammenfassende Entwicklungsgeschichte von Corydendrium parasiticum (L.) (Hydroida, Athecata, Clavidae) fehlt bis heute. Die letzte ausführliche Arbeit über diese Hydroide stammt von Wersmann (1883), der allerdings das Hauptgewicht seiner Untersuchungen auf die Entwicklung der Keimzellen legt und die weitere Embryonalentwicklung nicht behandelt. Hauptsächlich die Herkunft der Keimzellen, die nach WeIsManN ektodermal sein könne, war später noch umstritten (HARGITT 1904, TRINCI 1906, Goetre 1907, KüHN 1914). Diese unterschiedlichen Deutungen erfordern eine erneute histologische Untersuchung, die vor allem die in den früheren Arbeiten nicht beachteten interstitiellen Zellen (I-Zellen) berücksichtigen muß. Uber die Embryonalentwicklung selbst gibt es nur bei HaRgITT (1904) und NePPI (1917) einige Angaben, die ebenfalls durch neue Befunde ergänzt und erweitert werden sollen.

Die Vielzahl elektronenmikroskopischer Arbeiten aus neuerer Zeit, die sich mit submikroskopischer Struktur von Oocyten beschäftigt (vgl. NørRevang 1968), gab zudem Veranlassung, die Vitellogenese eines marinen Hydroidpolypen zu untersuchen. Bislang erfolgten derartige Studien nur an Hydra (STAGN \& Lucci 1964), an der Anthomeduse Spirocodon saltatrix (KAW AGUTI \& OGASA WARA 1967) und an einer nicht näher bezeichneten Trachylinen (Kessel 1968a).

Aufgabe dieser Arbeit ist, die unterschiedlichen Auffassungen über die Eientwicklung von Corydendrium parasiticum zu klären und die Embryonalentwicklung zu vervollständigen. Die feinstrukturelle Untersuchung der Dotterbildung ist als erste Analyse und Basis für weitere Arbeiten gedacht.

\section{MATERIAL UND METHODE}

Im Golf von Neapel kommt Corydendrium parasiticum fertil in den Monaten August bis September vor. Die untersuchten weiblichen Stöcke wurden unter Verwendung eines Tauchgerätes bei dem Castello dell'Ovo aus 10-20 m Tiefe, bei Gaiola aus 3-6 $\mathrm{m}$. Tiefe und bei Nisida aus 5-15 $\mathrm{m}$ Tiefe gesammelt.

Die Hälterung der Tierstöcke erfolgte in einem temperaturkonstanten Raum $\left(17^{\circ} \mathrm{C}\right)$ in einem 100-1-Aquarium mit Umwälzpumpe und Eheim-Filter für Seewasser. Zusätzlich dienten durchlüftete Becken im gleichen Raum und ein 40-1-Aquarium mit Sandfilter im Labor (Wassertemperatur: $23^{\circ} \mathrm{C}$ ) zur kurzzeitigen Hälterung der Tiere und zu Zuchtversuchen. Gefüttert wurden täglich junge Artemia-Nauplien in dafür bestimmte Futterschalen.

Boveri-Schalen $(\phi 10 \mathrm{~cm})$ auf einem Schïttelgestell im temperaturkonstanten Raum ermöglichten die Planula-Zucht. Die Schalen waren mit 2 Prozent Agar-Seewasser ausgegossen, um die festsitzenden Primärpolypen zur Fixierung schonend ablösen zu können (BonNer 1955). Zur Vermeidung von Bakterienwuchs wurde dem Seewasser 0,03 Prozent Kanamycin zugesetzt. Dies hatte allerdings eine bedeutende Verzögerung der Metamorphose zur Folge.

Für die lichtmikroskopischen Untersuchungen dienten folgende Fixiergemische: 
Carnoy (Romeis 1948; $\$ 226)$, Fleming $(\$ 290)$, Champy $(\$ 298)$, Bouin $(\$ 304)$, Lang $(\mathbb{3} 31)$, Susa $(\$ 344)$, Zenker $(\$ 336)$, Helly $(\$ 337)$, Maximow $(\$ 338)$, 5 prozentiger Glutaraldehyd (SABATINI et al. 1963) und 5- bis 10prozentiges FormalinSeewasser. Susa ergab im allgemeinen die besten Ergebnisse. Die Einbettung erfolgte über Iso-Propanol oder -Butanol direkt in Paraplast, Tissuemat oder Histowachs. Die Schnittdicke betrug $5 \mu \mathrm{m}$. Zur Schnittfärbung eigneten sich besonders Eisenhämatoxylin nach HeIdenhain $(\mathbb{S} 663)$ zum Teil mit einer Eosin-Gegenfärbung, die Trichromfärbung nach GoldNER $(\$ 1540)$ und die panoptische Färbung nach PAPPENHEIM $(\$ 1437)$. Die Präparate wurden entweder mit Hilfe eines Zeichenspiegels von LEITZ gezeichnet oder mit einer Orthomat-Kamera auf einem Orthoplan-Mikroskop (beides von LEITZ) fotografiert.

Als geeignete Fixiermittel für die elektronenmikroskopischen Untersuchungen erwies sich das Gemisch von PALADE (1952). Da die Differenz zwischen dem stark hypotonischen Fixiergemisch (ca. $400 \mathrm{mOsm}$ ) und dem Seewasser (ca. $1100 \mathrm{mOsm}$ ) $700 \mathrm{mOsm}$ betrug, wurden dem Fixiermittel noch $23 \mathrm{mg} \mathrm{NaCl} / \mathrm{ml}$ zugesetzt. Die mit einem Advanced Instruments-Osmometer gemessene End-Osmolalität lag nach der Salzzugabe bei $1050 \mathrm{mOsm}(\mathrm{pH} 7,6)$. Fixiert wurde 1 Stunde bei $4^{\circ} \mathrm{C}$. Nach Auswaschen in der entsprechenden Pufferlösung wurden die Objekte über Aceton entwässert. Im Verlauf der Entwässerung fand eine Stückkontrastierung durch Zusatz von 1 prozentiger Phosphorwolframsäure und 0,5prozentigem Uranylacetat zum 70prozentigen Aceton statt (Wohlfarth-Bottermann 1957). Der letzten Aceton-Stufe (100 Prozent) folgte als Intermedium zweimal je 5 Minuten Epoxypropan. Anschließend wurden die Objekte direkt in reines Durcupan ACM übertragen. Die Polymerisationsdauer im Vakuumofen (100 bis 200 Torr) betrug bei $60^{\circ} \mathrm{C}$ etwa 48 Stunden.

Die Schnitte wurden auf einem Reichert OmU2-Ultramikrotom mit Glasmessern hergestellt. Schnittkontrastierungen erfolgten entweder mit Bleicitrat nach VENABLE \& Coggeshall (1965) oder mit einem Vanadiummolybdat-Komplex nach Callahan \& Horner (1964). Die Schnitte wurden mit einem Zeiss-EM 9 bei $60 \mathrm{kV}$ untersucht und auf Agfa-Agepe-FF-Planfilmen aufgenommen. Zur lichtmikroskopischen Kontrolle und zum Aufsuchen geeigneter Eistadien dienten Semi-Dünnschnitte von 0,5-1 $\mu \mathrm{m}$ Dicke, die mit Toluidinblau gefärbt wurden.

\section{UNTERSUCHUNGSERGEBNISSE}

\section{Architektur und Feinbau der Kolonie}

Die ersten Bearbeiter von Corydendrium parasiticum haben sich mit der Gesetzmäßigkeit des Kolonieaufbaus kaum befaßt; für sie war einzig die Faszikulierung bemerkenswert. CAvolinis erste Abbildung eines Corydendrium-Stockes (1785) zeigt eine unregelmäßige Verteilung der Aste mit dichotomen Verzweigungen. Bei WeIsManN findet sich die erste Beschreibung des Baues (1883, p. 35): „... ihre Verästelung (der Stöckchen) ist reich und erfolgt rein dichotomisch und in sehr spitzen Winkeln. Die Aste entspringen nach allen Richtungen und unregelmäßig vom Stamm." $\mathrm{Zu}$ einem anderen Ergebnis kommt Driesch (1890). Nach ihm ist die Verzweigung von Corydendrium parasiticum racemös, was auch von KüHN (1914) bestätigt wird. 
Diese unterschiedlichen Deutungen des Stockaufbaues resultieren aus den Schwierigkeiten, welche die „Faszikulierung“ des Stockes einer Analyse bereitet. Den Begriff „fascicled“ hat AlLMAN (1871, p. 262) am Beispiel von Corydendrium parasiticum geprägt, und er versteht darunter: „A composition out of many longitudinally coherent tubes, each invested by its own perisarc."

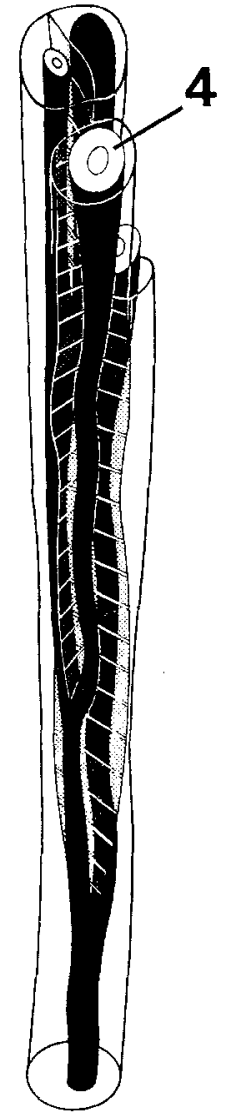

$\mathbf{a}$

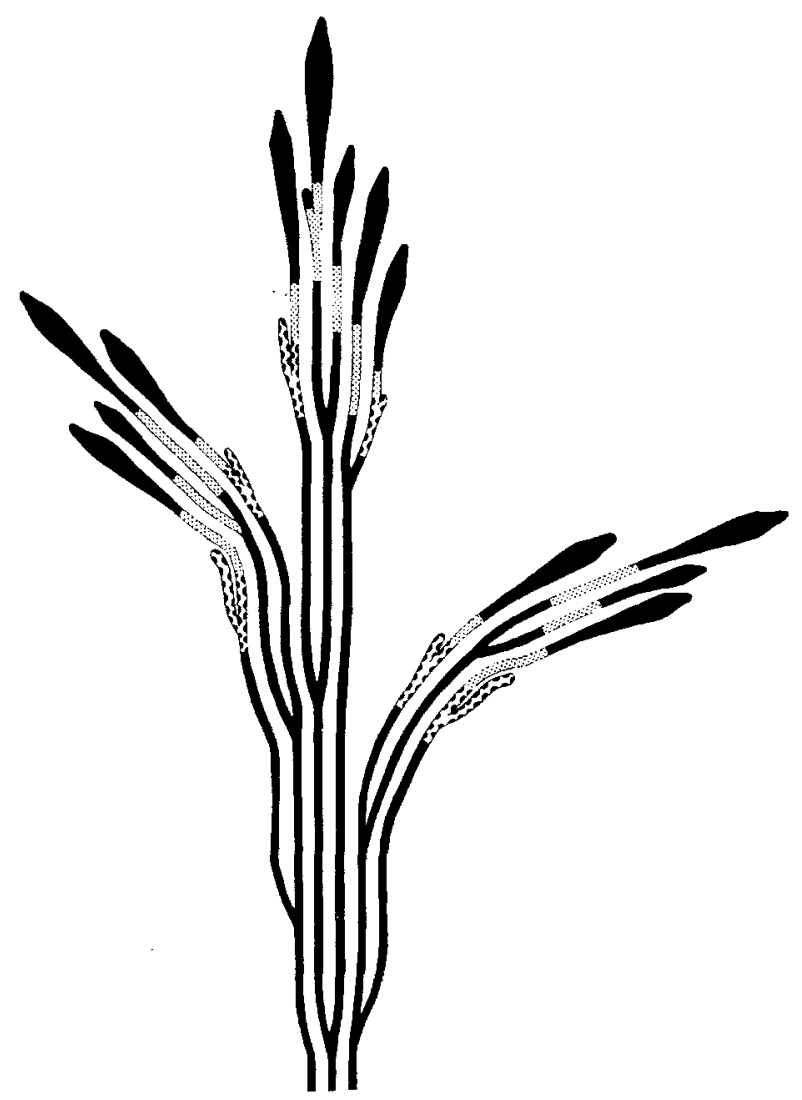

b

Abb. 1: a Rekonstruktion eines Zweigendes mittels ïbereinander projizierter Schnitte. Eingezeichnet ist nur das Entoderm (4); die Perisarc- "Septen“" stehen senkrecht aufeinander, die Verzweigungen erfolgen um $90^{\circ}$ zueinander versetzt $30: 1$; umgezeichnet von A. BLEICHNER, Gießen). $b$ Schema einer Kolonie. Die Gabelungen sind gleichwertig („dichotom"); Keimzonen punktiert, Gonophoren und Hydrocaulus-Abschnitte mit dotterbildenden Oocyten mit Randverdickungen; das Perisarc ist unberücksichtigt

Wie schon WeISMANN (1883) zeigte, entsteht die Faszikulierung nicht nur durch Verkittung von Perisarc-Röhren, sondern sie ist auch wachstumsbedingt. Entsteht nämlich an einem Hydranthenstiel eine Knospe, so bricht sie nicht sofort nach außen durch, sondern wächst innerhalb des alten, primären Perisarc einige Millimeter weiter. Gleichzeitig bilden das neue und das alte Coenosarc je eine neue Perisarc-Scheide, so daß im 
ursprünglichen, primären Perisarc zwei neue, sekundäre Perisarc-Röhren eingeschlossen liegen. Bei erneuten Knospenbildungen werden unter Umständen sogar tertiäre Röhren von sekundären und einer äußersten primären Röhre umgeben. Gleichzeitig erfolgen aber auch eine Verkittung von Asten durch einfache Anlagerung und eine Faszikulierung im Basalbereich der Kolonie durch Überwachsen mit Stolonen.

Corydendrium parasiticum bildet als Stockform Monopodien mit Endpolypen und subterminaler Knospung. Die Zugehörigkeit zu diesem Wuchstyp ist nicht ohne weiteres zu erkennen, da einige Kriterien der monopodialen Wuchsform fehlen. So besitzen alle Hydranthen einer fertilen Kolonie eine Keimzone und bilden zumindest an Seitenästchen alle Gonophoren aus. Nach WEISMANN sollten sogar „zu gewisser Zeit je ein Gonophor an jedem Hydranthen " entstehen. Das würde gegen die Gesetzmäßigkeiten des monopodialen Wuchses sprechen, da bei diesem der Haupthydranth definitionsgemäß steril ist. Ferner treten apikad oft ältere Entwicklungsstadien von Keimzonen beziehungsweise von Gonophoren auf als gegen die Stockbasis hin. Die altersmäßige Anordnung der Reproduktionsorgane folgt also keinem basal-apikalen Gradienten, wie es zum Beispiel das typische Monopodium von Eudendrium racernosum zeigt (Mergner 1957).

Die räumliche Rekonstruktion eines kleinen $Z_{\text {weigendes mit Hilfe übereinander }}$ projizierter Serienschnitte beweist die Gleichwertigkeit der Gabelungen (Abb. 1 a, vgl. auch Schema Abb. 1b). Doch kann auf das Vorliegen einer dichotomen Verzweigung nur bei einer gleichzeitigen Entstehung beider Knospen an einer terminalen Knospungszone geschlossen werden und nicht an Hand der Wachstumsergebnisse, wie dies WEISMANN offensichtlich tat. Erwähnenswert sind auch die Perisarc-,Septen“, die zwei Coenosarc-Stränge trennen und sich bei aufeinanderfolgenden Verzweigungen immer senkrecht zueinander bilden. Dadurch entstehen die Knospen immer um $90^{\circ}$ versetzt.

Über den prinzipiellen Gewebeaufbau der Hydroiden informiert sehr umfassend eine Arbeit von Boumlon (1968). Da die ebenfalls zu den Claviden gehörenden Gattungen Clava und Cordylophora histologisch schon eingehend untersucht wurden (Bourlion 1966, Tessenow 1960), soll an dieser Stelle nur eine kurze Beschreibung des histologischen Aufbaues von Corydendrium parasiticum erfolgen.

Am Hydranthen von Corydendrium sind folgende Zonen zu unterscheiden: das Hypostom, das Mauerblatt mit Tentakeln und der Hals*. Das Hypostom ist konisch gebaut und sehr erweiterungsfähig. Zum Ausstoßen unverdauter Nahrungsreste kann es sich weit nach rïckwärts über den Gastralhöhlenbereich stülpen, so daß die Tentakel fast vollständig bedeckt sind. Erleichtert wird dies durch entodermale Längsfalten (bei Hamann 1882: Taeniolen). Charakteristisch sind die beiden Drüsenzelltypen im Entoderm des Hypostoms: die Eiweißdrüsenzellen („cellules glandulaires spumeuse hypostomiales“, BouIllon 1963, 1968) und die Schleimzellen („cellules glandulaires sphéruleuses hypostomiales"). Im Bereich des Mauerblatts, wie auch im übrigen Coenosarc kommen nur noch die Eiweißdrüsenzellen vor. Diese liegen verstreut in der stark ausgebildeten Schicht entodermaler Epithelmuskelzellen, die überwiegend als Nährzellen

* Den Hydranthenhals von Corydendrium nennt WeIsmann "Cambiumzone". Da eine meristematische Funktion, wie es dieser historische Name impliziert, sicherlich nicht vorhanden ist, wird dieser Ausdruck nicht beibehalten. Als "Hals" bezeichnet WEISMANN die Übergangszone zwischen Mauerblatt und Hydranthenhals im hier gebrauchten Sinn. 
dienen. Außer durch die Gastralhöhle ist der auf das Hypostom folgende Hydranthenbereich durch die etwa 37 (30-45) regellos angeordneten, filiformen Tentakeln gekennzeichnet. Das Cnidom besteht aus zwei Cnidentypen: (1) Desmonemen (5 $\mu \mathrm{m} \times$ $3,1 \mu \mathrm{m})$ und (2) Stenotelen $(8,1 \mu \mathrm{m} \times 3,8 \mu \mathrm{m})$ (vgl. Werner 1965, Millard 1959).

Nach einer Übergangszone folgt auf das Mauerblatt der Hydranthenhals. Er entspricht der Sphinkter-Zone nach der Einteilung von Boulloon (1968) und ist durch hohen vakulären Entodermzellen ausgezeichnet. $\mathrm{Da}$ in diesem Bereich das Perisarc vom Ektoderm gebildet wird, könnten die offensichtlich turgeszenten Entodermzellen eine Art Stützentoderm darstellen, die den Übergang vom freien Hydranthen zum Perisarc umgebenen Coenosarc bilden. Der Übergang vom Hydranthenhals zum Coenosarc kann als Sphinkter angesehen werden, der die Passage größerer, unverdauter Nahrungspartikel in die Hydrocaulus-Kanäle verhindern soll. An dieser Stelle findet sich nämlich eine leichte Einschnürung; außerdem ist hier die entodermale Ringmuskelschicht im Vergleich zur Halszone am stärksten ausgebildet.

Muskelfasern der Epithelmuskelzellen sind nur im Hydranthen stark und offensichtlich schwächer im Coenosarc ausgebildet. Hydranth wie Tentakeln zeigen eine gut ausgebildete entodermale Ring- und eine ektodermale Längsmuskelschicht. Das Ektoderm des Hydranthen ist einschichtig. Zwischen seinen Zellen finden sich zahlreiche Cnidoblasten, vereinzelte I-Zellen und vor allem an den Tentakelbasen Sinnesnervenzellen.

Das Coenosarc von Corydendrium weist keine Besonderheiten auf und entspricht dem histologischen Bild, das schon mehrfach für Hydroiden beschrieben wurde. Auf den zum Coenosarc gehörenden Hydranthen-„Stiel“ mit seiner Knospungs- bzw. Keimzone wird an anderer Stelle eingegangen (vgl. pp. 220 ff.). In diesem Zusammenhang werden auch die ektodermalen I-Zellen und ihre Bedeutung für die Keimzellenbildung behandelt.

Die Feinstruktur der 0,5-0,7 $\mu \mathrm{m}$ dicken Mittellamelle von Corydendrium gleicht der von Eudendrium racemosum (HANISCH 1970): An ihr lassen sich die drei beschriebenen Strukturelemente unterscheiden: Grundsubstanz, Fibrillen und granulärer oder fibrillärer Randsaum. Die Fibrillen sind 70-100 ̊ dick und zeigen eine periodische Anordnung von Untereinheiten mit einem Abstand von etwa $75 \AA \AA$ (Abb. 10b). Besonders deutlich und in großer Dichte treten diese Fibrillen in den Verbindungsligamenten der Mittellamelle zum Perisarc auf. Diese Verbindungen sind von Mergner (1957) mehrfach bei Eudendrium racemosum als „brückenartige Stützlamellenligamente" dargestellt worden. Davis \& Haynes (1968) beschreiben ähnliche Fibrillen, die „periodische Schwellungen“ aufweisen und so ein perlschnurförmiges („beaded“) Aussehen bekommen, aus der Mesogloea von vier Hydra-Arten. Von den drei beschriebenen Fibrillen-Typen soll dieser in der Mesogloea der untersuchten Hydren vorherrschen.

Das gesamte Ektoderm eines Hydranthen einschließlich der Tentakeln ist von einer dünnen Peridermschicht bedeckt (Abb. 2), die häufig auch Cuticula genannt wird und am Anfang der Halszone kontinuierlich in das Perisarc übergeht*. Auf Paraffin-

* Der Terminologie von Bouillon (1968) folgend, wird die Chitin-enthaltende Hülle des Coenosarc "Perisarc“ genannt, die dünne, hauptsächlich aus Mucoproteiden bestẹhende Schicht des Hydranthen-Ektoderm "Periderm“" 


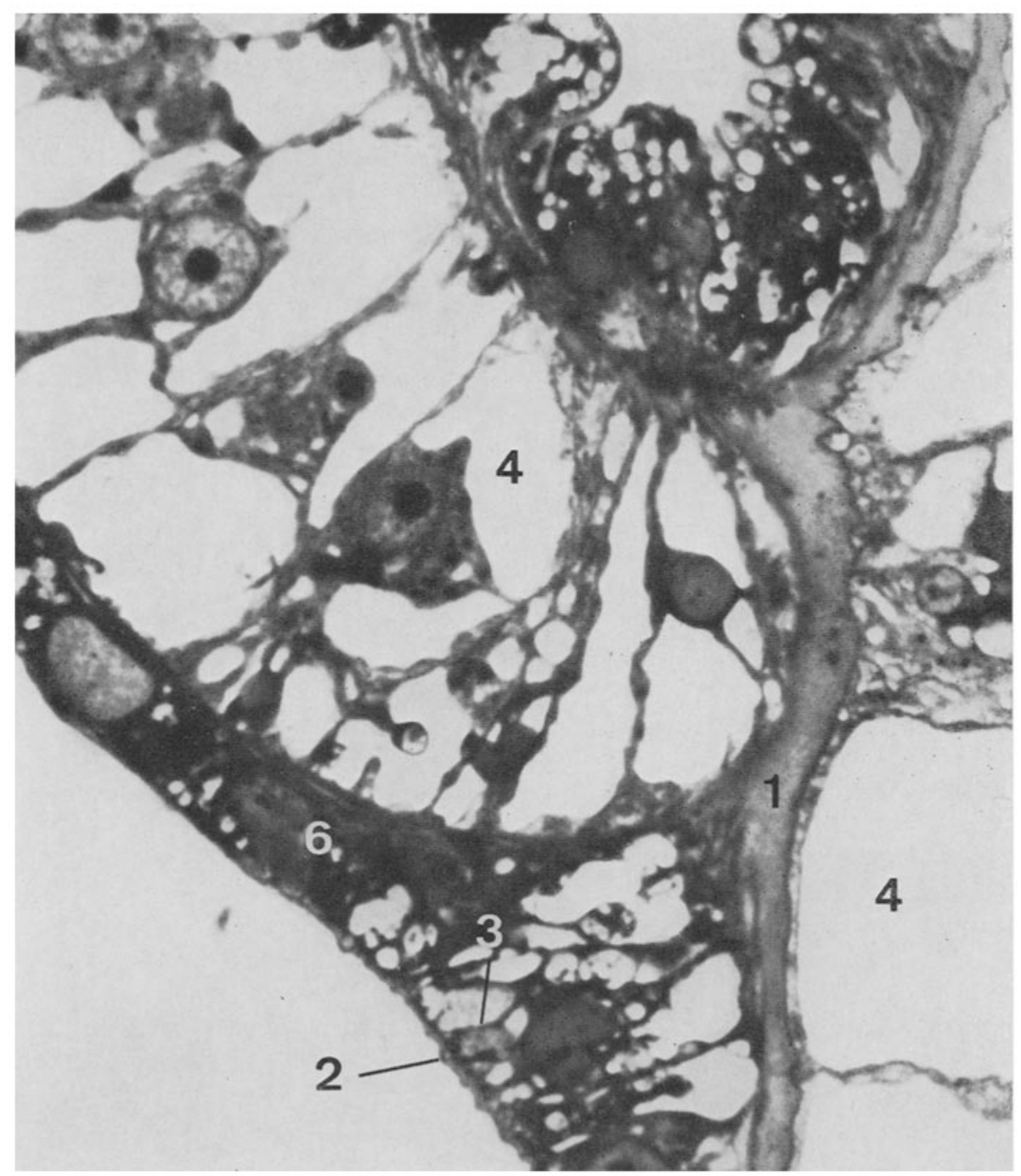

Abb. 2: Medianschnitt durch eine Tentakelbasis. Die dünne Periderm-Schicht (2) wird durch das in den Ektodermzellen sichtbare Sekret (3) gebildet. 1 Mittellamelle; 4 Entoderm; 6 Ekto$\operatorname{derm}(1700: 1)$

schnitten ist der Übergang oft nur schwer sichtbar. Das Perisarc beginnt im Schnittbild scheinbar unvermittelt als eine dünne, geknäulte Lamelle in einer kleinen Ektoderm-Einbuchtung des Hydranthenhalses. Die Ektodermzellen werden hier plötzlich größer und vakuolärer als die distad liegenden. Ferner treten in dieser Zone auf einmal dichte Ansammlungen von 0,9-2,2 $\mu \mathrm{m}$ großen Grana vor allem in den distalen Teilen der Ektoderm-Zellen auf (Abb. 6a), die auch überall im Ektoderm des Coenosarc zu funden und mit sauren Farbstoffen (zum Beispiel Azocarmin, Ponceau und 
andere) stark anfärbbar sind. Ihre Beteiligung an der Perisarc-Bildung wurde schon von Mergner (1957) erkannt. Eine eingehendere feinstrukturelle Untersuchung der Periderm-Bildung ist zum erstenmal von $\mathrm{HANISCH}_{\mathrm{A}}(1970)$ an Eudendrium racemosum durchgeführt worden. Mit seinen Ergebnissen verglichen, weist Corydendrium parasiticum bedeutende Unterschiede auf. Zudem zeigen elektronenmikroskopische Aufnahmen der Perisarc-Bildungszone von Corydendrium (Abb. 3b), daß lichtmikroskopisch dargestellte cytologische Details oft einen falschen Eindruck von der zellulären Substruktur geben. Dabei muß freilich vorausgesetzt werden, daß der Erhaltungszustand der für die elektronenmikroskopische Betrachtung vorbehandelten Zellen den Vitalstrukturen besser entspricht als die von Paraffinschnitten.

Auf Semi-Dünnschnitten sind im Bereich der Perisarc-Bildungszone keine Grana zu entdecken. Statt dessen finden sich mit Toluidinblau metachromatisch anfärbbare Tröpfchen, die teilweise konfluieren und dann einen Durchmesser bis zu $5 \mu \mathrm{m}$ erreichen können (Abb. 3a). Derartige Tröpfchen sind in allen Ektodermzellen zu finden, das heißt auch das Periderm des Hydranthen entsteht auf gleiche Weise wie das Perisarc des Hydrocaulus. Der Übergang vom Perisarc zum Periderm ist nur durch eine Abnahme der Tröpfchengröße, vor allem aber ihrer Lagerungsdichte, gekennzeichnet. Das unterschiedliche Bild der im Lichtmikroskop sichtbaren Grana beruht daher vermutlich auf einem Konzentrationsphänomen während der Fixierung. Osmiophile Sekretgrana, wie sie HaNISCH beschreibt, konnten nicht gefunden werden. Auch läßst sich eine Beteiligung bestimmter Organellen, wie etwa des Golgi-Apparates oder des endoplasmatischen Retikulums, an der Sekretbildung nicht erkennen. Bereits auf SemiDünnschnitten sind im Inneren der Sekrettröpfchen dunkle Einschlüsse bemerkbar, die sich im Elektronenmikroskop als parakristalline Strukturen erweisen (Abb. 3a). Ahnlich wie jene in den Cytosomen der Oocyten setzen sie sich aus tubulären Elementen von $225 \AA$ Durchmesser zusammen. Insgesamt ähneln daher die Tröpfchen verblüffend den Cytosomen (zum Beispiel Abb. 18), die ebenfalls auf Paraffinschnitten als Grana in Erscheinung treten.

Über den Vorgang der Perisarc-Bildung können zur Zeit noch keine Aussagen gemacht werden; zudem führen sie auch über den notwendigen Rahmen dieser morphologischen Übersicht hinaus. Das von Corydendrium gebildete Perisarc ist im Gegensatz zu dem von Eudendriwm nicht so heterogen aufgebaut: $Z$ wei dichtere, dünne Schichten, von denen die äußere zu Beginn der Halszone in das Periderm übergeht, begrenzen beiderseits den zentralen Hauptanteil der strukturlosen Perisarc-Substanz (Abb. 3b). Auch auf Semi-Dünnschnitten sind die begrenzenden Schichten als dunkel gefärbte Linien sichtbar. Auf jeden Fall stellt die im Lichtmikroskop sichtbare, lamelläre Struktur des Corydendrium-Perisarc eine Vergröberung der tatsächlichen Strukturverhältnisse dar.

\section{Entstehung und Wanderung der Eizellen}

Zur Zeit der Reife sind unterhalb der Hydranthen Zonen erkennbar, die sich durch eine leichte Verdickung deutlich von den anschließenden Hydrocauli abheben. Das Gewebe ist hier stärker pigmentiert und erscheint kompakter als in den angren- 

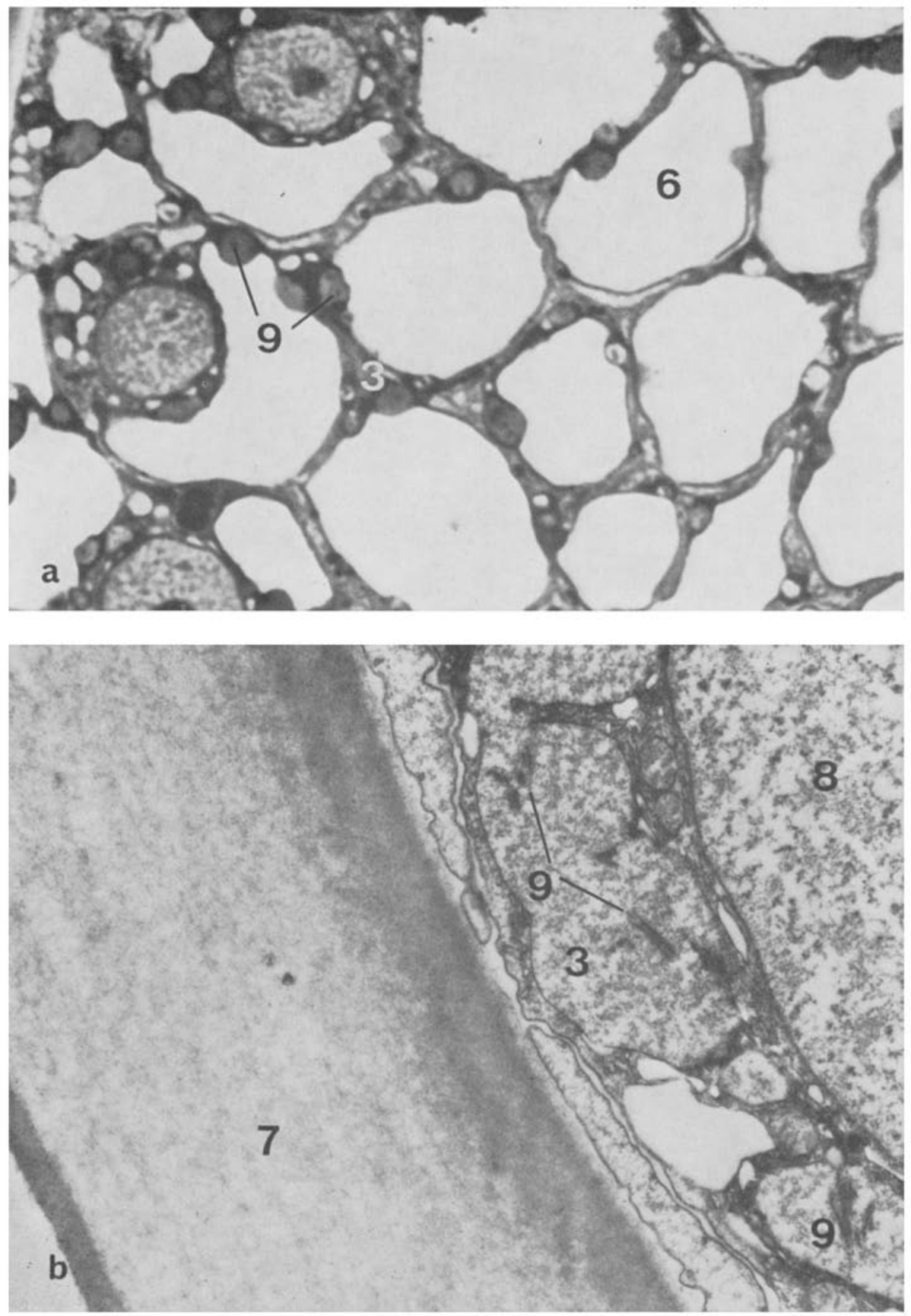

Abb. 3: a Schrägschnitt durch eine Perisarc-Bildungszone. Die Sekrettröpfchen zeigen dunkelgefärbte Einschlïsse (1900:1). $b$ Ektodermzelle mit anliegendem Perisarc. Die Sekrettröpfchen zeigen parakristalline Binnenstrukturen, die den dunklen Einschlüssen auf $b$ entsprechen. 3 Sekrettropfen; 6 Ektoderm; 7 Perisarc; 8 Kern; 9 Innenstruktur (14000:1:) 
zenden Hydrocaulusabschnitten. Ursache dieser Veränderung ist die Entstehung der Keimzellen in diesem Hydrocaulusbereich. WeIsMANN (1883) nennt ihn darum „Keimzone". Sie schließt sich unmittelbar der Kambiumzone eines Hydranthen an. Da auch tentakellose Hydranthenknospen schon Keimzellen besitzen, liegen diese zunächst in der Nähe des Knospenansatzes. Mit zunehmendem Alter bzw. Wachstum des Hydrocaulus wandert die Keimzone mit dem Hydranthen apikad. Doch sind später immer noch einzelne Oocyten über den ganzen Hydrocaulus verstreut $\mathrm{zu}$ finden, das heißt außerhalb der eigentlichen Keimzone.

Uber die Frühentwicklung der Keimzellen bei Corydendrium und über deren Herkunftsort gibt es, wie auch bei anderen Hydroidenarten, widersprechende Angaben. Weismann hält eine ektodermale Entstehung für wahrscheinlich, GoEtTE (1907) will hingegen beobachtet haben, daß sich Entodermzellen direkt in jeweils eine somatische Zelle und eine auf der Mittellamelle liegende Eizelle teilen. Unbestritten ist von allen Autoren die Tatsache, daß die jüngsten erkennbaren Eizellen immer im Entoderm liegen. WEISMANN schließt vor allem auf Grund seiner Theorie der Keimstättenverschiebung auf eine ektodermale Herkunft und versucht sie durch die Beobachtung zu stiitzen, daß Eizellen immer auf der Mittellamelle und unter Entodermzellen liegen. TRINCI (1906) führt das Problem zunächst auf die Frage zurück, welches die erste erkennbare Phase der Keimzellenbildung überhaupt sei. Er weist als erster auf die Bedeutung der Prophasestadien während der Meiose bei den Coelenteraten hin („periodo di sinapsi nucleare"), was später allerdings gänzlich in Vergessenheit geriet. Trincr selbst sagt aber, daß damit das Problem des Keimzellenursprungs bei den Coelenteraten noch nicht gelöst sei. Im Augenblick könne man nur sagen, daß nicht der Ursprung, sondern der Aufenthaltsort der Keimzellen zu Beginn der Wachstumsperiode variiere.

Eine große Bedeutung als embryonale Zellreserve und damit als potentielle Geschlechtszellen wird den I-Zellen beigemessen. Es kann heute als gesichert gelten, daß die Keimentwicklung der Hydroiden von diesen I-Zellen ihren Ausgang nimmt. MüLler (1967) konnte zudem bei Hydractinia nachweisen, daß das Geschlecht der I-Zellen und damit ihre prospektive Potenz zur Bildung von Eizellen bzw. Spermien genetisch determiniert ist. Damit bleibt aber die Möglichkeit einer Re- und Umdifferenzierung der restlichen Hydroidenzelltypen offen. Diese haben jedoch ihre Entwicklungspotenz zu Cnidoblasten und Keimzellen während ihrer Differenzierung für immer verloren.

Für Hydra allerdings verneinen BurnetT et al. (1965) eine Keimbahn. Den Verfassern zufolge kommt es zu keiner Sonderung von bestimmten Gruppen von I-Zellen. Differenzierte entodermale Drüsenzellen können sich unter geeigneten Bedingungen entdifferenzieren und über ein I-Zellen-Stadium zu Gescblechtszellen werden.

I-Zellen kommen fast nur im Ektoderm vor. In den Fällen, bei denen sie im Entoderm beschrieben wurden, handelt es sich meist entweder um embryonale Drüsenzellen, die im Gegensatz zu den I-Zellen eine „funktionelle Basophilie“ (TEssenow 1960) aufweisen, oder es sind schon junge Keimzellen. Besonders junge Spermatogonien sind leicht mit I-Zellen zu verwechseln (MülLER 1964, HANISCH 1970). Doch sollte der Name „interstitielle Zelle“ den totipotenten Zellen im Ektoderm vorbehalten bleiben. TEssenow (1960) grenzt ebenfalls die „omnipotenten, indifferenten Zellen" von Um- 

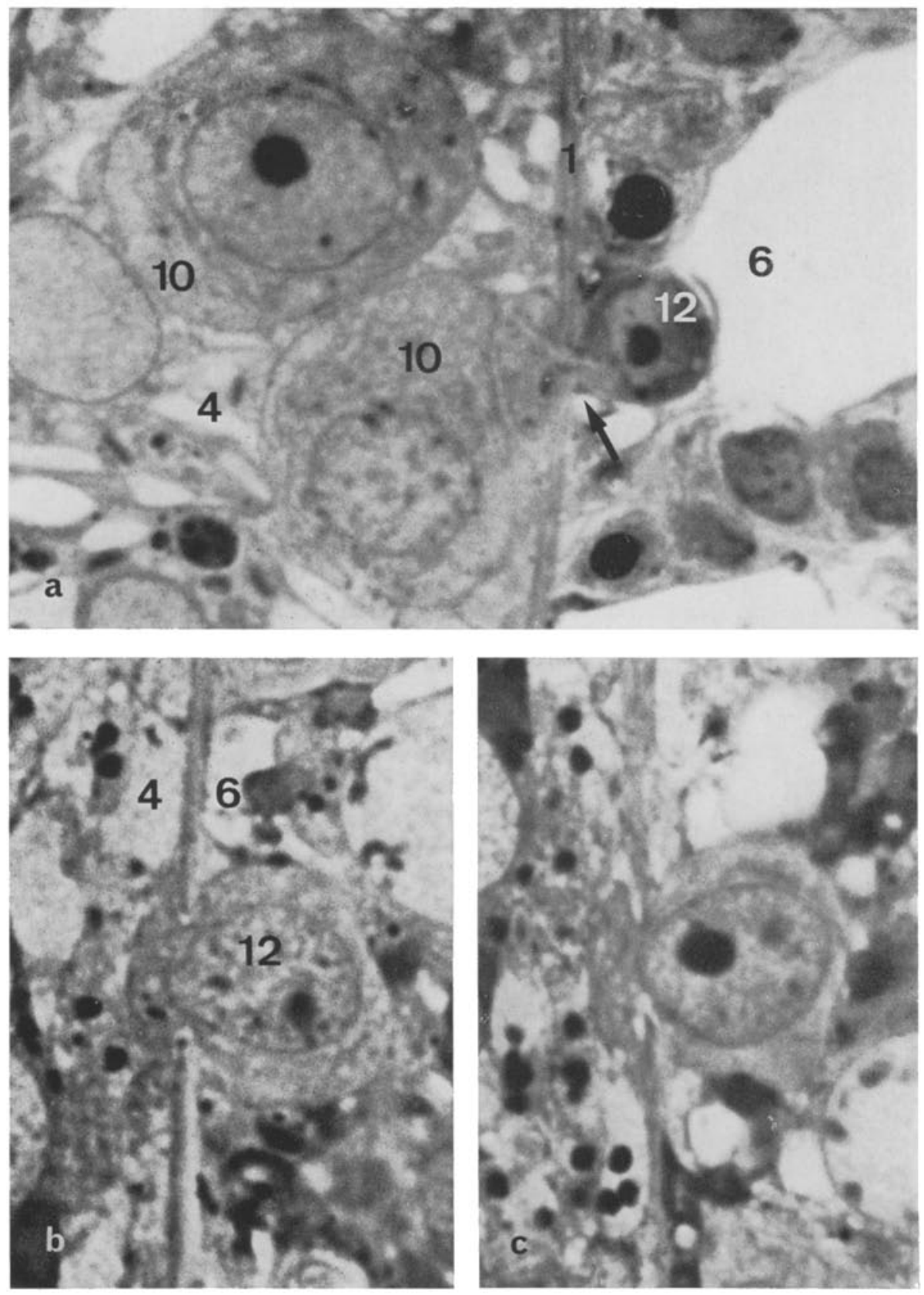

Abb. 4: a Keimzone mit zwei Oocyten im Entoderm und einer durch die Mittellamelle kriechende I-Zelle (Pfeil) (2700:1). $b$ Aus dem Ektoderm in das Entoderm wandernde I-Zelle in einer Hydranthen-Knospe (2800:1). $c$ Gleiche Zelle wie in b, jedoch im Schnitt tiefer getroffen (2800:1). 1 Mittellamelle; 4 Entoderm; 6 Ektoderm; 10 Oocyte; 12 I-Zelle 
bildungsstadien der I-Zellen ab, läßt aber für alle Formen den Oberbegriff I-Zelle bestehen.

Im Ektoderm der Keimzone von Corydendrium lassen sich lichtmikroskopisch drei Arten von I-Zellen unterscheiden:

(1) Zellen, die in pyramidenförmigen Nestern auf der Mittellamelle liegen und in erster Linie das Cnidoblasten-Reservoir bilden (Abb. 8). Von diesen I-Zell-Nestern stammen wahrscheinlich auch die beiden folgenden Typen ab.

(2) Langgestreckte Zellen mit flach-ovalen Kernen, die mit ihrer Längsseite der Mittellamelle dicht anliegen und eindeutig auf dieser zum Ort ihres Bedarfs entlangwandern. Sie sind von den wandernden Cnidoblasten gut unterschieden.

(3) Einzelne oder in Gruppen liegende Zellen, die durch ihren runden Zellkörper mit einem großen Kern ihre embryonale Natur deutlich zu erkennen geben. Sie sind offensichtlich, wie die I-Zellen in den Nestern, zunächst stationär. Dieser Zelltyp stellt vermutlich die prospektiven Keimzellen dar.

Um sich nun im Entoderm endgültig zu Keimzellen zu differenzieren, müssen diese Zellen durch die Mittellamelle ins Entoderm einwandern. KiRCHNER (1935) veröffentlicht als erster eine halbschematische Zeichnung einer die Mittellamelle passierenden I-Zelle, wobei letztere allerdings Entodermzellen-Ersatz darstellen soll. Indirekt ist die Einwanderung durch die relative Abnahme der I-Zellen in der Keimzone von Hydractinia echinata ebenfalls nachgewiesen worden (MüLLER 1964). Bei Corydendrium parasiticum wurden durch die Mittellamelle kriechende I-Zellen in Semi-Dünnschnitten gefunden und fotografiert (Abb. 4). Im einen Beispiel handelt es sich um die entstehende Keimzone einer Hydranthen-Knospe. Ein Ausläufer der durchkriechenden $6 \mu \mathrm{m}$ großen I-Zelle hat das Entoderm schon erreicht und ihr Kern befindet sich in Höhe der Mittellamelle (Abb. 4b, c). Wäre dies der einzige Beleg eines Zelldurchtrittes, ließe sich über die Wanderrichtung und prospektive Bedeutung dieser Zelle streiten. In der in verstärktem Wachstum befindlichen Hydranthenknospe liegen nämlich ähnliche Zellen auch im Entoderm. Ein weiterer Durchtritt konnte jedoch in einer voll ausgebildeten Keimzone beobachtet werden (Abb. 4a). In diesem Fall wird die Beziehung zu den im Entoderm benachbart liegenden Eizellen deutlicher. Für eine Wanderrichtung in das Entoderm spricht ebenso wie im ersten Fall der amboßförmige Ausläufer der durchtretenden Zelle. Dies ist keineswegs die Form, die man erwartet, wenn ein Zellteil sozusagen noch nachgezogen wird (vgl. Schema in Abb. 5c). Der Ausläufer muß die im Wege liegenden Entodermzellen wegdrücken und wird infolgedessen abgeplattet und amboßförmig. Damit bekommt die Zelle an der Mittellamelle ein Widerlager, das es dem weniger flexiblen, voluminösen Kern im restlichen Teil der Zelle ermöglicht, gegen den Widerstand der Mittellamelle in das Entoderm durchzutreten. In Paraffinschnitten konnte ein Durchtreten nicht eindeutig gefunden werden. Dies hängt in erster Linie von der Schnittdicke $(5 \mu \mathrm{m})$ und damit von dem zu großen Bereich für die Fokusebene im Lichtmikroskop ab. Zudem erschweren die lichtoptisch weniger distinkt als die elektronenmikroskopisch darstellbaren Zellgrenzen das Auffinden solcher Stadien.

Im Zusammenhang mit dem Durchtritt der I-Zellen taucht die Frage nach Perforationen in der Mittellamelle auf, die einen Austausch von Zellen ermöglichen könnten. Wie im Kapitel zur allgemeinen Morphologie von Corydendrium wird davon abgesehen, von einer Stützlamelle zu sprechen, die als starres Bindeglied zwischen Ekto- und 
Entoderm besteht. Uberwiegend dient das Geflecht von Fibrillen, das in einer Grundsubstanz liegt und von beiden Blättern gebildet werden kann, als Gleitsubstanz für die bei vielen Hydroiden nachgewiesene Wanderung verschiedener Zelltypen zum fortwährenden Auf- und Umbau des Stockes (z. B. SHostak et al. 1965, 1966). Es besteht

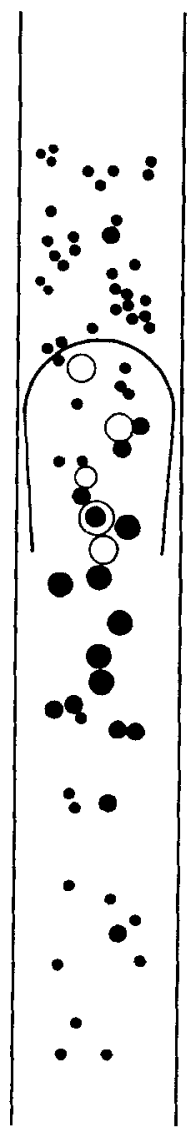

a

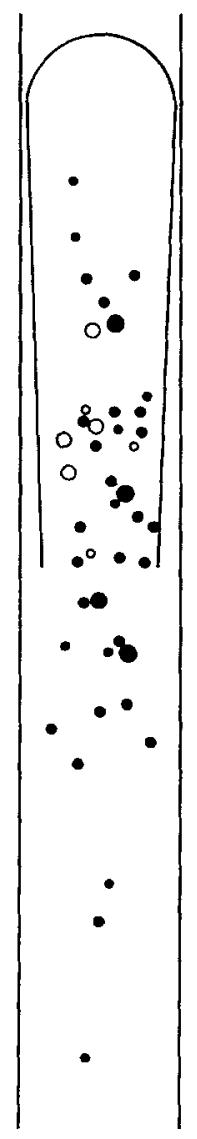

b

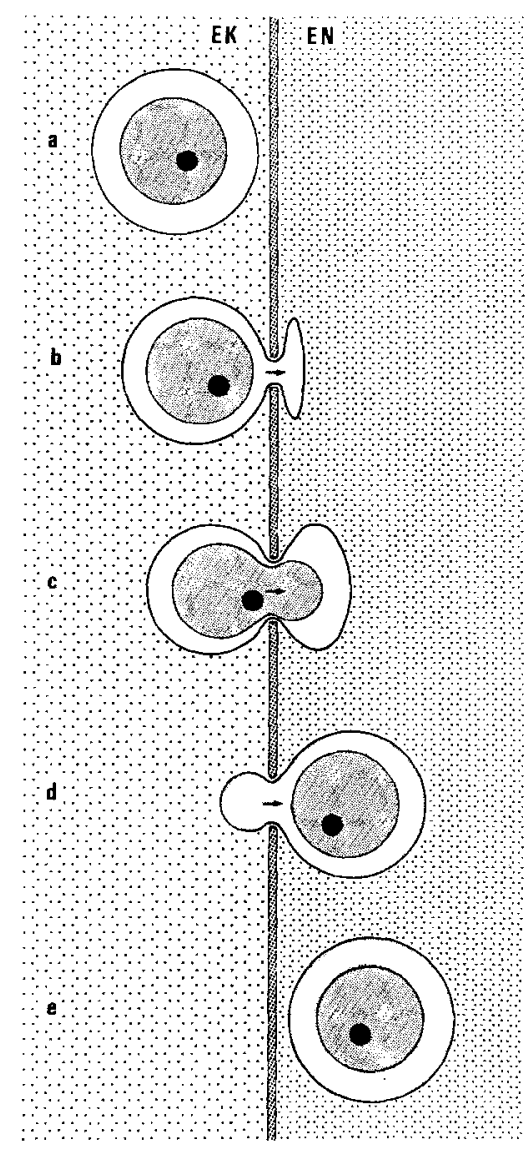

C

Abb. 5: Schema zur Knospen-Determination. a Entwicklung zu einem Gonophor (90:1). $b$ Entwicklung zu einem Hydranthen. Eikerne im Hydrocaulus entsprechend ihrer Größße als Punkte, in den Knospen als Kreise dargestellt (90:1). c Schema der Einwanderung einer I-Zelle (a-e) aus dem Ektoderm EK durch die Mittellamelle ins Entoderm EN

kein Grund, an der Fähigkeit der sehr beweglichen und amöboid verformbaren Hydroiden-Zellen zu zweifeln, dieses Fibrillen-Geflecht beim Passieren auseinanderzudrücken, um sich so einen Durchgang zu schaffen. Die lichtoptisch von Mergner (1957) und Müller (1967), elektronenmikroskopisch von Hess (1961) und HANISCH (1970) beschriebenen und auch bei Corydendrium zu beobachtenden Poren in der Mittellamelle sind offensichtlich beständigere Verbindungen zwischen Ekto- und Entoderm, die wahr- 
scheinlich dem Nahrungsaustausch dienen (Abb. 8). Der im lichtoptischen Bild zu rechtfertigende Begriff „Pore“ ist im elektronenmikroskopischen Bild nicht mehr zutreffend, da es sich hier um keine Offnung der Mittellamelle handelt, sondern das Ergebnis der durchtretenden Zellausläufer ist. In jedem Fall sind „Poren“ für den Zellaustausch, insbesondere beim Wechsel der prospektiven Keimzellen aus dem Ekto- in das Entoderm, bedeutungslos.

Auch wenn die Herkunft der Keimzellen aus ektodermalen I-Zellen gesichert ist, kann für diese I-Zellen der Begriff Urkeimzelle oder im weiblichen Geschlecht später Oogonie noch nicht angewandt werden. Zur Zeit ist eine eindeutige Charakterisierung dieser prospektiven Keimzellen im Vergleich zur Masse der anderen I-Zellen im Ektoderm noch nicht möglich. Das Prädikat Oogonie kann ihnen daher erst im Entoderm zugesprochen werden. Im allgemeinen werden als Oogonien die Eizellen in der Vermehrungsphase bezeichnet. Im Ektoderm der Keimzone sind äußerst selten Mitosen zu beobachten, wobei unentschieden bleiben muß, ob es sich um Teilungsstadien von Ioder von Ektodermzellen handelt. Vergleichsweise häufig sind jedoch Mitosen im Entoderm zu finden, so daß der Schluß berechtigt erscheint, ein Teil der eingewanderten I-Zellen teile sich mindestens einmal. Dies erklärt auch das häufige Auftreten von kleinen Nestern aus zwei oder drei Oogonien. Eine ausgeprägte Vermehrungsphase findet offenbar aber nicht statt. Die Oogonien treten bald nach Erreichen des Entoderms in die Prophase der Meiose ein und werden zu Oocyten I. Ordnung.

Prophase-Stadien der Meiose, besonders Stadien um das Leptotän, kennzeichnen die zuküntigen Eizellen eindeutig als solche. Die hierfür typische Kernstruktur erleichtert das Auffinden der sehr jungen Eizellen. Diese Zellen liegen einzeln oder in kleinen Gruppen im Entoderm. Liegen sie einzeln, können sie in den Verband der Entodermzellen eingeordnet sein, oder sie befinden sich unmittelbar unter einer Entodermzelle (Abb. 4a). Daraus resultiert ein Bild, das WeIsmanN zur Vermutung veranlaßte, daß die Keimzellen aus dem Ektoderm stammen und nach ihrem Durchtritt dann notgedrungen unter Entodermzellen zu liegen kommen. GoETTE interpretiert die Lage als Folge einer ungleichmäßigen Teilung einer Entodermzelle in eine proximale Ei- und eine distale, zukünftige Follikelzelle. Es können aber auch zwei Eizellen übereinander liegen. Gruppen von drei bis vier Eizellen sind ebenfalls nicht selten, was mit Goetres Annahme kaum in Einklang zu bringen ist. Ein Unterschied in der Nucleolen-Anzahl, wie ihn WEISMANN zwischen einzeln und in Gruppen liegenden Keimzellen beschreibt, konnte nicht gefunden werden. Auch trifft seine Beobachtung nicht zu, daß das Entoderm in der Keimzone immer mehrschichtig ist.

Sehr bald verlieren die jungen Eizellkerne ihre Prophase-Struktur, und es zeigen sich die ersten Anzeichen der Dotterbildung in Form granulärer Einlagerungen. Die Dotterbildung ist ausführlich auf den Seiten $238 \mathrm{ff}$. beschrieben worden, so daß hier auf lichtmikroskopische Ei-Strukturen nicht mehr näher eingegangen werden soll. Auch der Versuch einer Homologisierung der durch beide Techniken sichtbaren Einzelheiten kann hinsichtlich der lichtmikroskopischen Deutung der Vitellogenese nur mit Einschränkungen übernommen werden, wenn man von spezifischen histochemischen Nachweisen absieht. Die sich im Entoderm entwickelnden Eizellen wandern auf der Mittellamelle in Richtung der Gonophor-Bildungszone, die etwa in der Mitte der Keimzone liegt. Pseudopodienartige Ausläufer der Wander-Oocyten schieben sich zwischen die Entoderm- 
zellen und deuten auf eine sehr aktive Bewegung hin (vgl. Mergner 1967, Rebhun 1963). Allerdings konnten im elektronenmikroskopischen Bild mit den angewandten Präparationsmethoden keine Strukturen nachgewiesen werden, auf die sich die Beweglichkeit der Wanderoocyten zurïckfïhren ließe.

\section{Gonophoren-Entwicklung und Endwachstum der Oocyten bis zur Befruchtung}

Jeder Hydranth einer fertilen Kolonie besitzt seine eigene Keimzone, die jeweils ein Gonophor mit Oocyten versorgt. Ist das Gonophor einmal gebildet, kann sich der dazugehörende Hydrocaulus bis zum Ende der Reifezeit nicht mehr verzweigen. Das Wachstum beschränkt sich dann auf interkalare Streckung des Hydrocaulus und eine Verlängerung des Gonophors. Bei stärkerem Wachstum des Hydrocaulus mit nachfolgender Verzweigung bliebe nämlich das Gonophor im tieferen Perisarc liegen und könnte später nur noch unter extremer Verlängerung des Halsteils des sich entfernenden Hydranthen zur Abgabe der Eier erreichen. Falls die Kolonie jedoch weiterwächst, ist zu folgern, daß der Endhydranth eines Zweiges kein Gonophor bildet, obwohl er eine Keimzone mit sich entwickelnden Oocyten besitzt. Der Hydrocaulus bildet statt dessen an dieser Stelle eine Hydranthenknospe, die der Gonophoren-Knospe makroskopisch gleicht. Auf Grund ihrer Lagegleichheit läßt dies zunächst den Schluß zu, daß beide homologe Gebilde sind: Das Gonophor ist vermutlich eine phyletisch modifizierte Hydranthenknospe. Ahnlich schreibt schon Motz-KossowskA (1905, p. 62): „.. ceux (des gonophores) de Corydendrium ne dépassent pas la valeur d'un rameau, à l'intérieur du quel les produits sexuels subissent leur évolution sans qu'il y ait formation des gonophores. "Und obwohl GoETTE (1907) die Gonanthen von Corydendrium parasiticum ebenfalls für „nichts weiter“ als Hydranthen-Knospen hält, deren ursprünglich normale Entwicklung durch die Einwanderung von Keimzellen mehr oder weniger abgeändert wurde, zieht KüHN $(1910,1914)$ die phylogenetische Stellung dieser Gonophoren noch einmal in $Z$ weifel, da alle vermittelnden Übergänge fehlten.

Es stellt sich nun die Frage, warum aus einer Zone, die Eizellen hervorbringt, einmal ein Gonophor und einmal eine Hydranthen-Knospe hervorgeht. Ein augenfälliger Unterschied zwischen beiden Möglichkeiten besteht darin, daß, wie bei Eudendrium (vgl. Mergner 1957, pp. 81 ff.) schon eine kleine Gonophoren-Ausstülpung von Oocyten in der Größenordnung von $50 \mu \mathrm{m}$ erfüllt wird. Entsprechend große HydranthenKnospen weisen hingegen niemals Eizellen auf. Erst nach einer gewissen Längsstreckung liegen im proximalen Teil der Knospe etwa $30 \mu \mathrm{m}$ große Eier (Abb. 5b). Außerdem weist der distale Knospenbereich allein schon durch sein dichteres Gewebe auf den zukünftigen Hydranthen hin. Es erscheint daher möglich, daß eine Knospe durch Oocyten von einer bestimmten Größe ab zu einem Gonophor bestimmt wird. Eine HydranthenKnospe erhält dagegen nur auf Grund ihrer gleichartigen Entstehung am entsprechenden Ort kleinere Oocyten aus der Keimzone des Endhydranthen. Diese Oocyten sind vermutlich mit jenen identisch, die später verstreut im Hydrocaulus auftreten, wenn der Seitenzweig seine eigene Keimzone gebildet hat. Ein Grund, warum Oocyten des Endhydranthen eine gewisse Größe nicht überschreiten, könnte im raschen interkalaren 
Wachstum liegen, das ein Heranwachsen der Eizellen bis zu einer bestimmten Mindestgröße verhindert. Neue Knospen werden schon gebildet, ehe genügend große Eizellen diese zu Gonophoren bestimmen könnten. Dafür spräche auch, daß Endhydranthen 1. Ordnung relativ weniger Eier in der Knospungszone aufweisen als Endhydranthen
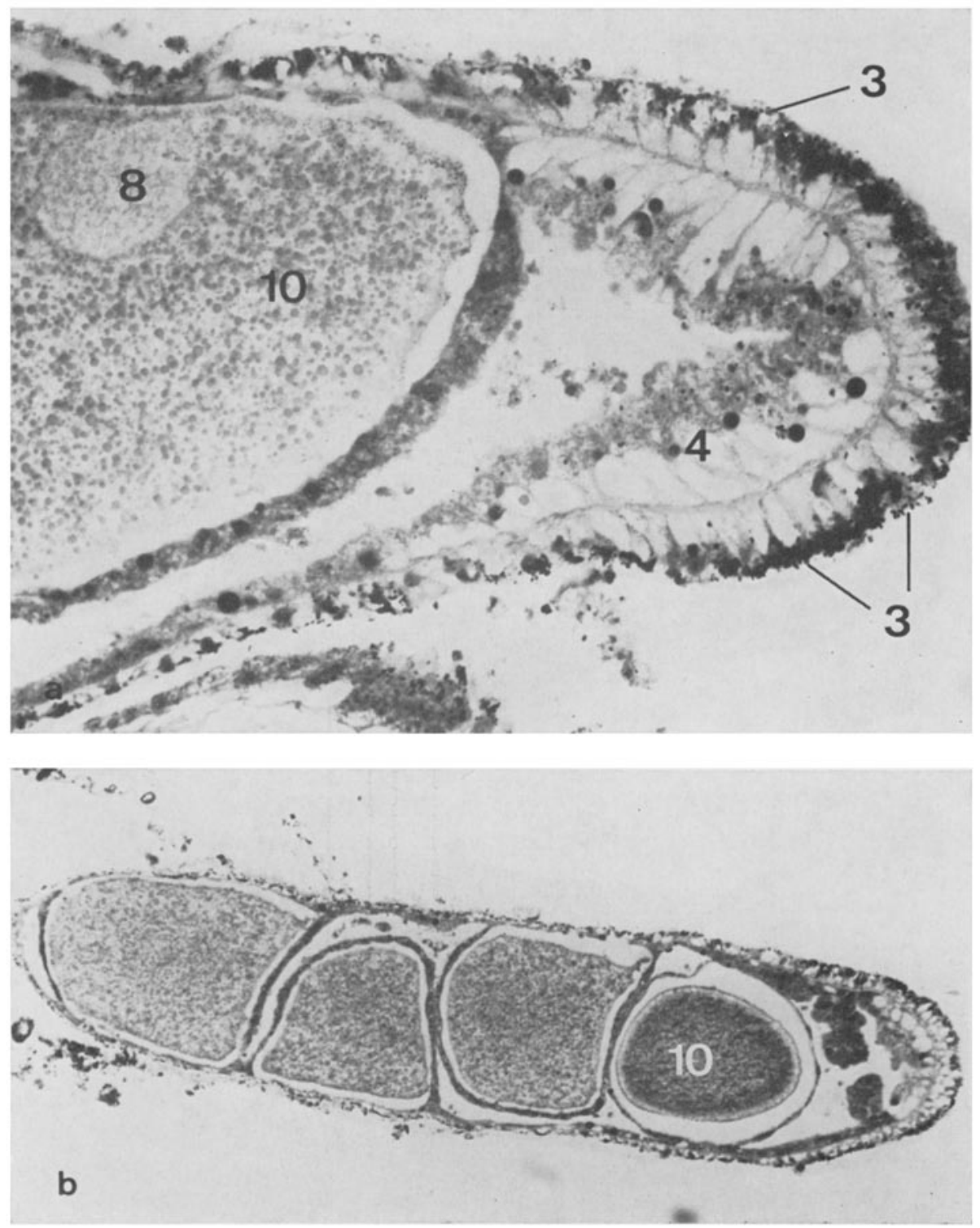

Abb. 6: a Spitze eines reifen Gonophors. Starke Anhäufung von Sekretgrana (3) im Ektoderm $(360: 1)$. $b$ Reifes Gonophor. Eizelle an der Spitze (10) nach vollzogener RichtungskörperBildung mit deutlicher Rindenzone. 4 Entoderm; 8 Kern; 10 Eizelle (125:1) 
2. Ordnung. Eine Versorgung der Seitenhydranthen mit Oocyten von einer Hauptkeimzone aus, wie sie MERgNer (1957) bei Eudendrium racemosum beschreibt, ist unwahrscheinlich, da die Keimzonen in den Seitenzweigen erst sehr spät das Maximum ihrer Eiproduktion erreichen. Zum Teil sind inzwischen zwei bis drei neue Seitenhydranthen gebildet worden.

Ein Gonophor ist ein geschlossener zweischichtiger Coenosarc-Schlauch, der neben je einem Hydranthen liegt. Haben wandernde Oocyten die Gonophoren-Knospungszone erreicht, werden sie anschließend, umgeben von einem Follikelepithel, von dem wachsenden Gonophor mitgeführt. Nachdem etwa 10 Oocyten auf diese Weise in das Gonophor gelangt sind, verengt sich das Coenosarc an der Gonophoren-Ansatzstelle zu einem dünnen Stiel. Das Gonophor ist nun von der weiteren Eizufuhr abgeschnitten; es erreicht ohne Stiel eine Länge um etwa $2 \mathrm{~mm}$. Die Oocyten liegen alternierend in zwei Reihen, umgeben von einem Follikelepithel, das sie vollständig umschließt. Das der Mittellamelle anliegende Follikelepithel ist allerdings sehr dünn und weist nur wenige Kerne auf, so daß es leicht übersehen wird. In den Follikeln vollzieht sich die Endphase der Vitellogenese.

Das Ende der Eireifung zeigt sich am Verhalten des Eikerns und des Follikelepithels im Umkreis einer Oocyte. Der Kern wird zum typischen Keimbläschen und erreicht einen Durchmesser von $50 \mu \mathrm{m}$. Gleichzeitig verlagert er sich an die Peripherie der Oocyten, und zwar immer nach außen an die der Mittellamelle benachbarte Seite. Die Keimbläschen sind nun schon bei geringer Vergrößerung in lebenden Gonophoren zu erkennen, die durch den großen Dottergehalt der Oocyten orangerot erscheinen. Das Follikelepithel löst sich gegen Ende der Reifephase vollständig von den dadurch "frei“ liegenden Oocyten. Sehr deutlich tritt zu diesem Zeitpunkt eine granuläre Rindenzone in den Eizellen auf. Gleichzeitig mit den Veränderungen in seinem Inneren schiebt sich das Gonophor mit seiner Spitze neben dem Hydranthen ins Freie. Zuerst nur von der eigenen Peridermschicht umgeben, bildet es bald auch festeres Perisarc. Die im einschichtigen Ektoderm und vor allem an der Spitze des Gonophors dicht gelagerten "Grana" entsprechen genau denen, die für die Bildung des Hydrocaulus-Perisarc verantwortlich sind (Abb. 6a). Die ungewöhnlich große Sekret-Konzentration weist auf dessen Bedeutung für die Anheftung der ins Freie gelangten Oocyten hin. Die Gonophoren-Spitze zeigt ebenfalls Veränderungen, die auf die bevorstehende Auslagerung der reifen Eier hindeutet: Ekto- und Entodermzellen werden nämlich vakuolär, wobei letztere den entsprechenden Zellen eines Hydranthen-Halses ähneln. Oft ist die Spitze leicht konisch ausgebildet, und die besondere Anordnung ihrer Ektodermzellen läßt eine apikale Offnung vermuten (Abb. 6a). Auffällig ist auch die starke Ausbildung der entodermalen Ringmuskulatur, während eine Längsmuskulatur schwer nachzuweisen ist.

Die Oocyten durchlaufen ihre beiden Reifeteilungen im Gonophor. Dies geschieht selten innerhalb der Follikel. Meist zerreißt das Follikelepithel schon vorher oder die Oocyte verläßt aktiv den Follikel. Die Follikelreste liegen daher entweder serial als ungeordnete Zellhaufen an der Gonophorenwandung oder als ausgezogene Stränge im Gonophor. Mit Sicherheit können Meiose-Stadien immer in solchen Eiern nachgewiesen werden, die frei im Gonophor liegen. Die Abbildungen 7a, b und c zeigen drei Stadien der Richtungskörper-Bildung, wobei $\mathrm{b}$ den $10 \mu \mathrm{m}$ großen weiblichen Vorkern darstellt. 
Die Reifeteilungen der Eier erfolgen nicht synchron im gesamten Gonophor, sondern sie beginnen an dessen Spitze zuerst. Danach ist das reife Ei ausschlïpfbereit und befruchtungsfähig.

Die Befruchtung erfolgt schon während des Ausstoßens der Eier oder unmittelbar danach. In einer Eizelle, die sich kurz zuvor außen an das Gonophoren-Perisarc angeheftet hatte, wurde ein männlicher Vorkern neben einem weiblichen gefunden (Abb. 25a). Vergleichsweise häufiger findet man aber Eistadien, die schon die ersten Furchungsteilungen durchlaufen haben und noch mit "schwanzförmig“ ausgezogenen Zipfeln in oder neben der Gonophoren-Spitze liegen. Das Spermium muß schon vor der Anheftung ins Ei eingedrungen sein, da man annehmen darf, daß später die vom Ei ausgeschiedene Embryonalhülle nach ihrer Verfestigung eine Befruchtung verhindert.

Beim Ausschlüpf- und Anheftungsvorgang beteiligen sich vermutlich Eizelle und Gonophor gemeinsam. Neben der amöboiden Beweglichkeit der Eizellen dürtte beim Ausschlüpfen auch die krättige Ringmuskulatur des Gonophors, welche die Eizellen mehr oder weniger "peristaltisch" hinausdrückt, eine wesentliche Rolle spielen. Diese Beteiligung der Ringmuskulatur zeigt sich häufig auch in einer Einschnürung des distalen Gonophors unterhalb des schlïpfenden Eies. Da ein Ei etwa eine Stunde oder mehr benötigt, um das Gonophor zu verlassen, ist eine genaue Analyse des Ausschlüpfvorgangs nur mit Hilfe der Zeitraffer-Technik durchzuführen. Nach dem Austritt aus dem Gonophor verklebt die of schon in diesem von der reifen Eizelle ausgeschiedene, zarte Embryonalhülle mit dem ständig neu gebildeten Perisarc des Gonophors. Währenddessen schiebt sich dieses weiter vor, so daß die nächstfolgenden Eier ausgestoßen werden können und mit dem Perisarc verkleben. Daraus resultiert oft ein Bild, das die Eier kranzförmig unterhalb der Gonophoren-Spitze zeigt. Die zuletzt ins Freie gelangten Eier bleiben dann nahe der Spitze liegen. Auf diese Weise bilden sich Eitrauben mit 7 bis 11 Eiern. Ist das Gonophor entleert, wird es langsam resorbiert, so daß die Eitrauben auf der leeren Perisarc-Röhre neben dem Hydranthen angeheftet sind.

Das Ausschlüpfen der Eier wird vermutlich durch die Nachbarschaft männlicher Stöcke bzw. der von diesen gebildeten Spermien induziert. Das ließ sich in einem ein. fachen Versuch zeigen: Ein isoliert gehaltener weiblicher Stock bildete nämlich schon seine Hydranthen zurück, ohne daß die Eier aus den prall gefüllten Gonophoren austraten. Erst nach Beigabe einer reifen männlichen Kolonie schlüptten über Nacht fast sämtliche Eier.

\section{Oocyten-Feinstruktur während der Vitellogenese}

Oocyten bilden ein bevorzugtes Studienobjekt der Ultrastrukturforschung und stellen vermutlich den bestuntersuchten Zelltyp dar. Dies beruht zum großen Teil auf ihrer besonderen Stellung im Leben eines Organismus als Ausgangspunkt der Ontogenese. Nach NøRREvang (1968) werden jährlich mehr als 50 elektronenmikroskopische Arbeiten über Oocyten veröffentlicht, von denen sich viele nur mit Teilproblemen der Oogenese, zum Beispiel der Eihüllen-Struktur oder bestimmten Phasen der Dotterbildung beschäftigen. Ein Hauptergebnis dieser Untersuchungen liegt vor allem darin, daß zwi- 

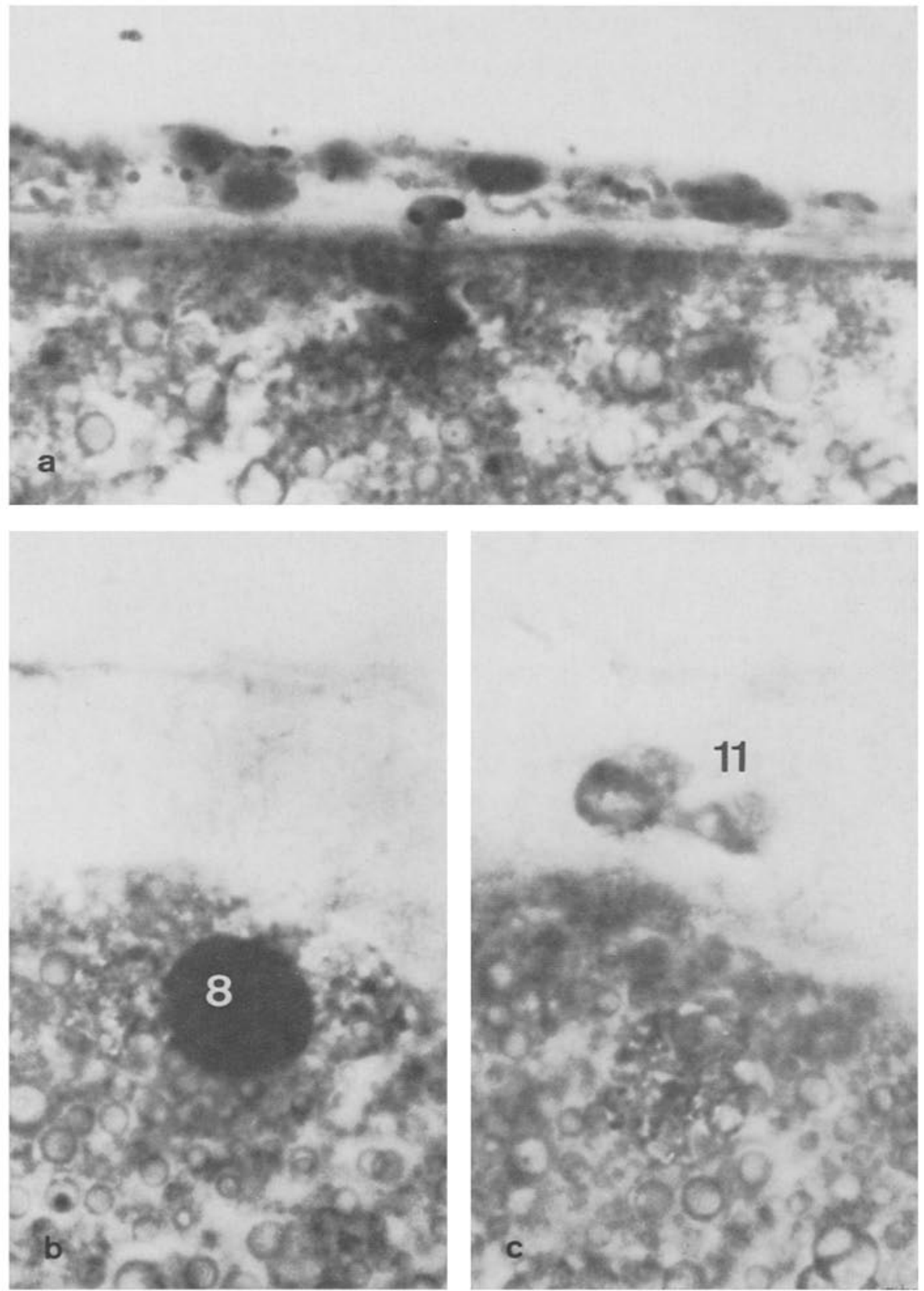

Abb. 7: Reifeteilungen. a Telophase. $b$ Weiblicher Vorkern (8). $c$ Richtungskörper (11) zu b (1700:1) 
schen den Oocyten verschiedener Tierarten nicht zu erwartende große Unterschiede in der Feinstruktur bestehen. Demzufolge ist es bei Untersuchungen zur Dotterbildung verständlich, daß fast allen Organellen der Eizelle eine Beteiligung am Dotteraufbau zugeschrieben wird. Um so mehr gilt noch immer die Feststellung von MAcBrIDE \& HEWER aus dem Jahre 1931: "The whole matter has, however, proved to be of extraordinary complexity, so that there are few fields of cytology in which there is more confusion and opinions are more hopeless divided" (zitiert nach BeAms 1964).

Daher kann die folgende Beschreibung der Oocyten-Strukturen von Corydendrium und ihrer Veränderungen im Verlauf der Dotterbildung auch nur ein weiterer Beitrag zu dieser "complexity“ der Dottergenese sein und in erster Linie die morphologische Basis für weitere Arbeiten bilden. Feinstrukturelle Untersuchungen an HydroidenOocyten gibt es meines Wissens nur von STAGNI \& LuCCI (1964) an Hydra, von KAWAgUTI \& Ogasawara (1967) an der Anthomeduse Spirocodon saltatrix und von KesSeL (1968a) an einer nicht näher genannten Hydromeduse.

Die Darstellung der Dotterbildung folgt der Einteilung, die Raven (1961) für die Eistadien gibt: (1) die prämeiotische Phase, (2) die prävitellogene Phase und (3) die Phase der Vitellogenese. Da die Grenzen zwischen den erkennbaren Prophase-Stadien der Prävitellogenese nicht genau zu erfassen sind, werden beide Stadien im Abschnitt über die junge Eizelle ohne Unterscheidung voneinander beschrieben. Daran schließt sich die Beschreibung der Dotterbildung im engeren Sinne, die Phase der Vitellogenese, an. Es hat sich dabei als zweckmäßig erwiesen, zwischen jungen und alten WanderOocyten bzw. zwischen jungen und alten Gonophoren-Oocyten zu unterscheiden. Die Abbildungsbelege halten sich oft nicht an die oben getroffene Einteilung der Eistadien, da einzelne Strukturen und vermutete Zusammenhänge in anderen Phasen der DotterGenese deutlicher gezeigt werden können als in der gerade zu beschreibenden.

\section{Junge Eizelle}

Die frühen Eistadien liegen bei Corydendrium parasiticum sehr verstreut im Entoderm der Keimzone. Im Unterschied hierzu enthalten die Gonaden am Manubrium einer Hydromeduse alle Eistadien auf engem Raum, was ihre Untersuchung sehr erleichtert (Kessel 1968a). Um also ein einigermaßen lückenloses Bild der Dottergenese zu erhalten, ist eine lichtmikroskopische Lokalisierung, besonders der frühen Stadien, an Semidünnschnitten erforderlich (Abb. 4).

Wie schon bei der lichtmikroskopischen Analyse kennzeichnen auch in Semidünnschnitten die Prophase-Stadien der Meiose eindeutig die zukünftigen Keimzellen. Klarer jedoch als auf Paraffinschnitten fallen die Keimzellen wie auch freiliegende, das heißt nicht in Nestern vereinte Embryonalzellen (interstitielle Zellen) in Kunstharzschnitten durch ihr relativ undifferenziertes Cytoplasma auf (Abb. 8, 9, 10a). Eine Gegenüberstellung zweier Embryonalzellen aus dem Ektoderm bzw. aus dem Entoderm mag dies belegen. Die entodermale Embryonalzelle stellt vernutlich eine prospektive Oocyte dar (Abb. 9b). Sie zeigt außer dem großen Kern wenige Mitochondrien und einige kurze Zisternen des granulären endoplasmatischen Retikulums. Die ektodermale Zelle auf Abbildung 9a erscheint durch den auf ihr angeschnittenen Dalton-Kom- 
plex und die konzentrisch um den Kern angeordneten Retikulum-Zisternen differenzierter als die Entodermzelle. Sicher sind es aber ähnliche Zellen, die aus dem Ektoderm kommen, durch die Mittellamelle wandern und im Entoderm zu Oocyten werden (vgl. p. 224).

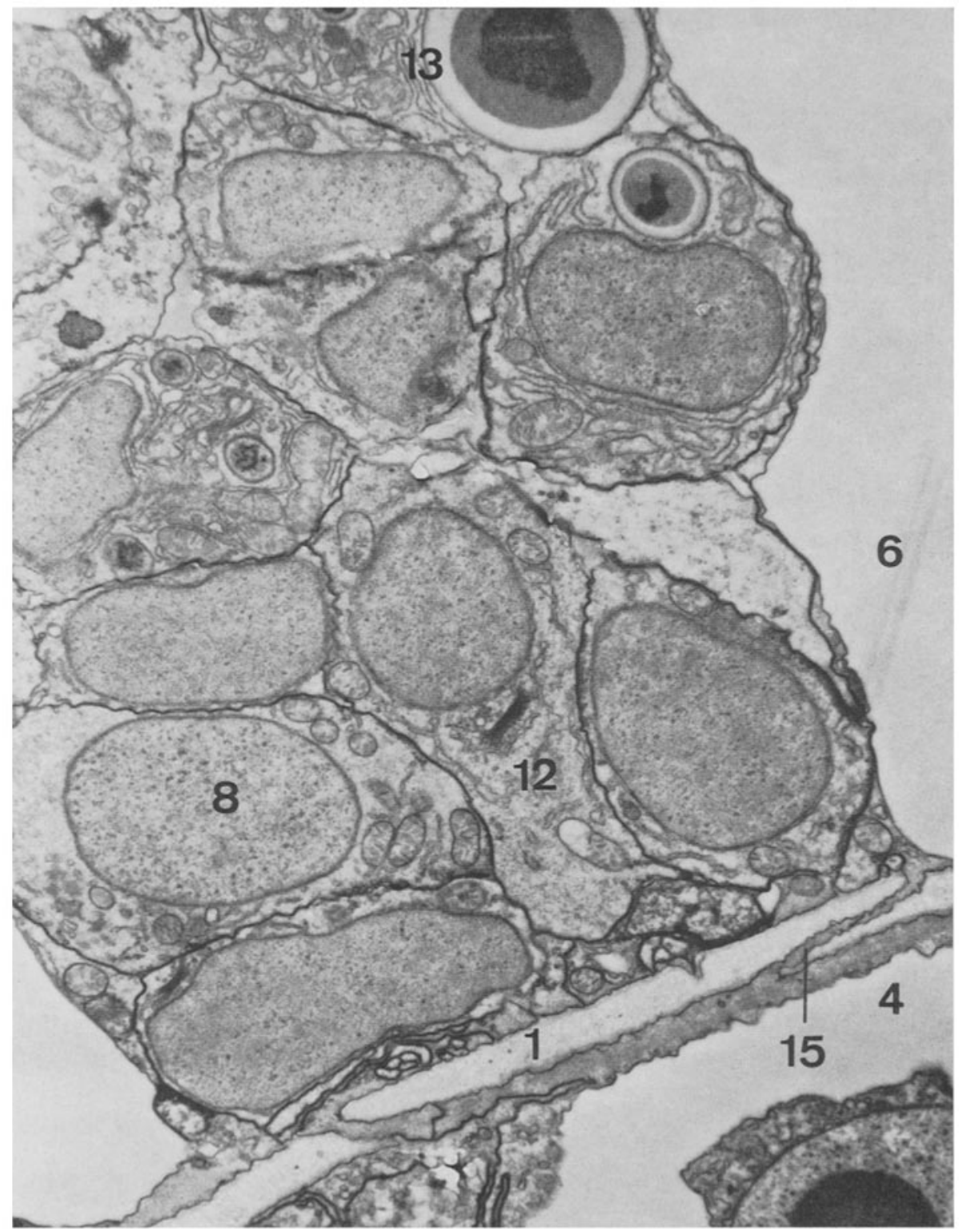

Abb. 8: I-Zellen-Nest im Ektoderm. 1 Mittellamelle; 4 Entoderm; 6 Ektoderm; 8 Kern einer I-Zelle; 13 Cnide; 15 Zellausläufer durch die Mittellamelle (8700:1) 

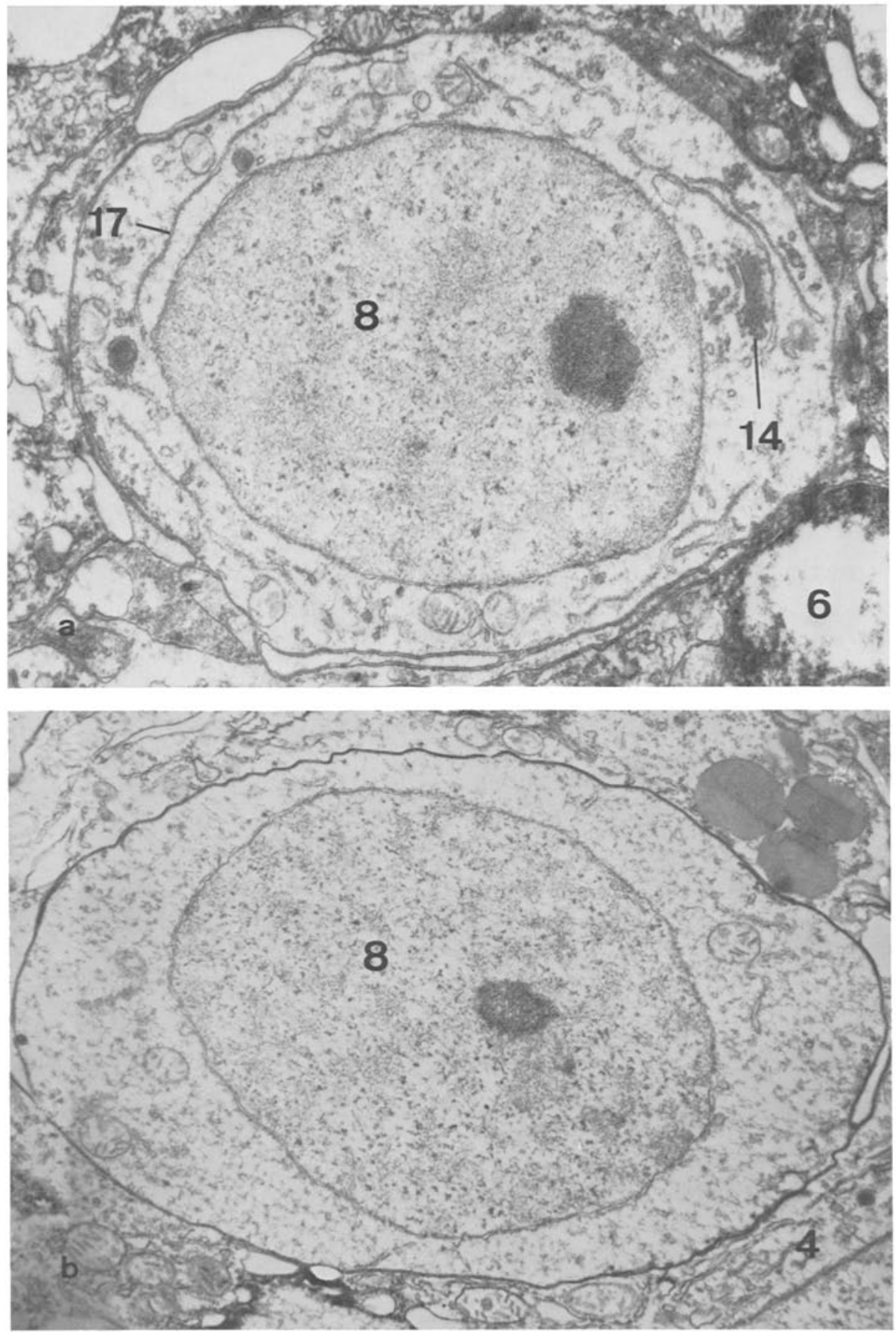

Abb. 9: a I-Zelle im Ektoderm (14600:1). $b$ Embryonalzelle (prospektive Keimzelle?) im Entoderm. 4 Entoderm; 6 Ektoderm; 8 Kern; 14 Dalton-Komplex; 17 endoplasmatisches Retikulum $(9800: 1)$ 

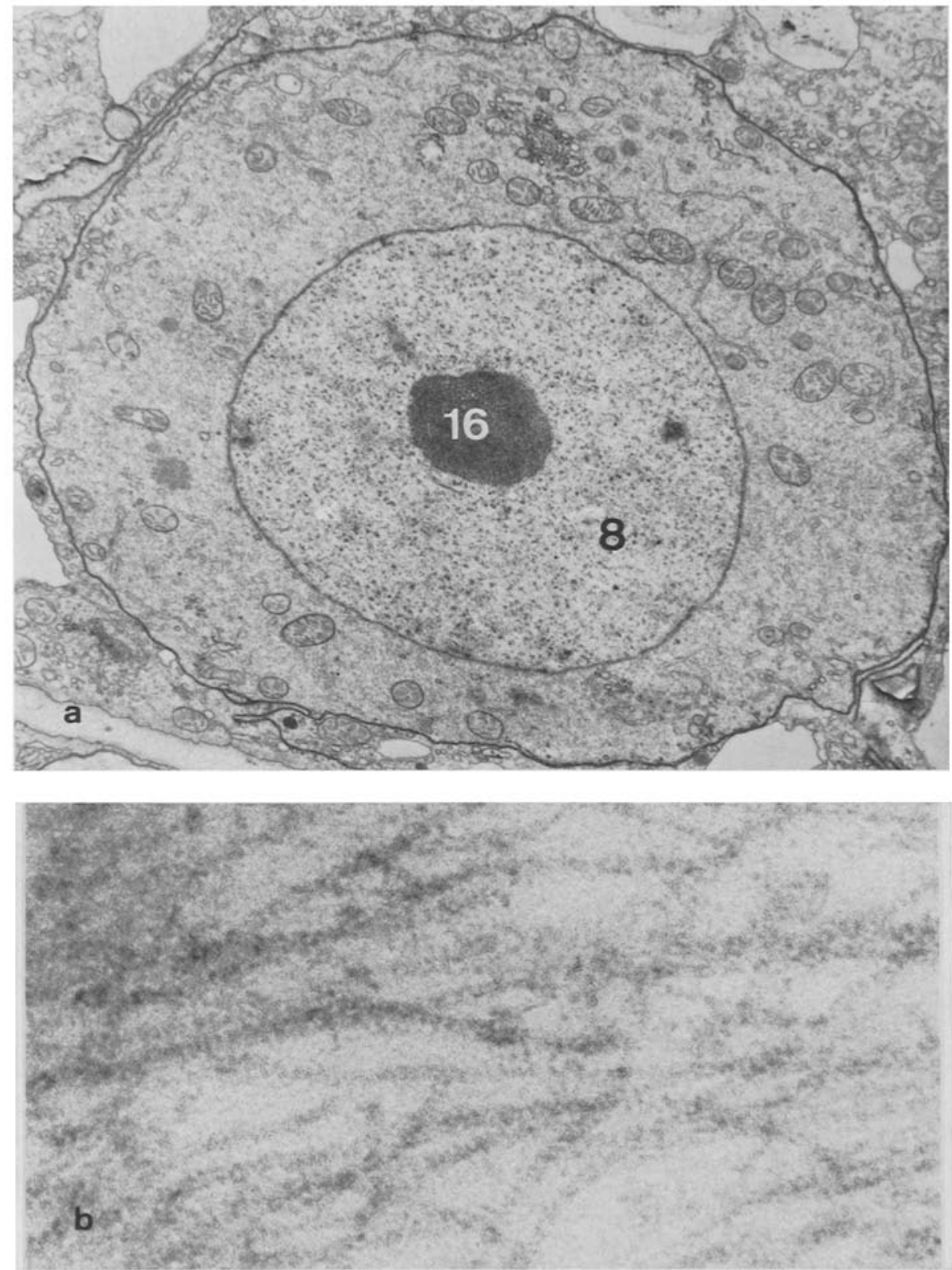

Abb. 10: a Junge Eizelle (10500:1). $b$ In die Mittellamelle eingelagerte Fibrillen, die eine periodische Anordnung von Untereinheiten aufweisen. Foto: Dr. D. ZisSLER, Freiburg (200000:1). 8 Kern; 16 Nucleolus 
Die jungen Oocyten fallen zwischen den meist langgestreckten Entodermzellen durch ihre runde oder ovale Form auf. Der Durchmesser der jüngsten im Entoderm beobachteten Oocyten beträgt etwa $12 \mu \mathrm{m}$. Der Kern mit einem Durchmesser von etwa $7 \mu \mathrm{m}$ liegt in der Zellmitte (Abb. 10a). Er besitzt einen großen Nucleolus, der aus 180 bis $200 \AA$ großen Grana zusammengesetzt ist. Befindet sich der Kern noch in einem Prophase-Stadium mit sichtbarer Chromosomenstruktur, zum Beispiel dem Leptotän, ist das Chromatin als lokale, fibrilläre Verdichtung im Kern zu sehen. Gelegentlich werden Chromosomen längs getroffen. Sie zeigen dann den bekannten axialen Aufbau und die ebenfalls häufig zu beobachtende enge Beziehung zur Kernmembran (Sotelo \& Wettstein 1964, Moens 1968, Sheridan \& Barrnett 1969). Später ist der Kern von einem fibrillären Grundgerüst, dem Grana-Aggregate von 300 bis $600 \AA$ A Durchmesser aufgelagert sind, mehr oder weniger gleichmäßig erfüllt (Abb. 12).

Die Kernmembran wird von Poren durchbrochen, die zum Teil die schon öfters beschriebene Annulus-Struktur besitzen. Ihr innerer Durchmesser beträgt etwa $600 \AA$. Durch diese Poren steht der Kern mit dem Cytoplasma in Verbindung. Gleichstrukturiertes, amorphes Material beiderseits der Kernmembran ist ein Hinweis für die direkte Kommunikation zwischen Kern und Cytoplasma (Abb. 11b, 14b).

Das „unstrukturierte“ Grundcytoplasma fällt durch seinen Reichtum an freien Ribosomen auf, die einen Durchmesser von etwa 100 bis $150 \AA$ besitzen. Sie sind Ursache für die bei jungen Oocyten regelmäßig zu beobachtende Basophilie. Als zweite granuläre Plasmadifferenzierung finden sich ribosomenähnliche Haufen von Grana verstreut in der Zelle (Abb. 11b). Kessel (1968a) beschreibt ebenfalls gleichartige Anhäufungen in jungen Oocyten einer Hydromeduse und $\mathrm{H}_{\mathrm{ANISCH}}$ (1970) in jungen Spermatoblasten von Eudendrium racemosum. Das granulierte endoplasmatische Retilulum ist sehr schwach ausgebildet und besteht nur aus wenigen Zisternen, die meist im peripheren Zellbereich liegen. Häufig lassen sich kurze Ausstülpungen der äußeren Kernmembran beobachten, die diesen Zisternen ähneln. Eine solche Verbindung ist nichts Außergewöhnliches und wird meist mit der Bildung von endoplasmatischem Retikulum aus der Kernmembran erklärt, u. a. BeAMs \& KEsSEL 1962, 1963, PARks 1962). Dalton-Komplexe treten in sehr jungen Oocyten nur vereinzelt auf; sie spielen offensichtlich in dieser Entwicklungsphase noch keine wesentliche Rolle. Die Mitochondrien vom Crista-Typ sind rund bis oval und kommen in größerer Anzahl in der Zelle vor. Daneben werden vereinzelt "multivesicular bodies“ beobachtet, die in späteren Stadien nicht mehr auftreten und oft mit charakteristischen Vesikelanhäufungen in Verbindungen stehen. Diese Vesikel liegen bevorzugt an der Zellperipherie und werden hier offensichtlich neu gebildet (Abb. 11, 12), da sie sich entlang der Zellmembran oft kettenförmig aufgereiht finden. Zudem liegen auch Membranstiicke so dicht an der Zellwand, daß sie ihre Entstehung einer Membran-Delamination verdanken könnten.

\section{Junge Wander-Oocyte}

Als Wander-Oocyte werden in der Dotterbildung begriffene Eizellen bezeichnet, die noch nicht in das Gonophor eingewandert sind. Als Beschreibungshilfen unterscheidet man die junge von der alten Wander-Oocyte, wobei letztere in ihrem Dotteraufbau weitgehend der jungen Gonophoren-Oocyte gleicht. 

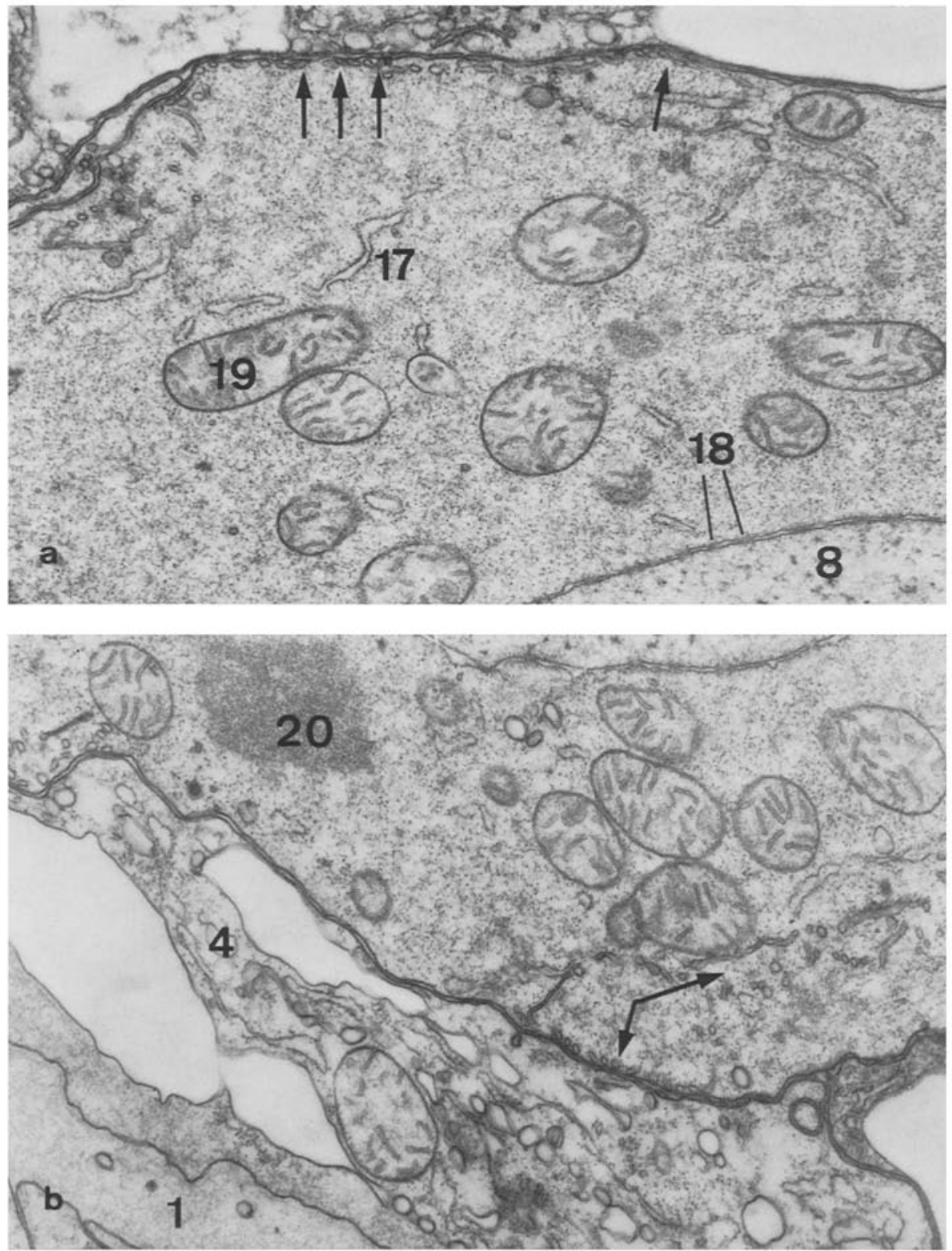

Abb. 11: $a$ (24600:1) und $b$ (23 500:1) Membranentstehung in einer jungen Eizelle (Pfeile). 1 Mittellamelle; 4 Entoderm; 8 Kern; 17 endoplasmatisches Retikulum; 18 Kernporen; 19 Mitochondrium; 20 Ansammlung von Grana 
Die junge Wander-Oocyte, die am Beginn der Dotterbildung steht, zeigt völlig andere Inhaltsstrukturen als die Oocyte in der Phase der Prävitellogenese. Die freien Ribosomen liegen nicht mehr gleichmäßig verstreut im Grundcytoplasma der Zelle, sondern bilden kleine Zusammenballungen, die dem Cytoplasma ein flockiges Aussehen verleihen. Das granuläre endoplasmatische Retikulum hat sich stark vergrößert und besteht aus vielen runden bis länglichen Vesikel, die oft kettenartig, konzentrisch um den Kern angeordnet sind. In engem Zusammenhang mit der Bildung des endoplasmatischen Retikulums steht die verstärlste Membrananhäufung an der Zellperipherie. Die Mitochondrien treten im Schnittbild der jungen Wander-Oacyte zurück. Auffallend sind die zahlreichen Dalton-Komplexe und das Erscheinen zweier neuer Zellorganellen. Ein Dalton-Komplex dieses Stadiums setzt sich aus vier bis sechs abgeflachten Zisternen zusammen, von denen sich viele kleine Vesikeln abschnüren. Regelmäßig findet sich parallel zum konvexen T'eil des Zisternenstapels oder der größten Vesikelanhäufung entgegengesetzt eine längere Zisterne des granulären endoplasmatischen Retikulums. Diese Zisterne und ein Teil der Golgi-Vesikel scheinen an der Entstehung der ersten neu auftretenden Organellen beteiligt zu sein (Abb. 12). Diese neue Organelle soll zunächst allgemein Cytosom genannt werden (vgl. p. 258). Die Cytosomen sind von nun an bestimmend für das weitere Bild der gesamten Dottersynthese. Es handelt sich um runde bis ovale Körper, die von einer Elementarmembran von 100 Å Dicke umschlossen sind. Ihr Durchmesser beträgt $z$ wischen 0,6 und 1,0 $\mu \mathrm{m}$. Das besondere Kennzeichen dieser Cytosomen ist der regelmäßig in ihnen vorkommende Einschluß, der je nach Schnittrichtung verschiedenes Aussehen hat. Es sind aufeinanderliegende Lamellen, die eine tubuläre Substruktur von $160 \AA$ D Durchmesser aufweisen (Abb. 13a, b; 19a). Of treten die Tubuli auch gebündelt auf. Meist kommen zwei Stapel dieser Innenstrukturen in den Cytosomen vor, die dann senkrecht zueinander stehen. In Anlehnung an das englische Schrifttum wird dieser parakristalline Innenkörper im folgenden "core" genannt. Ein zweites auffälliges Merkmal der Cytosomen ist die oft unterschiedliche Struktur ihrer Grenzmembran. Teile von ihr erweisen sich als glatte, distinkte Elementarmembranen, andere wiederum zeigen eine unregelmäßige Struktur mit granulärem Besatz und ähneln den Membranen des endoplasmatischen Retikulums. Diese Ähnlichkeit wird dadurch unterstützt, daß sich tatsächlich direkte Verbindungen zwischen dem endoplasmatischen Retikulum und den Cytosomen nachweisen lassen (Abb. 13a). Manche Cytosomen stehen noch in offener Verbindung mit dem Cytoplasma (Abb. 12, 18a). In diesem Fall ist ihre Grenzmembran immer glatt. Die mögliche Bedeutung derartiger Übergangsformen für die Genese der Cytosomen wird später noch diskutiert.

Die zweite, in diesem Stadium neu auftretende Organelle ist ebenfalls von einer Elementarmembran umschlossen (Abb. 13d, 14a). Sie tritt bis gegen Ende der Vitellogenese auf und stellt die erste geformte Dottervorstufe dar. Sie besitzt eine ellipsoide Form, deren Enden oft spitz ausgezogen sind. Je nach Schnittrichtung erscheinen sie demnach rund, elliptisch, tropfen- oder spindelförmig. Ihr großer Durchmesser beträgt 1,6 bis $2,2 \mu \mathrm{m}$, ihr kleiner liegt zwischen 0,8 und $1,2 \mu \mathrm{m}$, während die Elementarmembran $70 \AA \mathrm{A}$ dick ist. Die im elektronenmikroskopischen Bild sehr stark osmiophilen Körper zeigen eine regelmäßige Innenstruktur. Die Anordnung der fädigen Grundelemente ist am besten mit dem Anblick eines Springbrunnens zu vergleichen, wobei sich offenbar mehrere "Springbrunnen" überlappen können (Abb. 13d, 21a). Im folgenden werden 


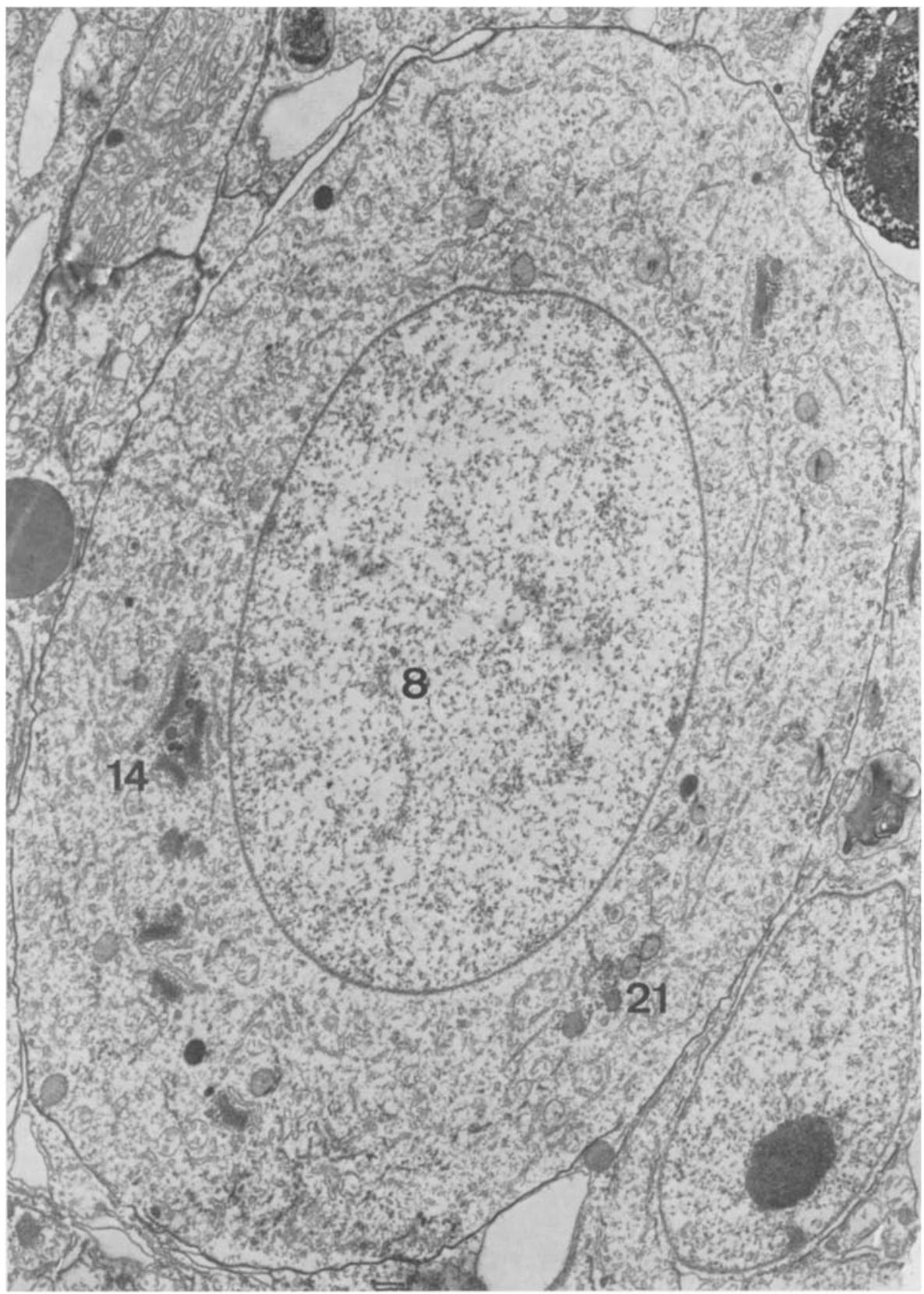

Abb. 12: Junge Wander-Oocyte zu Beginn der Vitellogenese. 8 Kern; 14 Dalton-Komplex; 21 Cytosom (6000:1) 

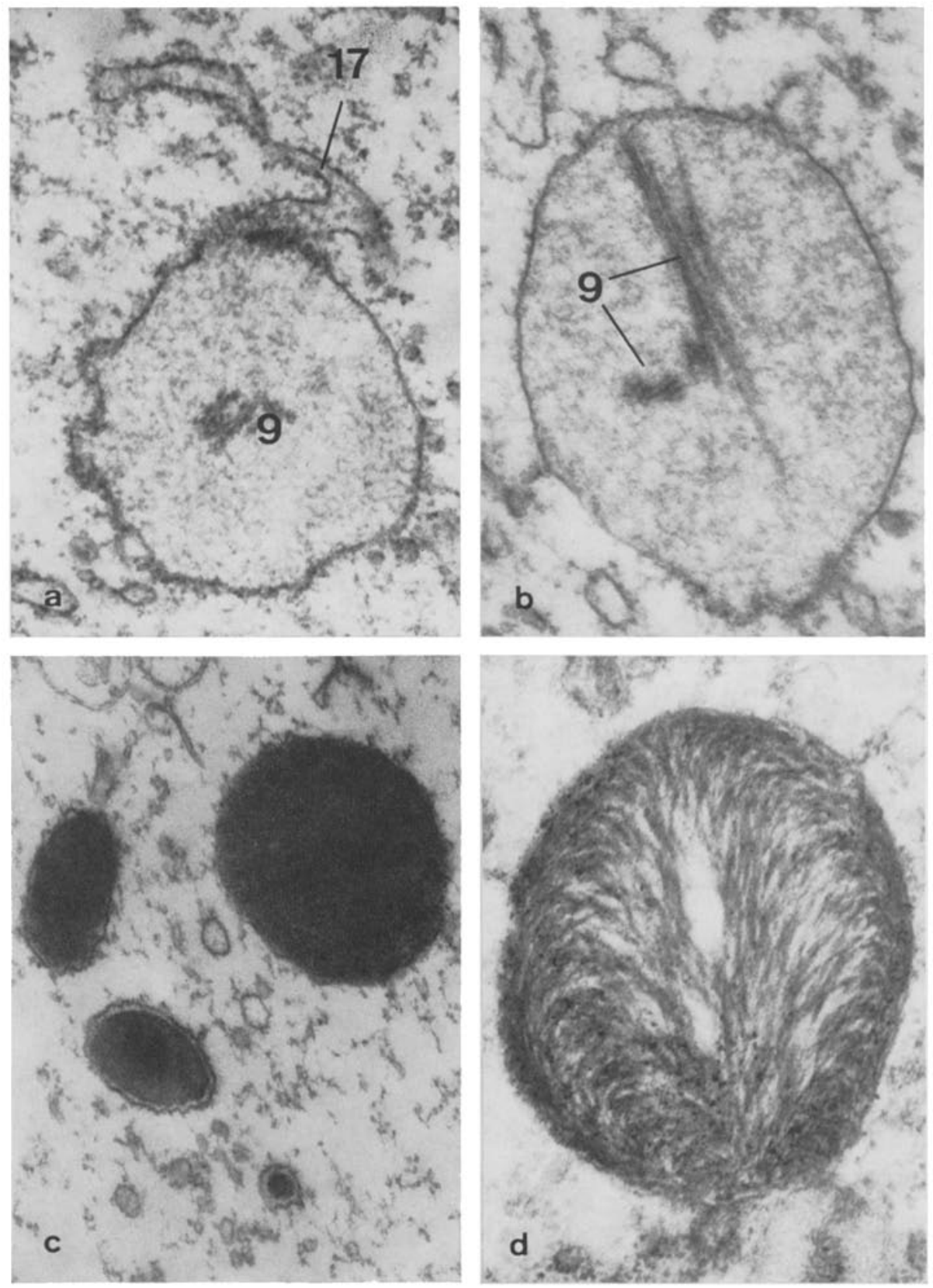

Abb. 13: a Cytosom in Verbindung mit einer Zisterne des endoplasmatischen Retikulums (42 500:1). $b$ Cytosom mit parakristalliner Innenstruktur (54000:1). $c$ Entwicklungsstadien der Springbrunnenkörper (d) (58 500:1). 9 Innenstruktur; 17 endoplasmatisches Retikulum 
diese Dottervorstufen daher bildhaft "Springbrunnenkörper" (,fountain body") genannt. Die Springbrunnenkörper entstehen aus kleinen Vesikel, die sich kontinuierlich vergrößern und osmiophiles Material enthalten. Vermutlich sind Golgi-Vesikel der Ausgangspunkt für ihre Bildung (Abb. 13c).

Kern und Nucleolus der jungen Wander-Oocyte verändern sich, von ihrer Volumenzunahme abgesehen, wenig. Wie bei der nun einsetzenden großen Syntheseleistung der Zelle zu erwarten ist, erhöht sich die Anzahl der Kernporen pro Flächeneinheit sehr stark.

\section{Alte Wander-Oocyte}

Ist der Organellenbestand junger Wander-Oocyten noch einigermaßen überschaubar, wird er in der alten Wander-Oocyte vielgestaltiger und unübersichtlicher.

Diese Oocyten sind nicht mehr weitgehend rund, sondern müssen sich infolge ihres Wachstums den räumlichen Verhältnissen im Entoderm anpassen und daher etwas abflachen. Größere Ausläufer der Oocyte schieben sich zwischen die Entodermzellen und geben einen Hinweis auf die Mobilität und Motilität der Eizellen in dieser Phase. Der im Durchmesser bis $45 \mu \mathrm{m}$ große Kern zeigt nun im Gegensatz zu dem der jungen Wander-Oocyte ebenfalls umfangreichere strukturelle Veränderungen. Die glatte Kernmembran ist von zahlreichen Poren durchbrochen, die am deutlichsten von allen Kernstadien ihre Annulus-Struktur zeigen (Abb. 14a, b). Die etwa 1500 Å langen Annuli sind auf der Kernseite meist länger als auf der dem Cytoplasma zugewandten Seite. Eine weitere, mehrfach beschriebene Substruktur des Porenkomplexes kann an Hand der vorhandenen elektronenoptischen Aufnahmen nicht mit Sicherheit nachgewiesen werden. Doch lassen, allerdings unbefriedigende, Markham-Analysen vermuten, daß die Kernporen ebenfalls eine 8strahlige Radiärsymmetrie besitzen, die wahrscheinlich allen Poren-Komplexen gemeinsam ist (Franke 1970).

Der inneren der beiden Kernmembranen ist granuläres, elektronendichtes Material von der Kernseite her angelagert. Dadurch erscheint die innere Membran dicker als die äußere (Abb. 14a, b). Die Zone der Auflagerung ist etwa gleich dick wie die gesamte doppelte Kernmembran, das heißt etwa 350 bis $380 \AA$.

Die größte Veränderung zeigt jedoch der bis zu einem Durchmesser von $12 \mu \mathrm{m}$ angewachsene Nucleolus. Drei Strukturkomponenten sind in ihm zu unterscheiden: (a) die Pars granulosa, die vorwiegend die Randzonen des Nucleolus bildet, (b) die Pars fibrosa, die die Pars granulosa im Inneren des Nucleolus unregelmäßig durchsetzt und (c) Vakuolen verschiedener Größen, die immer in der Pars granulosa liegen (Abb. 15, 17). Die Grana der Pars granulosa gleichen in ihrer Größe denen der Nucleoli junger Oocyten. Sie sind oft ungleichmäßig elektronendicht, was auf Untereinheiten ihres Aufbaus hinweist (Abb. 16a). Häufig sind eine lineare Anordnung und eine bevorzugte Orientierung der Grana zu beobachten (Abb. 15). Am Rande des Nucleolus wie auch am Rande der Vakuolen gehen die Grana offensichtlich in weniger elektronendichte (fädige?) Komponenten über, die strukturell dem übrigen Kerninhalt gleichen. Aus dem oben Gesagten ergibt sich weiter, daß der Inhalt der Vakuolen im Nucleolus ebenfalls dem übrigen Kerninhalt gleicht. Als Besonderheit zeigen die Vakuolen oft stark elektronendichte Körper von 900 bis $1600 \AA$ A Durchmesser, deren Bedeutung unbekannt ist 

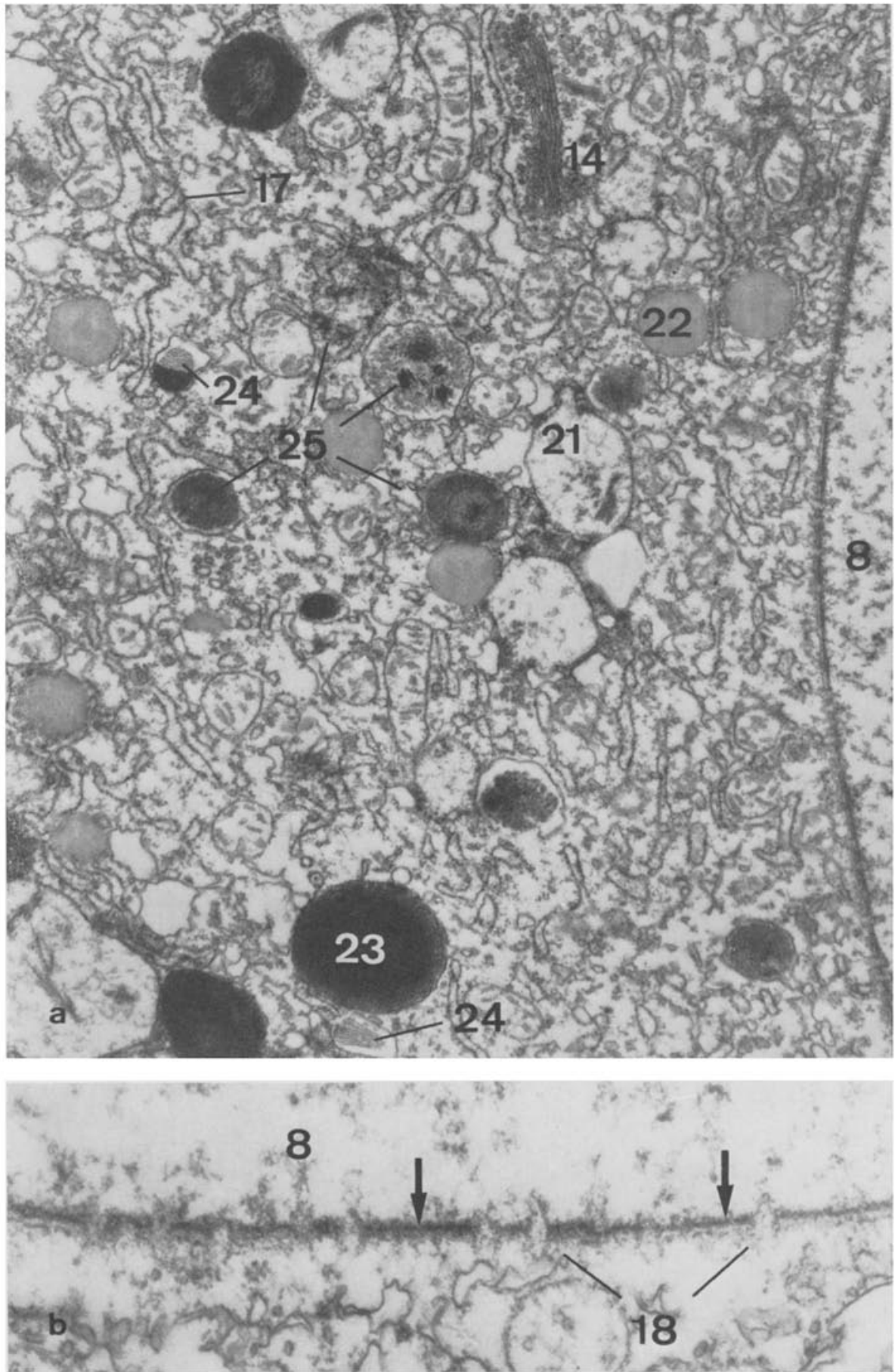


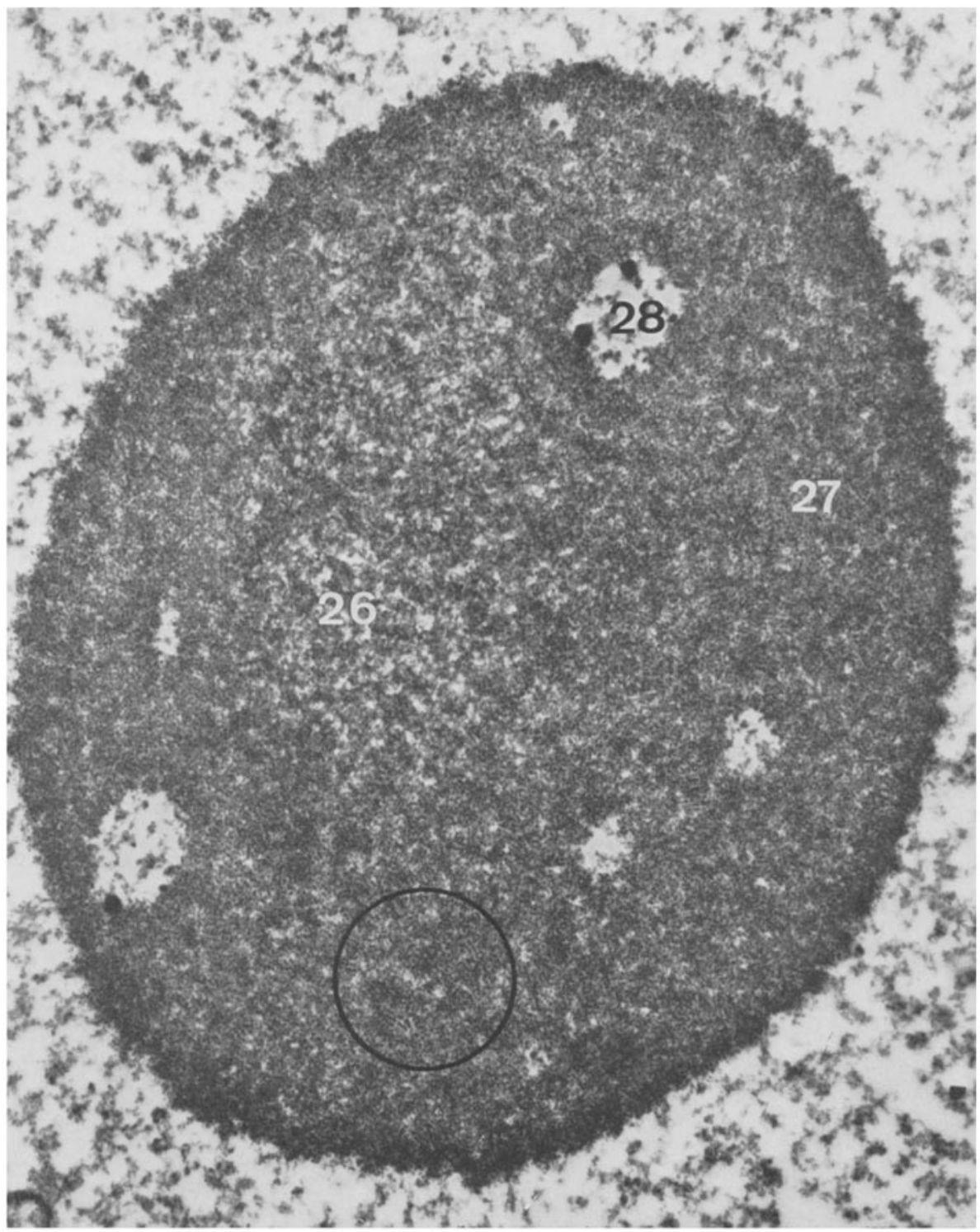

Abb. 15 (oben): Nucleolus einer Wander-Oocyte mit der Pars granulosa, Pars fibrosa und Vakuolen; die Grana sind teilweise kettenförmig angeordnet (Kreis). 26 Pars fibrosa; 27 Pars granulosa; 28 Vakuole (17 500:1)

Abb. 14 (links): a AlteWander-Oocyte mit zahlreichen Organellen für die Vitellogenese (17 500:1). $b$ Ausschnitt einer Kernmembran mit Annuli und Zonula nucleum limitans (Pfeile) (44 700:1). 8 Kern; 14 Dalton-Komplex; 17 endoplasmatisches Retikulum; 18 Annuli; 21 Cytosom; 22 Lipidtropfen; 23 Springbrunnenkörper; 24 Doppelkörper; 25 Stadien der Komplexdotter-Bildung 
(Abb. 15, 16b). Manchmal sind ähnliche Körper in Nucleolus-Nähe zu finden, was möglicherweise auf ihre Herkunft aus den Vakuolen schließen läßt.

Die im Inneren des Nucleolus liegende unregelmäßig begrenzte Pars fibrosa ist gegenüber der Pars granulosa durch ihr undeutlich strukturiertes aufgelockertes Material gekennzeichnet (Abb. 16a). Doch sind Fibrillen nicht eindeutig zu identifizieren. Zweifellos ist dieser Teil des Nucleolus mit der Pars fibrosa, wie sie in anderen Arbeiten beschrieben wird, identisch (HAY 1968).

Kennzeichnend für die alte Wander-Oocyte ist jedoch das Cytoplasma, das durch seine vielfältigen Strukturen eine Unterscheidung zwischen alter und junger WanderOocyte rechtfertigt (Abb. 17).

Hauptsächlich vier Entwicklungstendenzen bedingen das andersartige Bild der alten Wander-Oocyte: (1) Das Membranpotential der Zelle hat sich stark vergrößert. (2) Es treten zum erstenmal Lipidtropfen und (3) ein besonderer "Doppelkörper" ("double body") auf. (4) Die Cytosomen haben sich vergrößert und erscheinen jetzt eher als membranumschlossene Reaktionsräume denn als geformte Organellen.

Ferner beginnt nun die Bildung solcher Dotterpartikel, die neben den Lipidtropfen ein zweites Endprodukt der Dottergenese darstellen. Auf Grund ihres zusammengesetzten Aufbaus werden sie daher "Komplexdotter" genannt. Ihre Beschreibung erfolgt im Zusammenhang mit der Kennzeichnung der Gonophoren-Oocyte.

Die stark vermehrten Membransysteme im Cytoplasma können glatt oder granulär sein. Die granulären Membranen treten in Form der typischen langgestreckten Zisternen des endoplasmatischen Retikulums auf. Immer wieder sind ihre engen Verbindungen zu den Cytosomen zu beobachten (Abb. 14). Oft gleicht der Zisternen-Inhalt dem der Cytosomen, so daß sich auf einen Stofftransport von den Zisternen zu den wachsenden Cytosomen schließen läßt (Abb. 13a). Die glatten Membranen bilden dagegen eine Vielzahl runder oder unregelmäßiger geformter Vesikel, von denen ein großer Teil dem Golgi-Apparat entstammt. In ihrem Inneren ist häufig eine beginnende Substanz-Anreicherung in Form osmiophilen Materials zu beobachten (Abb. 14a).

Eine Bildung der glatten Vesikel ist möglicherweise der neu auftretende „Doppelkörper" (Abb. 14a, 18b, 19b). Der Name "Doppelkörper" kennzeichnet ein entscheidendes Merkmal dieser Partikel: Der ovoide 350 bis $760 \mathrm{~nm}$ lange und 200 bis $350 \mathrm{~nm}$ breite Doppelkörper setzt sich nämlich zu gleichen Teilen aus einem locker-fädigen und einem stark osmiophilen, feinfädigen, dichten Anteil zusammen, die ohne sichtbaren Ubergang aneinandergrenzen. Wie aus Quer- und Längsschnitten zu ersehen ist, verlaufen die locker-fädigen Strukturen mit einem Durchmesser von $220 \AA$ A nahezu parallel zur Längsachse des Doppelkörpers. Die Doppelkörper sind von einer Elementarmembran umschlossen, die eine Dicke von 100 Â zeigt. Auffallend ist dabei der unterschiedliche Verlauf der Membran: Dem feinfädigen Anteil des Doppelkörpers liegt sie unmittelbar an, um die locker-fädige Komponente verläuft sie jedoch in einem größeren Abstand, so daß der Doppelkörper insgesamt $800 \mathrm{~nm}$ lang und $450 \mathrm{~nm}$ breit werden kann. Welche Bedeutung die häufig zu beobachtende enge Nachbarschaft der Doppelkörper mit den Springbrunnenkörpern besitzt, entzieht sich noch einer Erklärung.

Als erste in ihrer endgültigen Form auftretende Reservesubstanz der Eizelle finden sich nunmehr die Lipidtropfen (Abb. 17, 14a). Diese membranlosen, runden Einschlüsse liegen ohne erkennbare Beziehung zu anderen Organellen vereinzelt oder in Gruppen 

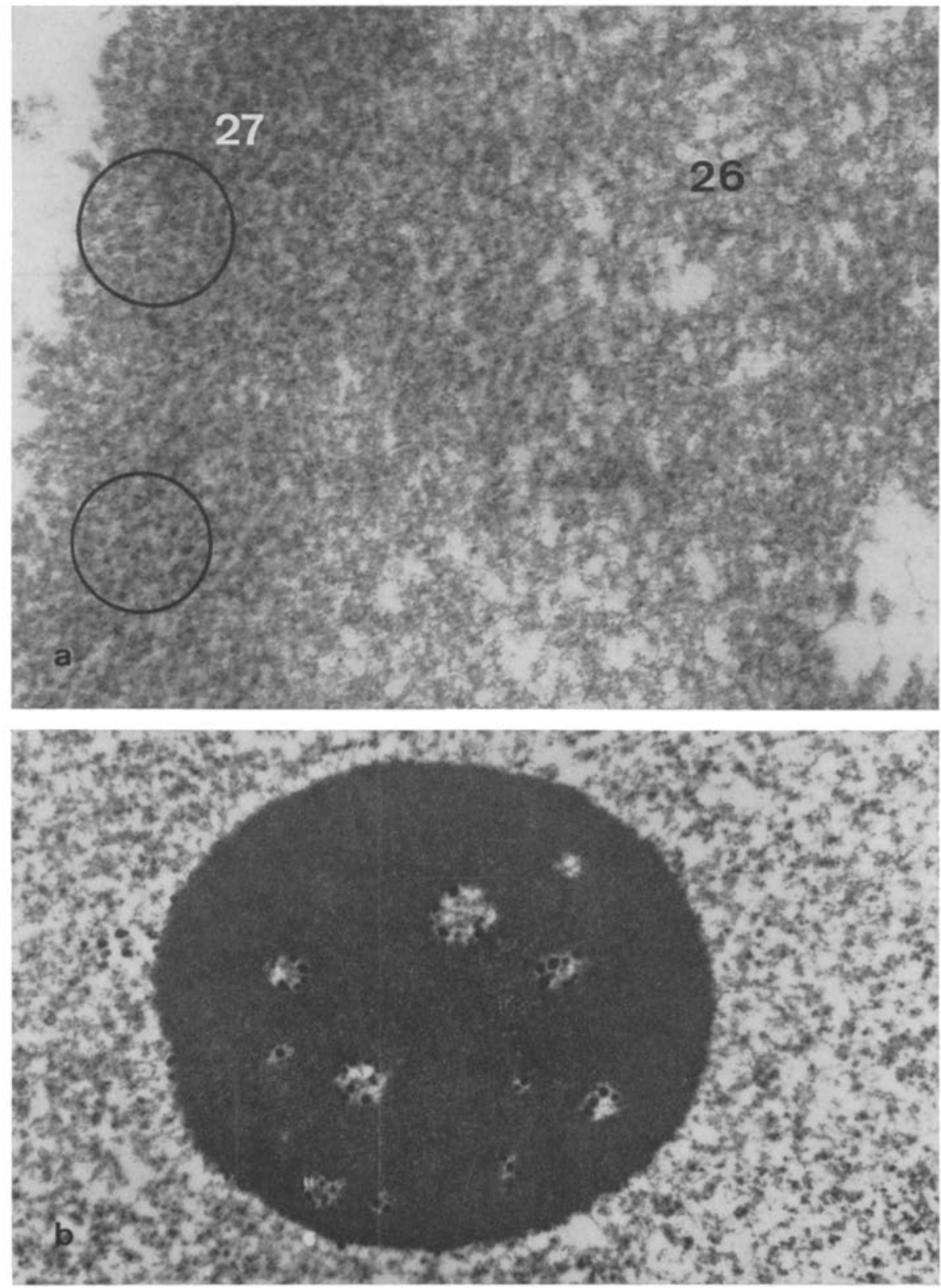

Abb. 16: a Nucleolus-Ausschnitt mit heterogen aufgebauten Grana im Pars granulosa (Kreise) (73000:1). $b$ Nucleolus mit stark osmiophilen Einschlïssen in den Vakuolen (14700:1). 26 Pars fibrosa; 27 Pars granulosa 


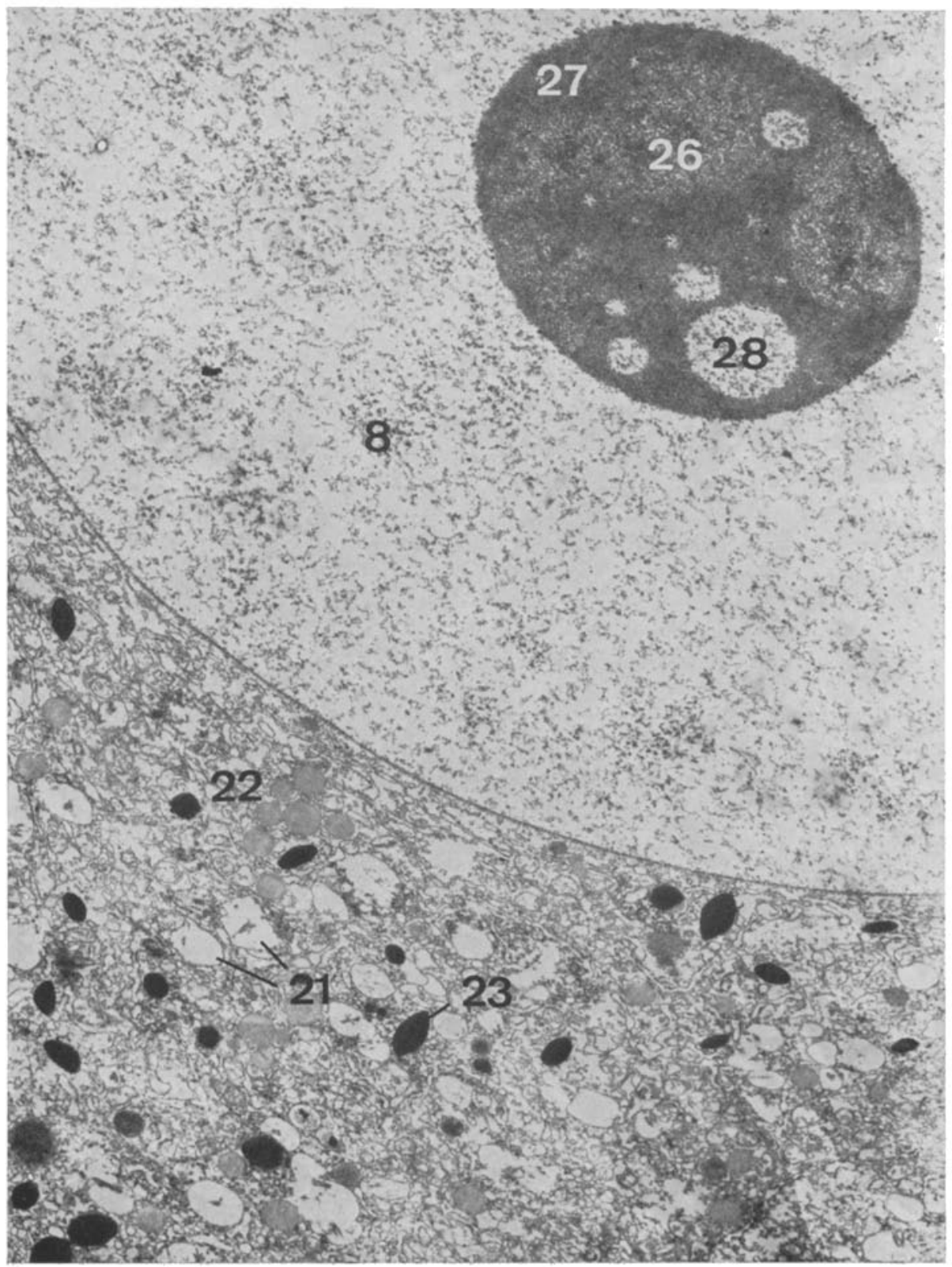

Abb. 17: Alte Wander-Oocyte mit Kernausschnitt und Nucleolus. 8 Kern; 21 Cytosom; 22 Lipidtropfen; 23 Springbrunnenkörper; 26 Pars fibrosa; 27 Pars granulosa; 28 Vakuole $(6000: 1)$ 
Ei- und Embryonalentwicklung von Corydendrium parasiticum
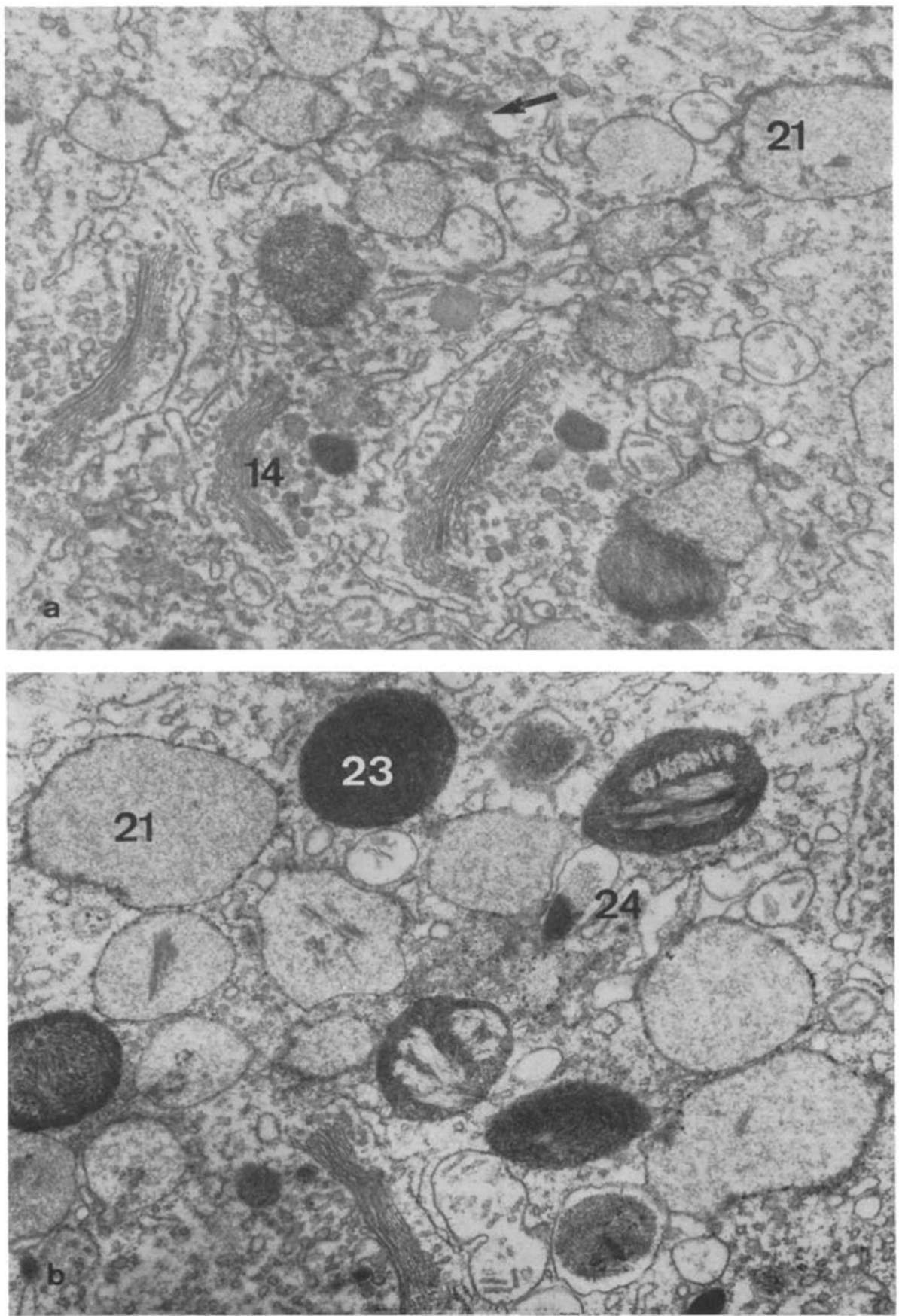

Abb. 18: Beginn der Komplexdotter-Bildung. a große Aktivität des Golgi-Apparates, Rückbildung von Cytoplasma-Anteilen (Pfeil) (16 200:1). $b$ teilweiser Abbau der Springbrunnenkörper (21000:1). 14 Dalton-Komplex; 21 Cytosom; 23 Springbrunnenkörper; 24 Doppelkörper 
im Cytoplasma. Ihr Durchmesser beträgt etwa $650 \mathrm{~nm}$. Die geringe Schwärzung durch Osmium läßt auf relativ gesättigte Fettsäuren in der Lipidzusammensetzung schließen.

Größere Veränderungen zeigen die Cytosomen und ein Teil der Springbrunnenkörper. Die Cytosomen verleihen nun dem Cytoplasma durch ihre große Anzahl, ihre Größe mit einem Durchmesser bis zu 1,8 $\mu \mathrm{m}$ und ihren zum Teil wenig elektronenoptisch dichten Inhalt besonders in Übersichtsaufnahmen ein vakuoläres Aussehen (Abb. 14a, 19a). Immer bleiben jedoch in ihnen die regelmäßigen, aus Tubuli zusammengesetzten cores nachweisbar. Die Abnahme des granulären Inhalts der Cytosomen ist vor allem dann zu beobachten, wenn diese zu größeren Einheiten verschmelzen. Aus derartigen Fusionen ergeben sich häufig die unregelmäßigen Formen der „Vakuolen“.

Die Veränderung der Springbrunnenkörper weist offenbar auf eine Ab- oder Umbauphase hin, die möglicherweise im Zusammenhang mit dem Beginn der Komplexdotter-Bildung steht. In ihrem Inneren und teilweise auch in ihrem Randbezirk zeigen sich nämlich Aufiösungserscheinungen (Abb. 18b), von denen zunächst die "Grundsubstanz" der Partikel betroffen ist. Dadurch wird die beschriebene SpringbrunnenStruktur wie ein fädiges Grundgerüst sichtbar.

\section{Junge Gonopboren-Oocyte}

Die Gonophoren-Oocyten sind nicht nur durch ihre Lage im Gonophor gekennzeichnet, sondern auch durch tiefgreifende strukturelle Unterschiede zu den WanderOocyten. In diesem Stadium haben nämlich die Oocyten ihre endgültige Reifungsstätte erreicht, an der sie bis zu ihrer Befruchtung verharren. Dieser stationäre Zustand hat zur Folge, daß die über jeder Eizelle liegende Endodermschicht zu einem Follikelepithel wird. Direkten Kontakt zur Eizelle zeigen jedoch nur einzelne Follikelzellen, die den 2,7 bis $3,5 \mu \mathrm{m}$ breiten perioocytären Raum zipfelartig überbrücken.

Es führte über den Rahmen dieses Kapitels hinaus, die feinstrukturellen Veränderungen der Entodermzellen zu Follikelzellen zu beschreiben, da optisch kein Einfluß dieser Zellen auf die Dotterbildung beobachtet werden kann. Daß allerdings eine stoffliche Beziehung zwischen Oocyte und Follikelepithel besteht, dokumentieren die zahlreich ausgebildeten, etwa $1,1 \mu \mathrm{m}$ langen Mikrovilli auf der Eizelloberfläche und die Grana im perioocytären Raum (Abb. 21a).

In den jungen Gonophoren-Oocyten vollzieht sich die Hauptphase der Komplexdotter-Bildung, die in der alten Wander-Oocyte bereits begonnen hat. Die zusammengesetzten Dotterpartikel („Komplexdotter") sind rund bis oval und erreichen einen

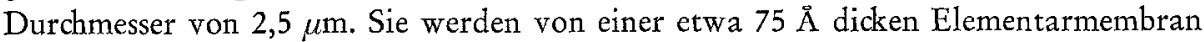
umgeben, die ihnen mehr oder weniger dicht anliegt. Der Komplexdotter besteht aus unstrukturiert erscheinendem Material, in das bis $1 \mu \mathrm{m}$ große, homogene Tröpfchen eingelagert sind (Abb. 20a). Anfangs gleichen diese Einschlüsse in Form und Kontrast den benachbarten Lipidtröpfchen. Sehr bald treten jedoch in ihnen granuläre Einlagerungen hervor, die später am deutlichsten in jungen Furchungsstadien zu erkennen sind (Abb. 20b). Im unstrukturierten Anteil der Dotterpartikel liegen mehrere $150 \mathrm{~nm}$ später bis $600 \mathrm{~nm}$ lange Strukturen, die Ahnlichkeit mit den cores der Cytosomen haben. $\mathrm{Da}$ es als sicher gelten kann, daß die Cytosomen direkt an der Bildung des Komplex- 

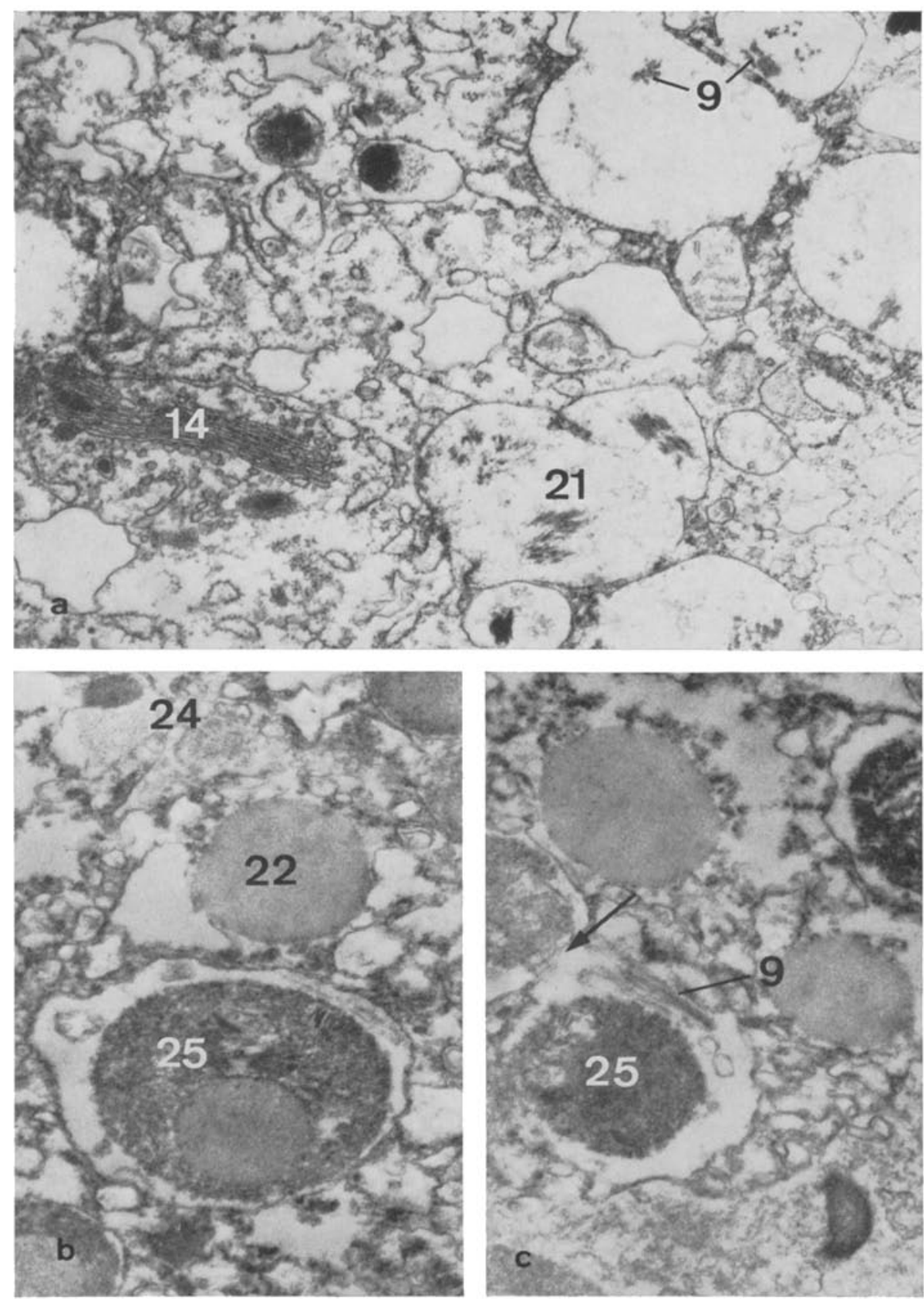

Abb. 19: a Konfluierende Cytosomen mit tubulären Innenstrukturen und wenig dichtem Inhalt $(28000: 1) . b(23000: 1)$ und $c(21600: 1)$ Komplexdotter-Bildung. Pfeil zeigt auf eine offene Verbindung mit einem angrenzenden Vesikel. 9 Innenstruktur; 14 Dalton-Komplex; 21 Cytosom; 22 Lipidtropfen; 24 Doppelkörper; 25 entstehender Komplexdotter 
dotters mitwirken, ist eine Herkunft dieser Strukturen aus den Cytosomen anzunehmen.

Der Komplexdotter entsteht offensichtlich auf verschiedene Weise. Eine dieser Möglichkeiten zeig̃ das Auftreten kleiner membranumgrenzter Partikel, die nach geringem Wachstum schon bald dem fertigen Komplexdotter gleichen (Abb. 19b, c). Alle drei sichtbaren Anteile sind in den anfangs etwa $300-450 \mathrm{~nm}$ großen Partikel enthalten: Ein meist in Einzahl vorkommender Innenkörper liegt in der unstrukturierten Grundsubstanz mit ihren kristallähnlichen Einschlüssen. Auf welche Weise die übrigen Organellen zum Wachstum des Komplexdotters beitragen, ist schwierig zu entscheiden. Neben einer autonomen Syntheseleistung scheinen die in sehr großer Anzahl im Cytoplasma vorhandenen Vesikel Material zu den Komplexdotter-Partikeln zu transportieren. Das transportierte Material würde dann durch Verschmelzung der Membranen in das entstehende Dotterkorn eingeschleust (Abb. 19b, c).

Die Cytosomen könnten in zweierlei Weise am Aufbau des Komplexdotters beteiligt sein: (1) Der Komplexdotter entsteht direkt in den Cytosomen (Abb. 14a). (2) Die Cytosomen treten erst in späteren Phasen in Kontakt mit dem schon sich bildenden Dotter, indem sie sich durch Membranverschmelzungen in die Dotterpartikel öffnen (Abb. 20a, Pfeil).

Das Cytosom-core kommt dabei neben den Komplexdotter-Inhalt zu liegen und könnte derart später in die unstrukturierte Randsubstanz verlagert werden. Dies ergäbe dann Übergangsstadien, die ein Bild vermitteln als ob der Dotter direkt in den Cytosomen gebildet würde. Der zweiten geschilderten Möglichkeit wird die größere Wahrscheinlichkeit eingeräumt.

Eine andere sehr häufige Entstehung des Komplexdotters beginnt mit dem Auftreten stark heterogener Körper. Durch Membranen unbekannter Herkunft werden zunächst Anteile des Cytoplasmas abgegrenzt, die Rückbildungserscheinungen, ähnlich der "focal cytoplasmic degradation", zeigen (Hruban et al. 1969) (Abb. 14a). Das eingeschlossene, großenteils sehr osmiophile Material ist meist von vielen kleinen Vesikeln durchsetzt und liegt häufig in der Nähe von Cytosomen. An seiner Herkunft sind wahrscheinlich der Golgi-Apparat, das endoplasmatische Retikulum und die Springbrunnenkörper beteiligt. Indirekte Hinweise dafür könnten im gänzlichen Verschwinden des granulären endoplasmatischen Retikulums der Gonophoren-Oocyte und in der zahlenmäßigen Abnahme der Springbrunnenkörper liegen, die mit der Bildung des Komplexdotters zusammenfällt. Morphologisch zeigen sich lokale Rückbildungen (wie Zisternenzerfall und Membranauflösung) des endoplasmatischen Retikulums meist in der Nähe von Cytosomen (Abb. 14a, 18a). Die Springbrunnenkörper liegen ebenfalls häufig in der Nähe sich bildender Dotterpartikel und verlieren hier stetig am Umfang. Dabei sinkt ihr großer Durchmesser auf $0,9 \mu \mathrm{m}$ und weniger ab. Möglicherweise steuern sie demnach Material zum Komplexdotter bei. Umstritten ist bei diesen Vorgängen die Rolle des Golgi-Apparates. Seine volle Ausbildung und damit die größte Vesikelproduktion erreicht er vor Bildung des Komplexdotters. Die Golgi-Vesikel zeigen zum Teil stark osmiophiles Material in ihrem Inneren, so daß sie unmittelbare Vorstufen der heterogenen Körper sein könnten (Abb. 18b, 19a). Eine Beteiligung des Golgi-Apparates wäre aber auch indirekt über die Bildung von Springbrunnenkörpern möglich. Schon bald tritt in den heterogenen Körpern die schon erwähnte 

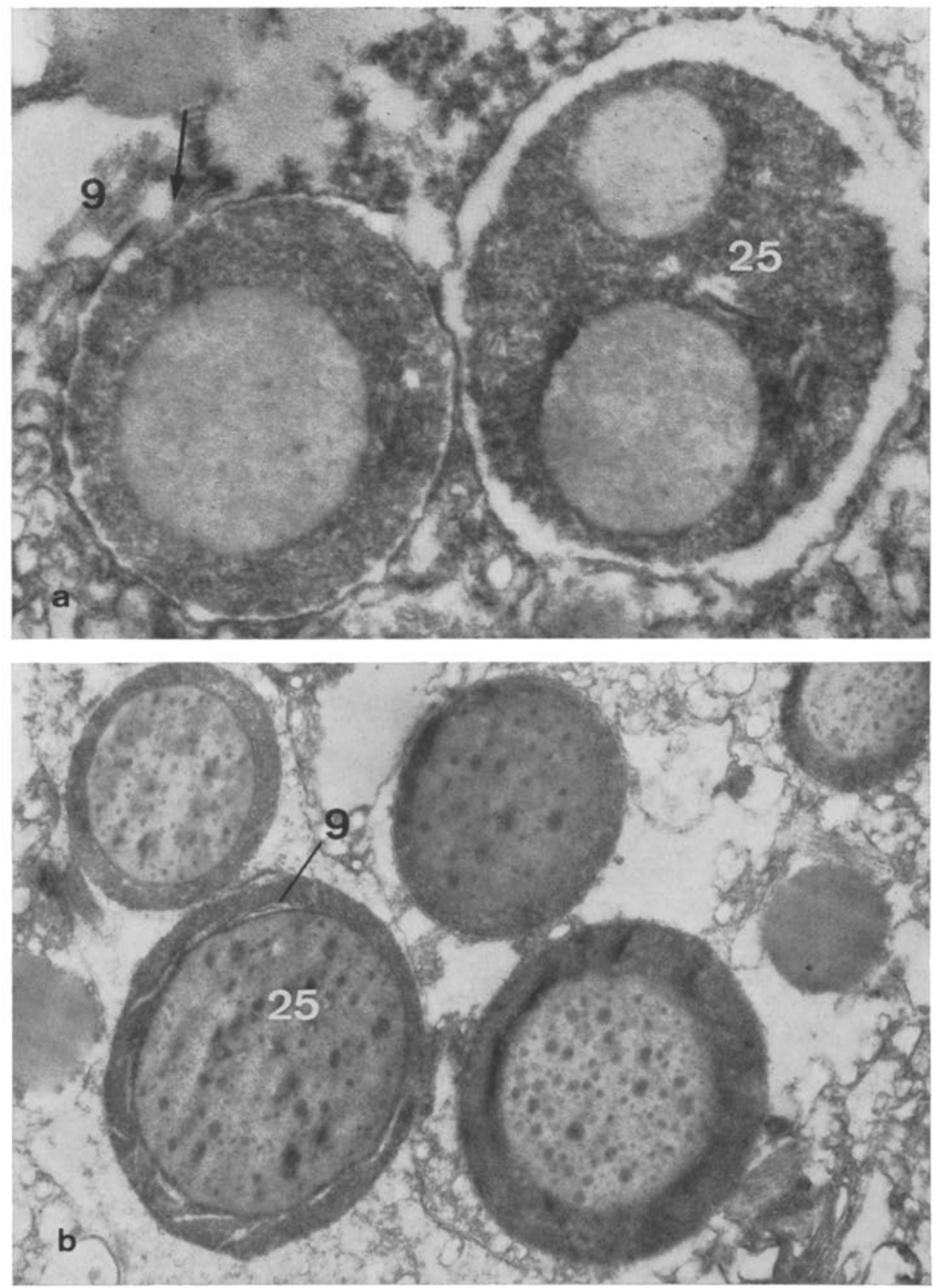

Abb. 20: a Komplexdotter in offener Verbindung mit einem Cytosom (Pfeil) (46000:1). $b$ Komplexdotter aus einem frühen Furchungsstadium mit seinen vier Komponenten: Randsubstanz mit parakristallinen, Innenkörper mit granulären Einschlüssen (16500:1). 9 parakristalliner Einschluß; 25 Komplexdotter 
kugelige Innenstruktur auf, und die heterogene Dottervorstufe gleicht immer mehr dem fertigen Komplexdotter.

Weitere Veränderungen in der jungen Gonophoren-Oocyte betreffen die Mitochondrien, die degenerieren und kaum noch als solche kenntlich sind. Erwähnenswert ist auch das vereinzelte Auftreten von Inseln strukturlosen Materials zwischen den Organellen. Am Kern und an seinem großen Nucleolus zeigen sich in diesem Stadium keine bemerkenswerten morphologischen Veränderungen.

\section{Alte Gonophoren-Oocyte}

Nach BIER (1967) stellt die Glykogen-Einlagerung in einer Zelle das Ergebnis eines plasmatischen Reifeprozesses dar, der die Zelle in die Nähe degenerativer Vorgänge führt. Die alte bis zu $170 \mu \mathrm{m}$ große Gonophoren-Oocyte ist durch das Auftreten von Glykogen gekennzeichnet. Uberall erscheinen zwischen den Organellen, jedoch ohne erkennbare Bezichungen zu diesen, Anhäufungen von Glykogen-Grana (Abb. 21a, b). Der Durchmesser dieser Aggregate des $\alpha$-Glykogens liegt zwischen 350 und $560 \AA \AA$. Möglicherweise steht die in einzelnen Inseln vorhandene Substanz mit dem Vorgang der Glykogenbildung in Zusammenhang.

Gegenüber der jungen Gonophoren-Oocyte hat sich die Vielfalt des Organellenbestandes und der Zellstrukturen verringert. Es dominieren nun die Reservesubstanzen, die auch noch in sehr jungen Furchungsstadien unverändert zu finden sind: Komplexdotter, Lipidtropfen und Glykogen. Außer diesen drei Dotterendprodukten zeigt die alte Gonophoren-Oocyte die schon erwähnten Inseln unstrukturierter Substanz, Doppelkörper, vereinzelt Springbrunnenkörper und einen neuen, ellipsoiden $1 \mu \mathrm{m}$ langen Partikeltyp, der „Homogenkörper" genannt werden soll (Abb. 21b). Seine Form ist mit der der Springbrunnenkörper vergleichbar, sein Inhalt jedoch ist vollkommen homogen und nicht so stark osmiophil. Frühstadien, die auf den Entstehungsmodus schließen ließen, wurden nicht gefunden. Alle letztgenannten Organellen haben gemeinsam, daß sie, bis auf wenige in jungen Furchungsstadien vorkommende Doppelkörper Ubergangsstrukturen sind.

Verständlicherweise ist der Ablauf der Dottergenese aus den Momentaufnahmen der Elektronenmikroskopie ohne histochemische und autoradiographische Methoden nur sehr unvollständig zu ermitteln. Die folgende tabellarische Ubersicht (Abb. 22) und das Schema (Abb. 23) können daher nur den Organellenbestand der einzelnen Eistadien aufzeigen. Doch an Hand vermuterer Übergangsformen zwischen den verschiedenen Organellen kann der Versuch einer Rekonstruktion der gesamten Dottergenese unternommen werden. Dabei sollen der Organellenbestand und die wesentlichen Strukturveränderungen während der Dotterbildung in ihrem zeitlichen Ablauf auf einen Blick gezeigt werden. Dadurch läßt sich unabhängig von Verteilungsdichte und Größenverhältnissen der Organellen zueinander, am ehesten ein Bild von der bedeutenden Umgestaltung des Cytoplasmas während der Vitellogenese vermitteln (Abb. 23).

\section{Diskussion der Vitellogenese}

Die elektronenmikroskopische Analyse der Dotterbildung bei Corydendrium parasiticum offenbart das Zusammenwirken vieler Organellen. Ein derart beziehungs- 

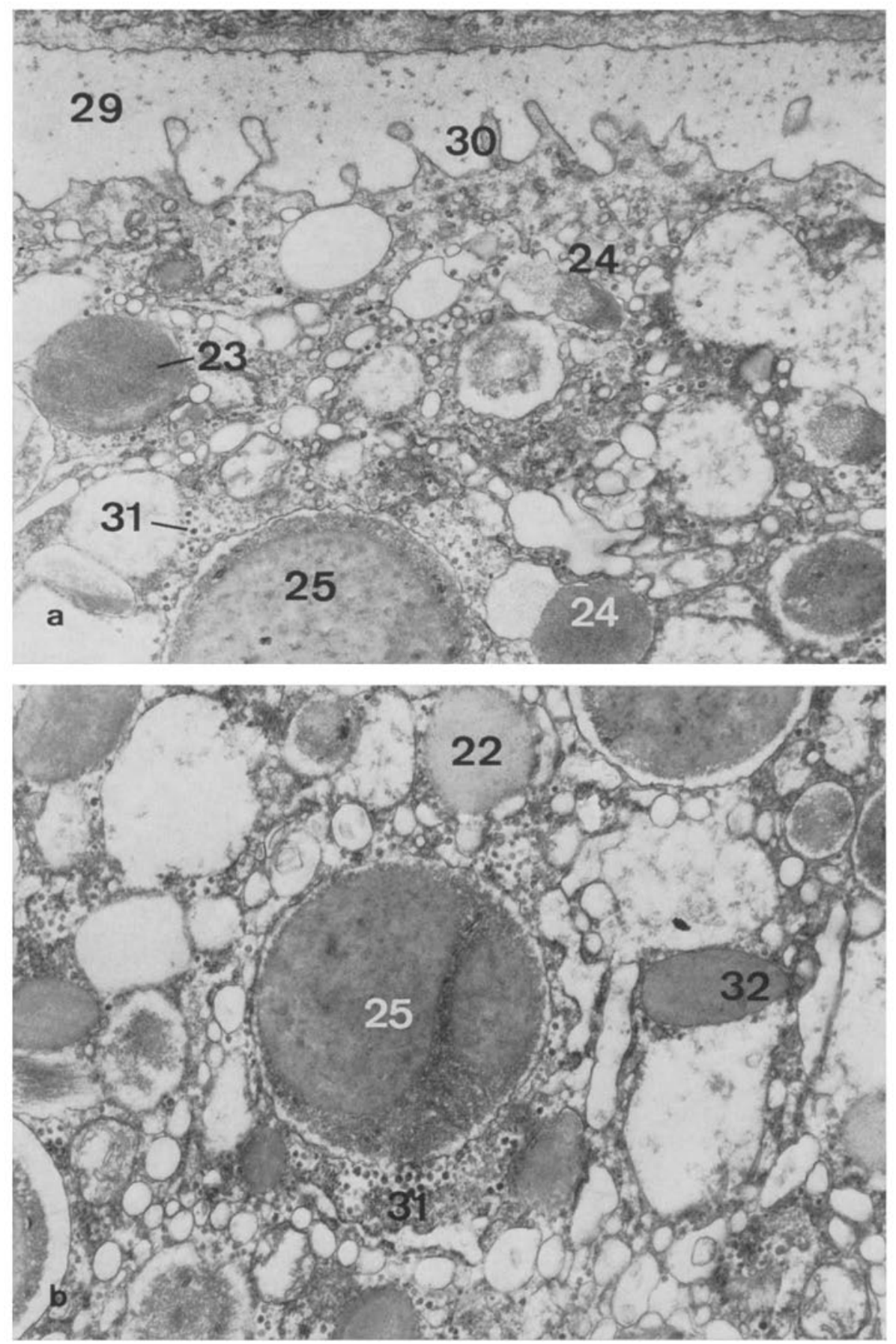

Abb. 21: a Randzone einer alten Gonophoren-Oocyte (20000:1). $b$ Organellen einer aiten Gonophoren-Oocyte (21 800:1). 22 Lipidtropfen; 23 Springbrunnenkörper; 24 Doppelkörper; 25 Komplexdotter; 29 perioocytärer Raum; 30 Mikrovilli; 31 Glykogen; 32 Homogenkörper 


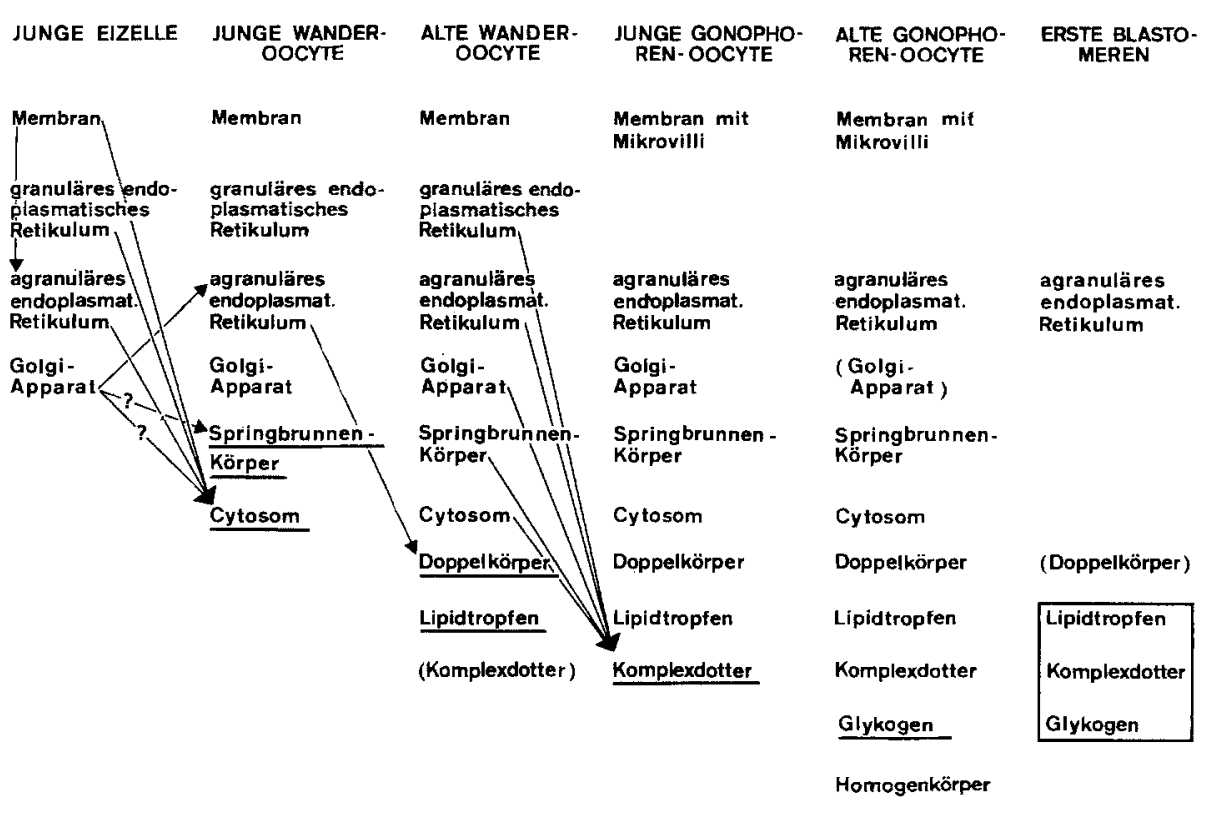

Abb. 22: Übersicht über die Stadien der Vitellogenese von Corydendrium parasiticum. Die durch Pfeile gekennzeichneten Beziehungen zwischen den Organellen sind in folgenden Stadien an entsprechender Stelle zu denken; für die einzelnen Stadien charakteristischen Organellen sind unterstrichen, die Dotterendprodukte umrandet (gezeichnet von A. Bleichner, Gießen)

reiches Cytoplasma-Gefüge von der jungen Oocyte an bis zum befruchtungsfähigen Ei bereitet der Interpretation große Schwierigkeiten. Entsprechende Arbeiten an Hydroiden gibt es nur wenig (Stagni \& Lucci 1964, Kawagutr \& Ogasawara 1967, Kessed 1968a). Daher müssen Untersuchungen über die Oogenese anderer Tiergruppen zum Vergleich herangezogen werden (Anderson 1968, Kessel 1968b, c, Kessel \& Beams 1968, Millonig et al. 1968, Emanuelsson 1969, Hinsch \& Cone 1969, Pasteels 1969, Thomas 1969 und andere*).

Da eine histochemische Analyse der Eientwicklung von C. parasiticum noch aussteht, soll auf die Stoffnatur der Dotterpartikel nur insoweit eingegangen werden als sie morphologisch eindeutig ist, zum Beispiel die von Lipidtropfen oder Glykogen. Mit dem Fehlen der stofflichen Charakterisierung der Dotterpartikel bzw. ihrer Vorstufen entfällt ein wesentlicher Bezugspunkt beim Vergleich verschiedener Vitellogenesen. Als eine andere, oft benutzte Ausgangsbasis für den Vergleich bietet sich aber der Bestand an regelmäßig in der Zelle auftretenden Organellen an wie etwa des Kerns mit seinem Nucleolus, der verschiedenen Membransysteme des granulären und agranulären endoplasmatischen Retikulums, des Golgi-Apparates und der Mitochondrien. Infolge vergleichbarer Strukturveränderungen und ähnlicher Beziehungen dieser Organellen zueinander wird dabei die Deutung der beobachteten Dotterbildung erleichtert.

* Vor 1968 veröffentlichte Arbeiten sind bei NørRevang (1968) zitiert. 


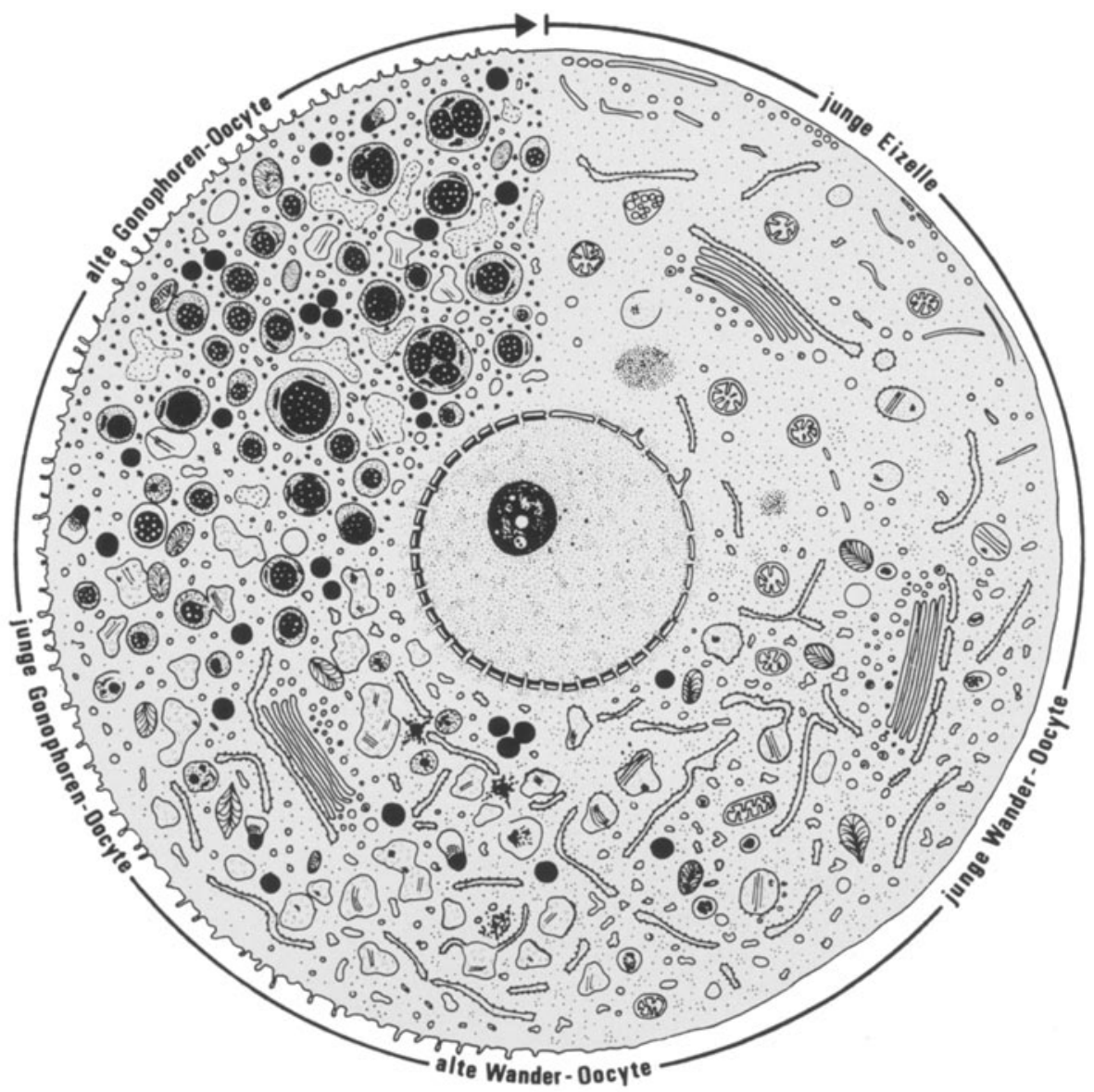

$\begin{array}{llll}\text { Granuläres ER } & \text { Doppelkörper } \\ \text { Cytochondrium } & \text { Springbrunnenkörper } & \text { Komplexdotter-Stadien } \\ \text { Lipidtropfen } & & \text { Homogoter }\end{array}$

Abb. 23: Schema der Vitellogenese von der jungen Eizelle bis zur reifen Oocyte (alte Gonophoren-Oocyte). Die Beziehungen der verschiedenen Organellen zueinander sind der Abbildung 22 zu entnehmen 
Der Kern als Steuerzentrale für das Riesenwachstum der Eizelle ist Objekt zahlreicher Einzeluntersuchungen (vgl. Dalton \& Haguenau 1968). Insbesondere die Art seiner Beziehung zum Cytoplasma und die Funktion seines Nucleolus sind nur teilweise gelöst und werden daher immer wieder in Angriff genommen.

Als Grenze zwischen Karyo- und Cytoplasma spielt die Kernmembran eine bedeutende Rolle. Thre erste Untersuchung bei Amphibien-Oocyten war der Beginn der Feinstrukturanalyse dieser Zellen überhaupt (CALLAN \& TomLin 1950). Die Kernmembran besteht aus zwei Elementarmembranen, die einen perinucleären Spalt von wechselnder Breite begrenzen. Kennzeichnend für die Kernmembran der Wander-Oocyte von Corydendrium parasiticum ist eine Verstärkung der inneren Membran, die ihr eine Ähnlichkeit mit der von FAwCETT (1966) beschriebenen $300 \AA$ Ả dicken „fibrous lamina" verleiht. FAwCETT führt als Beispiele die Kernmembranen der Darmepithelzellen von Amphiuma, die von Amoeba proteus und die von Nervenzellen verschiedener Invertebraten an. In einer späteren Untersuchung berichten PATRIZI \& Poger (1967) von einer "Zonula nucleum limitans", die außer ihrer etwas abweichenden Dimension (400-600 Å) der "fibrous lamina" entspricht. Die Autoren werten dabei außer eigenen Aufnahmen auch Abbildungen verschiedener anderer Veröffentlichungen aus und schreiben der "Zonula nucleum limitans" eine wichtige, nicht näher ausgeführte Funktion zu. FAwCETT glaubt, daß die „fibrous lamina“ aus einem Skleroprotein besteht und Stützfunktion besitzt. Infolge ihrer Größe ist bei den Oocyten-Kernen eine Membranverstärkung in der beschriebenen Weise wahrscheinlich.

Eine besondere Bildung der Kernmembran sind die Kernporen, mit zusätzlichen Strukturen, auch Porenkomplexe genannt (WATSON 1959). Da sie die einzige offene Verbindung zwischen Kern- und Cytoplasma darstellen, wird ihnen eine große Bedeutung beim Stoffaustausch zwischen beiden Zellbereichen beigemessen. Daß aber neben den Poren noch andere Eigenschaften der Kernmembran für den Stoffaustausch

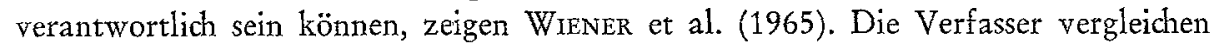
Kernmembranen, die sich als starke Ionenbarrieren erwiesen haben (Speicheldrüsenzellkerne von Drosopbila und Chironomus) mit solchen, die für Ionen durchlässiger sind (Oocyten-Kerne von Xenopus und Triturus). Doch konnte hinsichtlich ihrer Porengröße, -zahl, -verteilung und -inhalt zwischen beiden Gruppen kein Unterschied festgestellt werden, so daß dieses Problem offensichtlich nicht elektronenmikroskopisch $\mathrm{zu}$ lösen ist.

Der morphologische Nachweis eines Stofftransportes vom Kern ins Cytoplasma und umgekehrt durch die Kernporen ist vielfach erbracht worden (z. B. FELDHERR 1962, Wessing 1965, Kessel \& Beams 1968, Scharrer \& Wurzelmann 1969, Merriam 1969). Auf einen derartigen Transport läßt sich auf Grund gleichstrukturierten Materials beiderseits der Kernmembran indirekt auch bei der Corydendrium-Oocyte schließen.

Da zur Feinstruktur des Porenkomplexes im vorliegenden Kapitel wenig gesagt werden kann, mag der Hinweis auf seine 8strahlige Radiärsymmetrie genügen. Ein auch ohne Markham-Analyse (MARKham et al. 1963, Agrawal et al. 1965) eindrucksvolles Beispiel dafür sind die Kernporen der Amoebe Pelomyxa carolinensis (Daniels et al. 1969). In Detailstrukturen bestehen allerdings noch größere Unterschiede (ABELson et al. 1970, Franke 1970, Franke \& Scheer 1970a, b, Kessel 1969). Diskutiert 
wird neuerdings auch die Bildung von Polyribosomen in den Kernporen (Mepham \& LANE 1969).

Eine zentrale Stellung während der Vitellogenese nimmt der Nucleolus ein. In keiner tierischen Zelle ist seine Tätigkeit intensiver als in heranwachsenden Oocyten. In der Hauptsache liefert er ribosomale RNS, die vermutlich als Ribosomenvorstufen ins Cytoplasma gelangen. Wie allgemein bei kleineren Eiern, z. B. von Schwämmen, Echinodermen und Säugern zu beobachten ist, besitzen auch die Oocyten von Corydendrium parasiticum einen einzelnen, großen Nucleolus. Seine höchste Differenzierung, die vermutlich auch das Funktionsoptimum bedeutet, erreicht er in der alten Wander-Oocyte, wenn die Dotterbildung in die entscheidende Phase, nämlich ins Stadium zwischen alter Wander-Oocyte und Gonophoren-Oocyte eintritt.

Mit Hilfe von Verdauungsexperimenten und anderen Methoden konnten GHosH et al. (1969) das im kompakten Nucleolus von Fibroblastenkernen maskiert vorliegende Nucleolonema sichtbar machen und analysieren. Es zeigt dabei einen sehr komplexen Aufbau aus DNS-, DNS-RNS-Hybriden, RNS, RNS-Protein-Komplexen Proteinen und Lipiden. Das elektronenmikroskopische Bild dieser Struktur vermittelt daher nur einen stark vergröbernden unvollkommenen Eindruck. Die aufgereiht angeordneten Grana im Nucleolus verschiedener Vertebraten-Zellarten konnten erstmals Horstmann \& KNOOP (1958) zeigen, Wartenberg (1962) auch am Oocyten-Nucleolus von Triturus. Die stellenweise regelmäßige Anordnung von Grana in der Pars granulosa weist ebenfalls auf eine hochdifferenzierte Struktur des Nucleolus hin, von der wir bis heute noch keine allgemeingültige Modellvorstellung besitzen. Der beobachtete heterogene Bau der Grana könnte auf Untereinheiten hinweisen, wie sie FLORENDO (1969) an Ribosomen von Mäuse-Leberzellen beobachtet hat. Doch ist eine unmittelbare morphologische Beziehung zwischen Ribosomen und Nucleolus-Grana unwahrscheinlich. Möglicherweise sind diese Grana ähnlich wie die Ribosomen im Cytoplasma, an der Proteinsynthese im Kern beteiligt und gehören zu der Art von RNS, die später wieder abgebaut wird, ohne im Cytoplasma zur Translation zu gelangen. MonNeron $8 x$ Bernhard (1969) lehnen den Ausdruck „Kern-Ribosomen" als unbewiesen ab.

Die Vakuolenbildung im Nucleolus wird von WARTENBERg (1962) als Vergrößerung der inneren Oberfläche des hochaktiven Nucleolus gedeutet. Besonders deutlich wird dies in Nährzellen von Drosophila (Dapples \& KING 1970). Ihr Nucleolus formt nämlich nahe der inneren Kernmembran ein dickes, schalenförmiges Netzwerk, dessen runde Zonen (Vakuolen) wie aus Serienschnitten rekonstruiert wurde, allseitig von Nucleolusmaterial umgeben sind. Strukturell gleicht der Vakuoleninhalt dem Karyoplasma, doch wird ihm häufig ein erwähnenswerter Proteingehalt zugeschrieben (Hay 1968, Dapples \& King 1970). In jedem Fall steht aber die Ausbildung der Vakuolen in einer bestimmten Beziehung zur Tätigkeit des Nucleolus (WEssing 1965). Bislang nicht zu deuten sind die in den Vakuolen auftretenden dichten, osmiophilen Körper.

Eng mit dem Nucleolus hängen offenbar die beiden granulären Differenzierungen in Cytoplasma der jungen Oocyte zu Beginn der Vitellogenese zusammen. Freie Ribosomen sind ein allgemeines Kennzeichen junger Eizellen. Ihre Herkunft aus dem Kern dürtte unbestritten sein (z. B. JonEs 1965). Bemerkenswerter ist aber das Auftreten einer zweiten granulären Bildung. BALINSKI \& Devis (1963) verfolgen die Her- 
kunft ähnlichen Materials aus dem Oocyten-Kern und dessen spätere enge Beziehung zu den Mitochondrien (,intramitochondrial cement“). Vergleichbare Granula-Anhäufungen beschreiben auch KesSel (1966, 1968b, c), WEAkLEY (1969) und HaNisCH (1970) und vermuten deren Ursprung im Nucleolus. WEAKLEY diskutiert drei Möglichkeiten der Bedeutung dieser BILDUNGEN, wovon die nachstehende Deutung für Corydendrium eine gewisse Wahrscheinlichkeit haben könnte: Die Ansammlung unstrukturierten Materials stammt aus dem Kern und stellt Vorstufen der Ribosomen dar. In den ersten Stadien der Dotterbildung verschwinden nämlich diese Ansammlungen, und auch die Ribosomen kommen anscheinend nur noch membrangebunden im granulären endoplasmatischen Retikulum vor.

Alle Dottervorstufen sind von einer Elementarmembran umgeben. Demnach würden sie also in Vesikeln entstehen oder hier akkumuliert. WARTENBERG (1962) faßt die Summe der Vesikel und Cytosomen in der Amphibien-Eizelle unter dem von SchмrDT (1962) geprägten Begriff, „vakuolärer Apparat" zusammen. Er begründet dies mit einer gleichgerichteten Funktion dieser verschiedenartigen Bildungen. Damit wird jedoch, um „alle Theorien auf einen Nenner" bringen zu können (p. 456), die unterschiedliche Beteiligung der verschiedenen Organellen an der Zelleistung verschleiert. Der Begriff „vakuolärer Apparat" setzt etwas als bekannt voraus, was häufig noch nicht der Fall ist. Ahnlich dürfte der Begriff „agranuläres endoplasmatisches Retikulum“ für das System der glatten Membranen eine Vereinfachung darstellen. Die ungenügende Kenntnis über die verschiedenen Funktionen dieser Zellstrukturen läßt jedoch zur Zeit keine weitergehende Differenzierung zu.

Das agranuläre und granuläre endoplasmatische Retikulum und der Golgi-Apparat sind die Lieferanten der Vesikel im Ei-Cytoplasma. Alle drei Membransysteme, die nach ihrer Entstehung untereinander in Verbindung stehen, sind an der Dotterbildung beteiligt. Schwierigkeiten macht jedoch die Interpretation des zeitlichen Ablaufes ihrer Zusammenarbeit. So werden als erste Bildung dieser Organellen die Cytosomen von zwei unterschiedlichen Membrananteilen begrenzt. Der granuläre Anteil stammt eindeutig vom granulären endoplasmatischen Retikulum ab. Am glatten Anteil können sowohl der Golgi-Apparat als auch das agranuläre endoplasmatische Retikulum beteiligt sein. Auch eine Neubildung im Cytoplasma ist möglich. Für alle diese Entstehungsmöglichkeiten finden sich Hinweise in den Abbildungen.

Für die Cytosombildung kommt der Golgi-Apparat vermutlich nicht in Frage. Die Membranen der Vesikel, die ihm entstammen, sind nämlich dicker als die der Cytosomen. Zudem zeigen sich Unterschiede in der Struktur des Inhalts beider Vesikelformen. Glatte Membranen entstehen in großer Zahl in Form von Bläschen an der Zellperipherie. Sie bilden, neben sicherlich auch neu im Cytoplasma der Eizelle geformten Membranen, das agranuläre endoplasmatische Retikulum. Aus diesem entsteht dann durch Auflagerung von freien Ribosomen teilweise granuläres endoplasmatisches Retikulum. Eine derartige Entstehung diskutieren auch Godman \& PORTER (1960). Für eine Bildung des granulären endoplasmatischen Retikulums aus der äußeren Kernmembran der Corydendrium-Oocyte gibt es gewisse, jedoch nicht sehr ausgeprägte Hinweise.

GöTTING (1966) hat an Teleosteer-Oocyten in der Phase des intensiven Wachstums ebenfalls langestreckte Membranen beobachtet, die in Vesikel zerfallen. Er nimmt aber an, daß sie in die Oocyten-Membran eingebaut werden. Bei Corydendrium wird 
auf den umgekehrten Vorgang geschlossen, da der Membranbedarf im Cytoplasma offensichtlich bedeutend höher ist als an der wachsenden Oocyten-Membran. Eine andersartige Beteiligung der Zellmembran beschreibt Kessel (1968a) bei einer Hydromeduse. Hier bilden tiefe Ausstülpungen des Oolemms mit dem granulären endoplasmatischen Retikulum Membranstapel, in denen beide Anteile alternieren. Die enge Verflechtung von agranulärem und granulärem endoplasmatischem Retikulum spiegelt sich im Membranaufbau der Cytosomen. Es kann angenommen werden, daß einerseits eine im Cytoplasma neugebildete, glatte Membran einen chemisch schon veränderten Cytoplasmabezirl umschließt, zum anderen können sich an der Zellperipherie gebildete Vesikel direkt zu Cytosomen vergrößern. Anschließend fusionieren Vesikel oder Zisternen des granulären endoplasmatischen Retikulums mit den neugebildeten Cytosomen, indem sie ihren Inhalt in sie entleeren und ihren Membrananteil mit den Cytosomen verschmelzen. Bis zum Ende der Dotterbildung sind die Cytosomen durch den parakristallinen Einschluß und ihre enge Verbindung zum granulären endoplasmatischen Retikulum gekennzeichnet. Diese beiden morphologischen Charakteristika zusammen kommen sonst nur noch den „microbodies" $\mathrm{zu}^{*}$.

Der Begriff „microbody“ wurde zuerst von RHodin (1954) für Cytoplasma-Einschlüsse in Zellen von Nieren-Tubuli der Maus geprägt. Roumlner \& BernHard (1956) beschrieben ähnliche Einschlüsse, die dazu eine elektronendichte Struktur im Inneren zeigen, aus Leberparenchymzellen der Ratte. Erstmals berichten HrubAN \& SwIFT (1964) von einer vieltubulären Struktur des „crystalloids“ in Lebermicrobodies. Die Matrix der Microbodies wird gewöhnlich als feingranulär (z. B. MAunsBach 1966) und weniger häufig als homogen (u. a. TRump \& ERICSSON 1964) beschrieben. Der parakristalline Innenkörper besitzt so mannigfaltige Ausprägungen, daß HRUBAN \& RECHCIGL (1969) eine nach SHNITKA (1966) modifizierte Klassifizierung mit 12 verschiedenen Typen vorschlagen. Nach dieser Einteilung könnte man die cores der Oocyten-Cytosomen den fein-multitubulären Kristalloiden zuordnen. Microbody-ähnliche Strukturen wurden auch in anderen Geweben als denen von Leber und Niere gefunden wie etwa in Sertoli-Zellen der Katze, Endothelzellen der Fischkiemenkapillaren, Mucosazellen des Hundemagens und andere mehr (vgl. Hruban \& Rechcigl 1969). Das Enzym-Spektrum als entscheidendes Kriterium beim Vergleich mit den Nieren- und Lebermicrobodies blieb dabei freilich oft unberücksichtigt. Microbodies enthalten nämlich Katalase und ein bis mehrere oxidative Enzyme. Solange also der entsprechende Enzymnachweis bei den Oocyten-Cytosomen nicht geführt worden ist, kann nicht mit Sicherheit von Microbodies gesprochen werden. Zieht man aber in Betracht, daß in Leberzellen wie auch in Oocyten der Kohlenhydratstoffwechsel eine entscheidende Rolle spielt, dann erscheint eine Verwandtschaft zwischen beiden Bildungen als durchaus möglich. Weitere Untersuchungen könnten hierüber Aufschluß geben.

Die Aufgabe des Golgi-Apparates bei der Dotterbildung wird bei den verschiedenen untersuchten Tieren uneinheitlich beurteilt. Auffällig ist aber die enge topographische Beziehung eines Teils des granulären endoplasmatischen Retikulums zu den Dalton-Komplexen, wie sie offensichtlich bisher nur bei Hydroiden-Oocyten beob-

"Die angeführten Arbeiten zum Thema "microbody" sind ausnahmslos nach dem umfangreichen Referat von HRUBAN \& ReCHCIGL (1969) zitiert. 
achtet wurde (KESSEL 1968a). Dies läßt auch auf eine enge funktionelle Verflechtung beider Organellen schließen, wie sie ihren Ausdruck in der gegenseitigen Konvertibilität beider Membransysteme finden kann (z. B. GRIMSTONE 1969, ESSNER \& NovIKOFF 1962; siehe auch das ausführliche Referat von BEAMS \& KESSEL 1968). Eine direkte Zusammenarbeit von Golgi-Apparat und granulärem endoplasmatischem Retikulum, wie sie Kessel schildert, kann bei Corydendrium nicht nachgewiesen werden. Nach Kessel liefert der Golgi-Apparat die Hauptmenge des Kohlenhydratanteils, das granuläre endoplasmatische Retikulum dagegen die Proteinkomponente des Dotters. Letztlich sind aber bei Corydendrium beide Systeme gemeinsam am Aufbau des Komplexdotters beteiligt, nämlich das Retikulum über die Cytosomen und der Golgi-Apparat über die Springbrunnenkörper. Die Mitwirkung des granulären endoplasmatischen Retikulums an der Dotterbildung wurde bereits im Zusammenhang mit den Cytosomen diskutiert. Die Beteiligung des Golgi-Apparates an der Vitellogenese könnte sich einerseits in der Membranlieferung erschöpfen (u. a. Wartenberg 1962, BeAms \& KesseL 1963, GötTINg 1966), andererseits aber in der unmittelbaren Dotterbildung bestehen (u. a. Worley \& Moriber 1961 bei Crepidula, Hsu 1962 bei dem Tunicaten Boltenia villosa und Droller \& Roth 1966 bei Lebistes). Häufig, wie auch bei Corydendrium, liefern die Dalton-Komplexe jedoch Vorstufen zur Dottersynthese (z. B. BeAms $8 z$ Sekhon 1966, Kessel 1966, 1968a, Hinsch \& Cone 1969). Bei Corydendrium wird der Springbrunnenkörper als eine vom Golgi-Apparat abstammende Dottervorstufe angesehen. Eine ihm entsprechende Struktur ist in Oocyten noch nicht beschrieben worden. Allerdings könnten die Golgi-Vesikel auch Primärstadien für die Komplexdotterpartikeln darstellen.

$\mathrm{Da}$ es über den Beginn der Komplexdotterbildung vorläufig nur Spekulationen geben kann, soll er hier auch nicht ausführlicher diskutiert werden. Sicher ist jedoch, daß am Aufbau eine Vielzahl cytoplasmatischer Strukturen mitwirkt. Eine histochemische Analyse seiner vier Komponenten würde wahrscheinlich unsere Kenntnis vom großen Potenzgehalt der Eizelle erweitern. Vor allem wäre von Interesse, in welcher Form die für die spätere Embryonalentwicklung so wichtige m-RNS maskiert vorliegt (vgl. Dusprva 1969), und ob die parakristallinen Strukturen den in Dotterschollen schon nachgewiesenen Enzymen entsprechen (z. B. PAsteELs 1969).

Unabhängig von bestimmten Membransystemen scheint die Bildung der Lipidtröpfchen abzulaufen (u.a. Hsu 1962, PAsteEls \& DE. HARven 1963, Norrevang 1965). Auch das Glykogen, das die alte Gonophoren-Oocyte auszeichnet, liegt ohne Beziehung zu bestimmten Organellen im Cytoplasma. Bei der Anthomeduse Spirocodon saltatrix ist Glykogen sogar neben zahlreichen granulahaltigen Vesikel die einzige Form der Reservesubstanz (Kawaguti \& Ogasawara 1967).

Da die Komplexdotterpartikel, die Lipidtröpfchen und das Glykogen bei Corydendrium-Oocyten sicherlich die drei einzigen Formen der Reservesubstanz sind, bleibt nur noch die Rolle der Doppelkörper und der Homogenkörper zu klären. Vor der Furchung bildet die Eizelle eine Art Periderm als Embryonalhülle aus, die sie an die Außenwand des Gonophors festkittet. Möglicherweise sind die Doppelkörper an diesem Prozeß beteiligt, wie sich aus ihrem relativ häufigen Vorkommen in Nähe der Eirinde schließen ließe. Sie sind aber wahrscheinlich nicht den cortikalen Granula vieler Oocyten gleichzusetzen, obwohl ihre Ahnlichkeit etwa mit den Rindengranula von 
Mytilus edulis verblüffend ist (Humphreys 1967). Welche Rolle die ovoiden Homogenkörper spielen, bleibt ebenfalls unklar. Immerhin ist die Beteiligung der beiden letztgenannten Strukturen an einer Art Befruchtungsreaktion der Eirinde nicht auszuschließen.

Ahnlich wie bei der von KesSEL (1968a) beschriebenen Hydromeduse dürfte die intraoocytäre Dotterbildung bei Corydendrium parasiticum die extra-oocytäre überwiegen. Die morphologischen Veränderungen der Eioberfläche (Mikrovilli) und der Follikelzellen (Ausläufer) während der Dotterbildung sind aber ohne Zweifel Ausdruck einer aktiven physiologischen Beziehung zwischen ihnen. Der Beweis eines Stoffaustausches kann jedoch nur mit autoradiographischen Methoden erbracht werden.

\section{Die Embryogenese}

\section{Frïbe Furchung}

Eine Untersuchung der Furchungsschritte unter genauer Zeitdeterminierung der Stadienfolge war nicht möglich. Diese mußten daher aus Schnittserien von Eitrauben rekonstruiert werden. Nur einmal gelang es, aus Gonophoren gequetschte Eier künstlich zu befruchten. Die angegebenen Zeiten für das Einsetzen der einzelnen Furchungsteilungen nach der Befruchtung gelten daher nur für diesen Fall. Die Furchung von Corydendrium parasiticum ist total und äqual. Wie bei allen Hydroiden mit totaler Furchung ist die erste Furche schneidend. Vermutlich beginnt sie am animalen Pol; doch war dessen Identifizierung mit den normalen histologischen Methoden nicht möglich, da er kein entsprechendes morphologisches Merkmal aufweist wie etwa die vegetative Eihälfte von Sertularia (Amphisbetia) operculata das organgefarbige Pigment

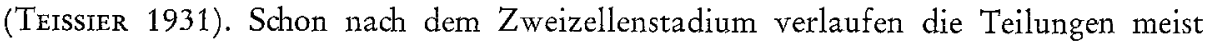
nicht mehr synchron, wie sich aus der Häufigkeit der mit drei getrennten Blastomeren und vier Kernen gefundenen Stadien schließen läßt.

Beim zweiten Furchungsschritt sind zwei Arten der Kernstellungen möglich: (1) Die Verbindungsachsen der Tochterkerne stehen parallel zueinander und (2) sie stehen senkrecht aufeinander.

In einem. Fall standen sie nur im Winkel von $45^{\circ}$ zueinander, also in einer Art Zwischenstellung. $\mathrm{Ob}$ die Kreuzstellung der Tochterkernachsen und damit der vier resultierenden Blastomeren primär durch die Kreuzstellung der Spindeln bedingt ist, oder ob sie durch nachträgliche Verschiebung der Blastomeren bzw. Wanderung der Tochterkerne hervorgerufen wird, muß offenbleiben. Die Drehung der ersten beiden Blastomeren könnte nämlich schon während der Teilung erfolgen. Dies würde auch erklären, warum im 2-Zellenstadium parallele wie auch gekreuzte Verbindungsachsen der Tochterkerne vorkommen (vgl. p. 272). Letztlich aber stehen die Blastomeren des vollendeten 4-Zellenstadiums immer auf Lücke oder „kreuzförmig“. Ihre Abstammung voneinander ist dann nicht mehr festzustellen (Abb. 24).

Abbildung 24 zeigt ein Schema der möglichen und beobachteten Teilungsrichtungen bis zum 4-Zellenstadium (8). Die Blastomeren sind ohne Rücksicht auf ihre gerundete Form als Kugelhälften bzw. -segmente gezeichnet. Das natürliche Bild eines 
4-Zellenstadiums, z. B. rechts neben Stadium 8, würde die einzelnen abgerundeten Blastomeren in die Furche zweier angrenzender, dabei etwas auseinanderweichender Blastomeren eingezwängt zeigen.

Ausgangsphase des Schemas ist das zweikernige 2-Zellenstadium (1). Zwei Möglichkeiten für die beiden folgenden Teilungen sind die parallele Stellung der Furchungsspindeln (2) und die gekreuzte Stellung (3). Eine parallele Spindelstellung konnte nicht

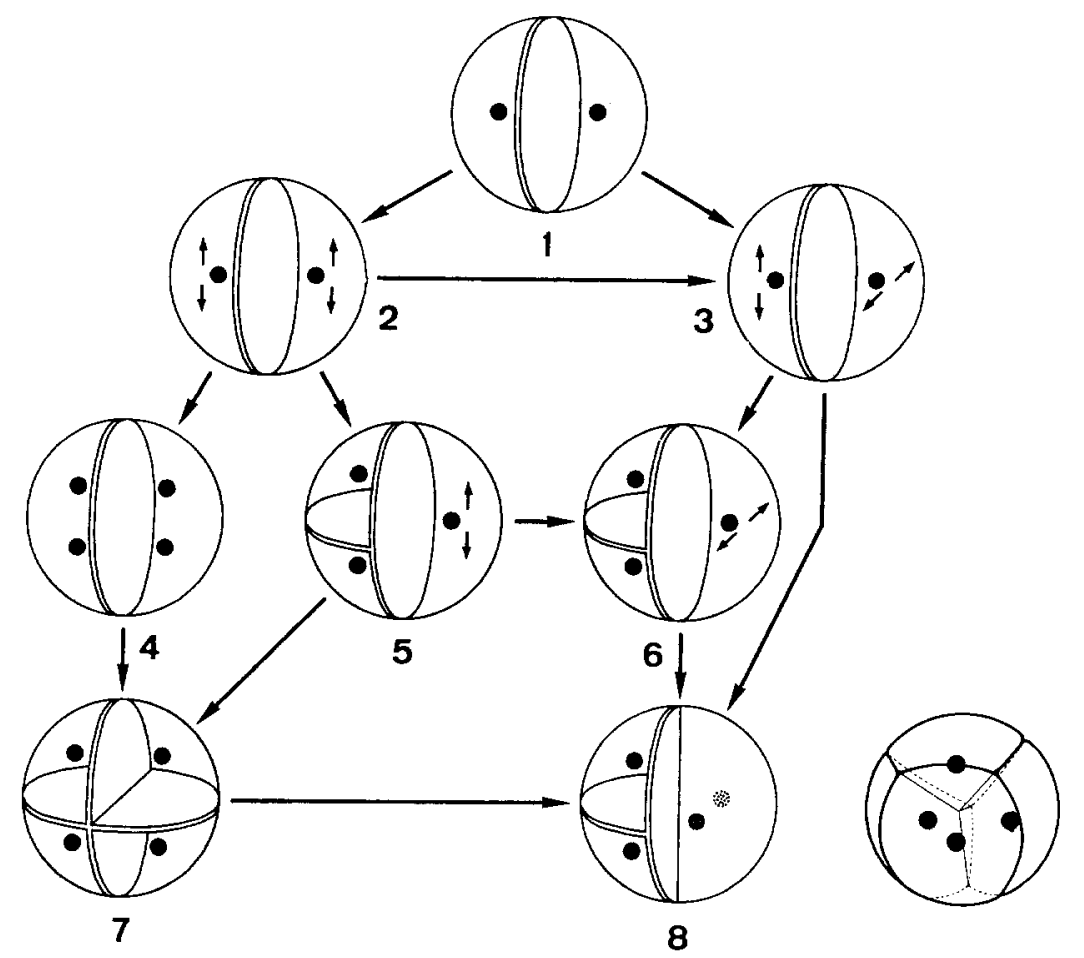

Abb. 24: Schema der möglichen Spindelstellungen und Blastomeren-Anordnungen während der ersten beiden Furchungsteilungen. Waagerechte Pfeile bedeuten Blastomerdrehungen gegeneinander (nähere Erläuterungen im Text)

beobachtet werden. Daß sie jedoch vorkommt, zeigt das vierkernige 2-Zellenstadium (4). Die eingezeichnete Möglichkeit einer Drehung beider Blastomeren um $90^{\circ}$ gegeneinander ist nicht wahrscheinlich $(2 \rightarrow 3)$. Teilen sich die Blastomeren von Phase 2 bzw. 3 synchron, so resultiert daraus direkt das vierkenige 4-Zellenstadium; je nach der Ausgangslage ergibt dies eine parallele (7) oder eine gekreuzte Stellung (8) der Kerne bzw. Blastomeren. Phase 4 ist ein beobachteter Ubergang von. Phase 2 zu Phase 7 . Ein entsprechendes Stadium darf als Übergangsphase von Phase 3 nach Phase 8 ebenfalls erwartet werden, wurde aber nicht gefunden und fehlt daher im Schema. Eine Verlagerung der Blastomeren der Phase 7 zu einer sekundären Kreuzstellung ähnlich der von Phase 8 ist wahrscheinlich. Verlaufen die zweiten Furchungsteilungen nicht synchron, ergeben sich Stadien mit drei Blastomeren und 3 bzw. 4 Kernen. Je nach Ausgangslage 
(2 bzw. 3) resultieren daraus die Phasen 5 bzw. 6; die entsprechenden 4-Kernstadien sind im Schema nicht besonders aufgeführt. Eine Drehung der noch ungeteilten Blastomeren in die „Lücke“ zwischen die beiden schon gebildeten Tochterblastomeren ist zu vermuten $(5 \rightarrow 6)$. Letztlich führen aber beide Stadien wieder zur Phase 8 .
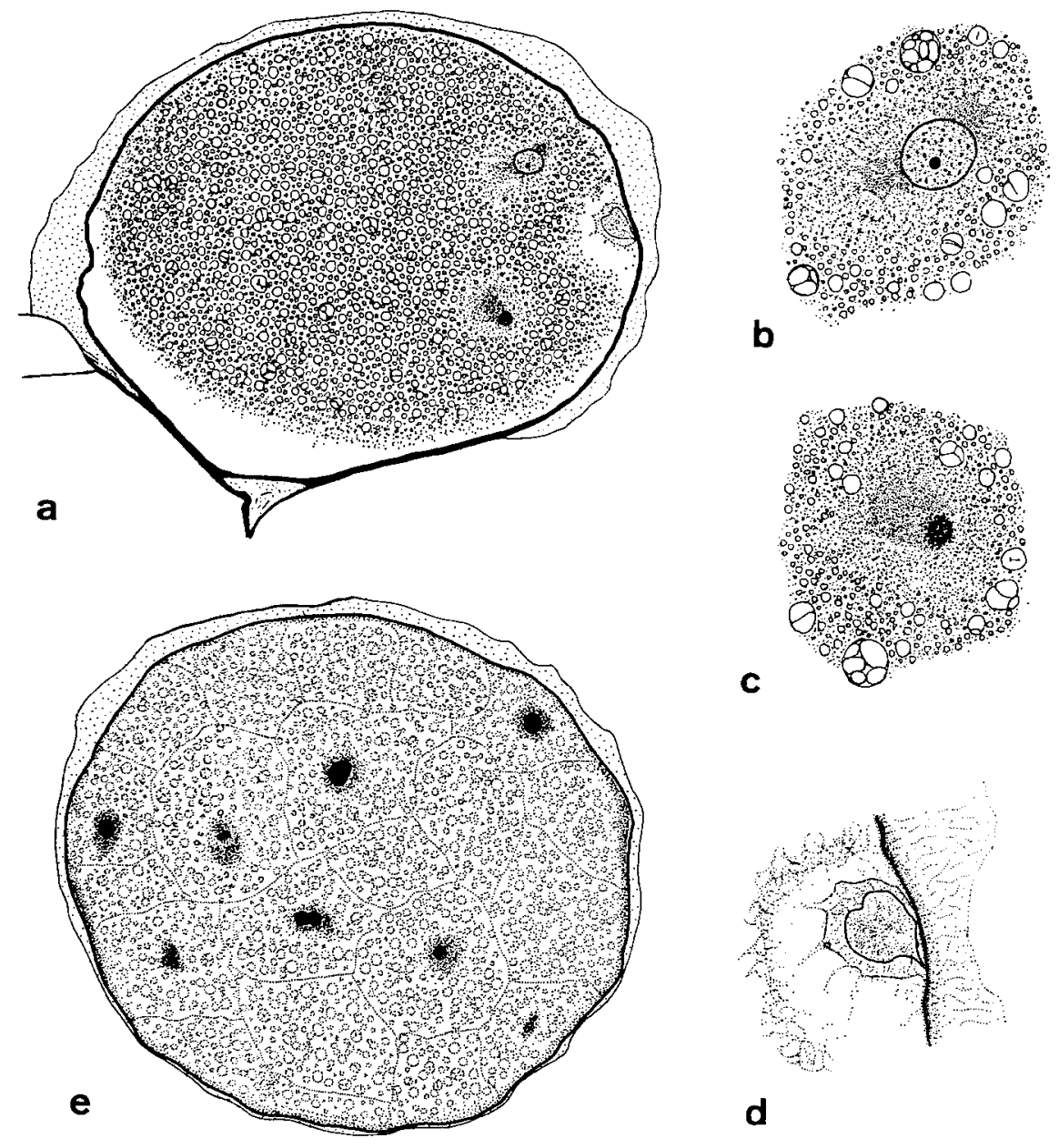

Abb. 25: a Am Gonophor angeheftete, befruchtete Eizelle mit männlichem und weiblichem Vorkern (380:1). b weiblicher, $c$ männlicher Vorkern. $d$ Vermutlicher Rest des Richtungskörpers (860:1). e Morula um das 64-Zellen-Stadium (400:1)

Die Blastomeren lösen sich leicht voneinander und sind damit auch leicht gegeneinander verschiebbar, so daß eine Verlagerung aus räumlichen Gründen zwangsläufig erfolgen kann. Nach NyHolm (1943) ist eine „spiralige“ Anordnung offenbar für die Arten vorteilhaft, deren Blastomeren groß sind und sich bei Totalfurchung leicht voneinander lösen. Eine ähnliche Anordnung der Blastomeren im 4-Zellenstadium (wie 
auf Abb. 24 rechts unten) zeigt die Totalfurchung zahlreicher und verschiedener Tierarten (SIEWING 1969). Sie wird als „Pseudospiralfurchung" bezeichnet.

Von der Befruchtung bis zum äußerlich sichtbaren 2-Zellenstadium vergehen etwa 21/2 Stunden. Die Dauer der nächst folgenden Teilungen liegt zwischen 80 und $90 \mathrm{Mi}-$ nuten. Vom 16-Zellenstadium ab sind äußerlich keine Zellgrenzen mehr am lebenden bzw. fixierten Ei zu erkennen, so daß nur noch Schnitte einen Aufschluß über den weiteren Furchungsablauf geben können. Abbildung 25e zeigt einen Schnitt etwa eines 64-Zellenstadiums, demzufolge die Blastomeren isodiametrisch sind. Die Furchungsspindeln bilden sich im peripheren und inneren Keimbereich zunächst ohne bevorzugte Richtungen aus. Lassen sich anfangs im Umkreis der Kerne noch deutliche Plasmahöfe erkennen, so vermindern sich diese später zu kaum noch erkennbaren Resten. Eine Furchungshöhle tritt nie auf. Der Keim hat sich zu einer soliden „Furchungs-Morula" entwickelt, deren Blastomeren keine besonderen Differenzierungen aufweisen.

\section{Späte Furchung und Keimblätterbildung}

Furchung und Keimblätterentwicklung gehen kontinuierlich ineinander über. Die Zeitspanne, in der die Ektoderm-Ablösung erfolgt, variiert daher. Dies kann vor allem aus der unterschiedlichen Blastomerenzahl medianer Schnitte durch die entsprechenden Stadien geschlossen werden. Die im Keim peripher liegenden Zellen beginnen sich im Schnittbild deutlich von den inneren abzuheben (Abb. 26a). Zunächst unterscheiden sie sich von den prospektiven Entodermzellen durch ihre dotterfreie, „dichtgranuläre" Randzone. In der Folge teilen sich die prospektiven Ektodermzellen viel häufiger als die prospektiven Entodermzellen. Da ihre Teilungsspindeln zudem überwiegend paratangential stehen, werden die zukünftigen Ektodermzellen im Vergleich zu denen des Keiminneren schlanker; außerdem nimmt ihre Anzahl pro Raumeinheit rasch zu. Als Ergebnis dieser Sonderung umkleidet nun eine einschichtige, relativ dichte Lage schlanker, hochzylindrischer Zellen die größeren vollständig mit Dotter angefüllten prospektiven Entodermzellen. Oft sind die Zellkerne dieser äußeren Schicht auch noch in gleicher Höhe angeordnet (Abb. 26b).

Der Modus der Keimblätterbildung muß als Morula-Delamination bezeichnet werden; bei letzterer sind die randständigen Zellen auf Grund ihrer Lage zur Bildung des Ektoderms determiniert. Nur dies ist eine im Sinne des Wortes echte Morula-Delamination, bei der von vorneherein die Furchung auf die Herstellung der Morula zielt, also keine Delamination von Tochterzellen ins Innere erfolgt wie bei der BlastulaDelamination. Die kein Randmaterial enthaltenden Zellen im Keiminneren werden zum prospektiven Entoderm.

Die Ektoderm-Ablösung ist beendet, wenn eine Mitrellamelle die einschichtige periphere Zellage von den inneren Zellen abgegrenzt hat. Da das prospektive Ektoderm bei der Keimblattablösung das entscheidende Moment darstellt - das Ektoderm ist früher ausdifferenziert und mit seiner Basis bereits geordnet-ist anzunehmen, daß diese Zellen auch die Mittellamelle bilden. Auf vergleichbare Weise wird die Mittellamelle von Eudendrium-Gastrulae gebildet (MERGNER 1957). Im allgemeinen ist jedoch die Mittellamelle ein Produkt beider Körperschichten, und nur in Sonderfällen, wie die 

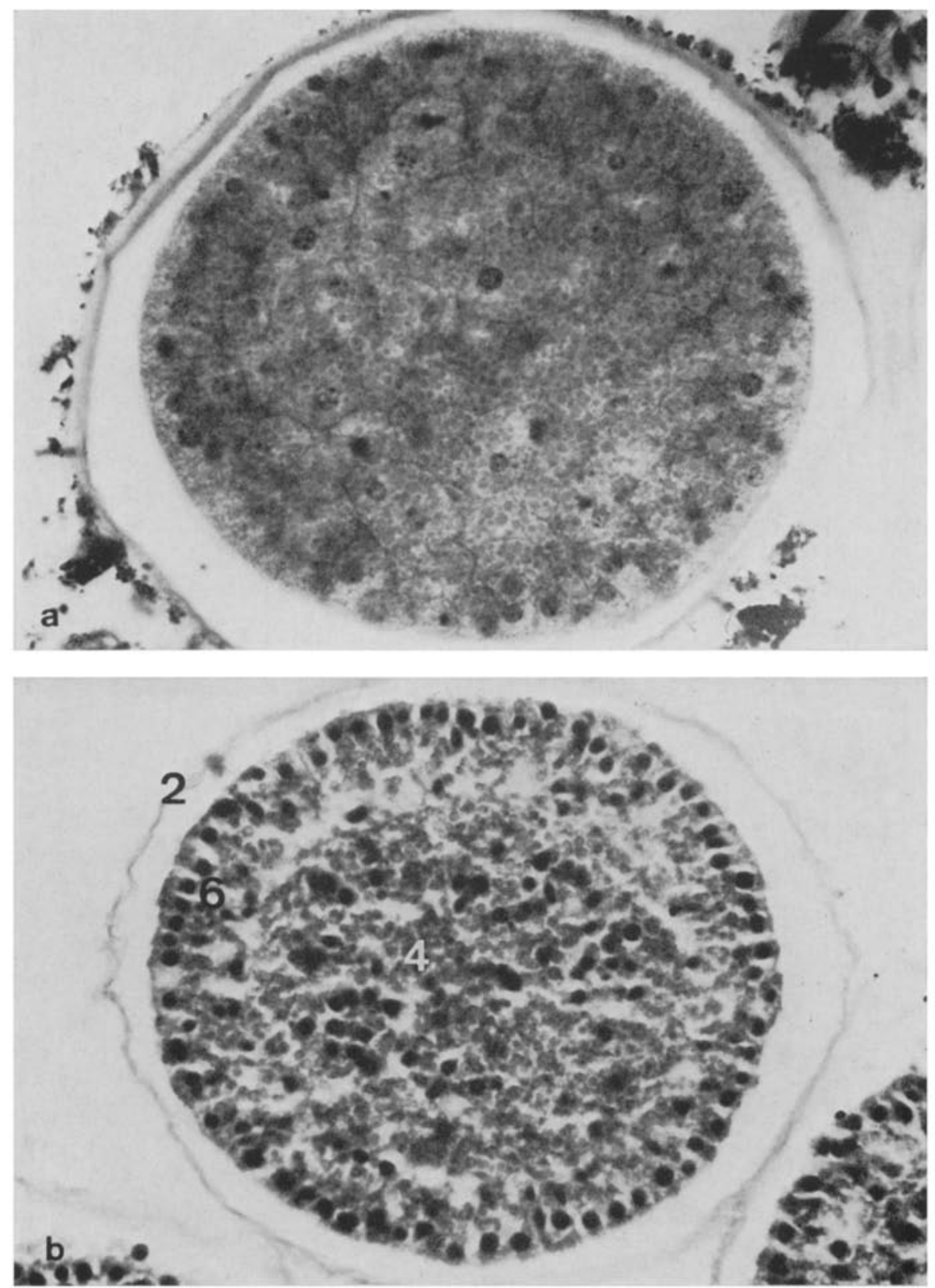

Abb. 26: a Morula vor Beginn der Ektodermablösung (470:1). $b$ Gastrula mit einreihiger Anordnung der ektodermalen Zellkerne; Beginn der Entoderm-Differenzierung (500:1). 2 Perisarc; 4 prospektives Entoderm; 6 Ektoderm 
Abgrenzung der Eier im Gonophor von Eudendrium racemosum (MERGNER 1957) und des Hodenraums bei den männlichen Gonophoren der selben Art (Hanisch 1970), ist allein das Entoderm beteiligt.

Während der Morula-Delamination können Mitosen am besten von allen Phasen beobachtet werden. Dennoch war es ohne besondere Technik unmöglich, die genaue Zahl der sehr kleinen Chromosomen zu ermitteln. 2n dürfte bei 20 bis 26 liegen.

Mit der Bildung der Mittellamelle ist die Keimblättersonderung beendet. Thr Ergebnis stellt eine zweischichtige Gastrula dar, deren Zellen nun ihre Ausdifferenzierung für das freie Planula-Stadium erfahren.

\section{Gastrulastadium bis zur auschlüpfbereiten Planula}

\section{Entoderm}

Bis zum Beginn der Ektoderm-Differenzierung* zeigen die Entodermzellen nur eine geringe Teilungsaktivität und noch keine Spezialisierung. Während der Differenzierung der Gastrula verändert sich jedoch dieses Bild völlig. Vor allem das Kernverhalten weist auf die nun einsetzende Differenzierung hin. Zunächst tritt ein Unterschied im Kerndurchmesser auf, der sich in zwei deutlich erkennbaren Größenklassen darstellt: (1) kleine, etwa 2,5 $\mu \mathrm{m}$ große Kerne und (2) etwa doppelt so große, $5 \mu \mathrm{m}$ im Durchmesser erreichende Kerne.

Letztere sind in ihrem Inhalt homogener und nicht so stark anfärbbar wie die erstgenannten. Im Verlauf der weiteren Differenzierung lassen sich die vorher distinkten Zellgrenzen nur mehr schwer erkennen. Um die kleineren Kerne treten nun färberisch darstellbare Plasmazonen auf, die meist keine Dotterpartikel mehr enthalten. Die Plasmahöfe liegen teils spindelförmig um ihre Kerne, teils zeigen sie zipfelförmige Ausläufer, wodurch der Eindruck amöboider Beweglichkeit der Zellen vermittelt wird (Abb. 27a, 28b). Die zusätzlich auftretende Basophilie läßt den Schluß zu, daß diese Zellen Vorläufer von I-Zellen oder schon I-Zellen selbst sind. Gleichzeitig erscheinen diese, wenn auch vorläufig nur vereinzelt, unmittelbar an der Mittellamelle zwischen den Ektodermzellen. Ihre I-Zellen-Natur wird in der nächsten Differenzierungsstufe des Entoderms noch deutlicher: Zellen mit vergleichbarer Kernstruktur bilden die ersten Cniden, und zwar zunächst nur Stenotele. Eine Trennung der amöboid beweglichen I-Zellen von den Cnidoblasten scheint bereits frühzeitig zu erfolgen. Stets sind erstere mit ihren Plasmafortsätzen deutlich von den Cnidoblasten zu unterscheiden. Vermutlich gehen beide Zellarten auf die gleiche, von den prospektiven Entodermzellen gesonderte Urform zurück. Ahnliche Befunde über die frühzeitige Sonderung der Cnidoblasten im entodermalen Keimbereich hat MERGNER (1957) erstmals an Eudendrium racemosum erhoben.

Im Verlauf der Entoderm-Differenzierung gewinnen die „alstiven “ I-Zellen ein zahlenmäßiges Übergewicht. Vor allem werden verhältnismäßig viele Stenotele gebil-

* Im folgenden wird immer von Entoderm gesprochen, obwohl es tatsächlich „prospektives" Entoderm ist. Entoderm-Epithel im Sinne einer Körperschicht wird erst während der Metamorphose der Planula zum Primärpolypen ausdifferenziert, 
det. Eine unterschiedliche, das heißt in einer bestimmten Weise polare Verteilung der Entodermzellen, insbesondere der Cridoblasten, ist zunächst nicht oder nur andeutungsweise festzustellen. Diese wird erst nach der Einkrümmung des Keimes und damit kurz vor dem Auschlüpfen der Planula erkennbar. Der Dotter bleibt während dieser Vorgänge in seiner lichtmikroskopischen Struktur unverändert. Morphologisch faßbare Abbaustadien wie etwa bei Eudendrium racemosum (MERGNER 1957) treten bei Corydendrium parasiticum nicht auf. Sein Abbau ist nur an der Abnahme der Verteilungsdichte bemerkbar.

Die ausdifferenzierte Gastrula enthält, wie aus den vorstehenden Angaben ersichtlich, zumindest drei unterscheidbare Entoderm-Zelltypen: gewöhnliche Entodermzellen, I-Zellen und Cnidoblasten.

\section{Ektoderm}

Das Ektoderm zeigt gegenüber dem Entoderm weiterhin eine erhöhte Teilungsaktivität. Seine Zellen werden immer schlanker und damit hochzylinderisch. Das Verhältnis von Höhe zu Durchmesser beträgt etwa 4:1 und vergrößert sich immer mehr zugunsten der Höhe. Der runde Kern liegt genau an der Grenze zwischen der dotterfreien Randzone und dem dotterhaltigen Basalteil jeder Zelle. Als einzige Differenzierung ist in Kernnähe oft jeweils eine stark phloxinophile, geknäulte Struktur zu erkennen, die vermutlich dem Golgi-Apparat entspricht. Sie ähnelt dem für die Schleimzellen der mittleren und alten Gastrula von Eudendrium racemosum (MERGNER 1957) beschriebenen Zellbestandteil. Ob es sich aber um eine Organelle prospektiver Drüsenzellen handelt, kann nicht entschieden werden. Erst kurz vor dem Auskriechen der Planula sind nämlich vakuoläre Zellen im Ektoderm nachweisbar, die vermutlich Drüsenzellen darstellen. Im einschichtigen Ektoderm treten unmittelbar an der Mittellamelle Zellen auf, die den I-Zellen des Entoderms gleichen. Ihr stark anfärbbares Cytoplasma zeigt eine unregelmäßige Kontur. Wahrscheinlich sind sie aus dem Entoderm ins Ektoderm eingewandert, ähnlich wie dies für die prospektiven Keimzellen nachgewiesen wurde.

Infolge der raschen Vermehrung der Ektodermzellen sind diese I-Zellen später kaum noch von den übrigen Ektodermzellen zu unterscheiden. Nur in ihrer Kernstruktur lassen sich vereinzelt noch Unterschiede feststellen. Die Ektoderm-Zellkerne sind im Schnittbild nun nicht mehr einreihig angeordnet, sondern innerhalb einer breiten Zone gegeneinander verschoben (Abb. 27a, b). Infolge der engen Lagerung der Zellen zeigen sie länglich-ovale Umrisse; dabei beträgt der große Durchmesser oft das Dreibis Vierfache des kleinen. Ahnlich wie im Entoderm lassen sich auch hier zwei Kerntypen unterscheiden: (1) relativ homogene, ovale Kerne und (2) rundliche, stärker anfärbbare Kerne.

Die ovalen Kerne sind im Ektoderm gegenüber den stärker kondensierten weit in der Uberzahl und gehören vermutlich den I-Zellen an. Vereinzelt sind nun auch schon Cnidoblasten im Ektoderm nachweisbar, die zum Teil bereits gut ausgebildete Stenotelen aufweisen. Sie sind ohne Zweifel aus dem Entoderm ausgewandert.

Im Verlauf der fortschreitenden Differenzierung wächst das Ektodẹrm an einer 

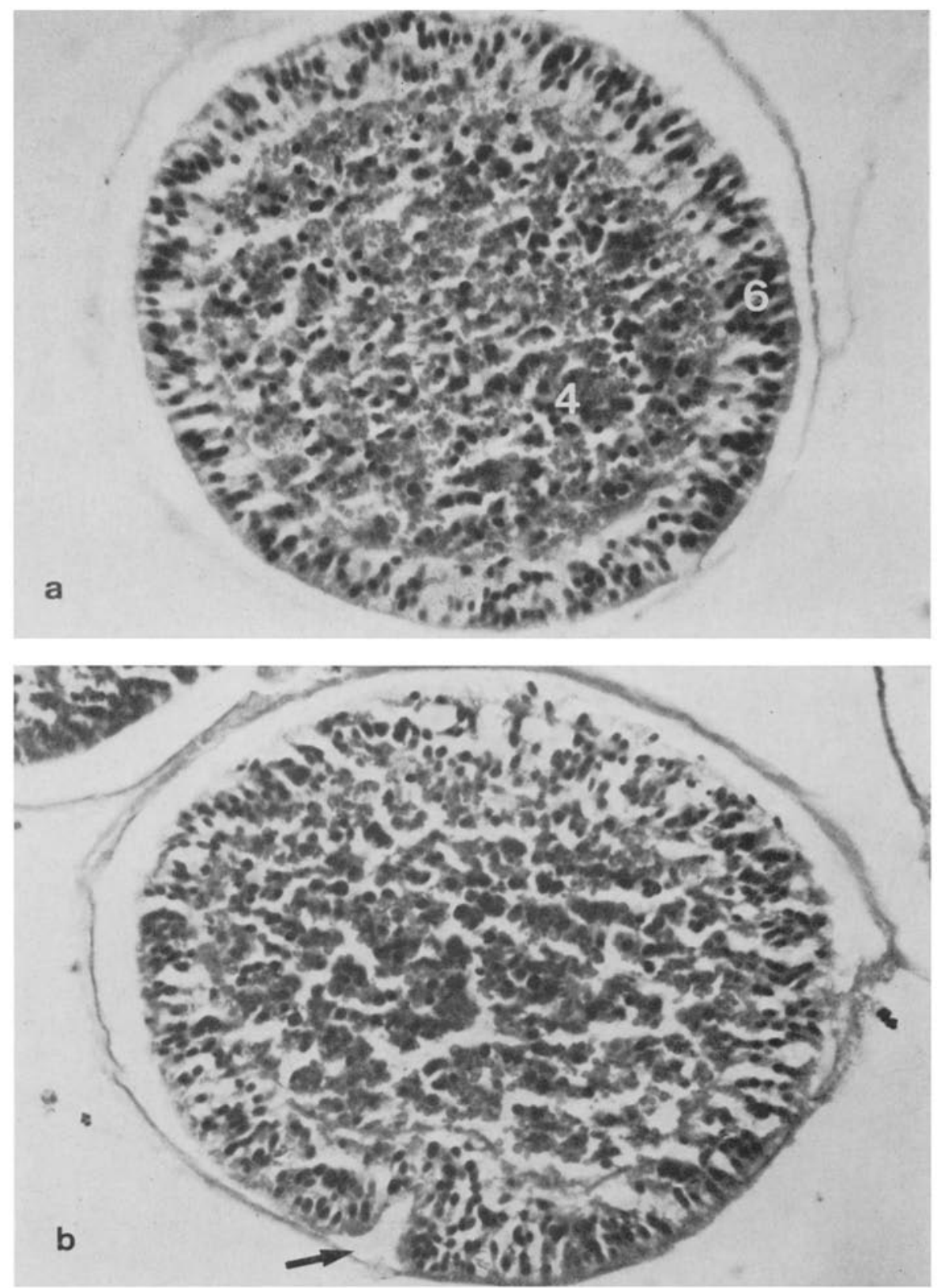

Abb. 27: a Gastrula mit mehrreihiger Anordnung der Kerne im Ektoderm; der Dotter ist auf das prospektive Entoderm beschränkt (460:1). $b$ Beginn der Einbuchtung des Ektoderms (Pfeil) $(480: 1) .4$ Entoderm; 6 Ektoderm 

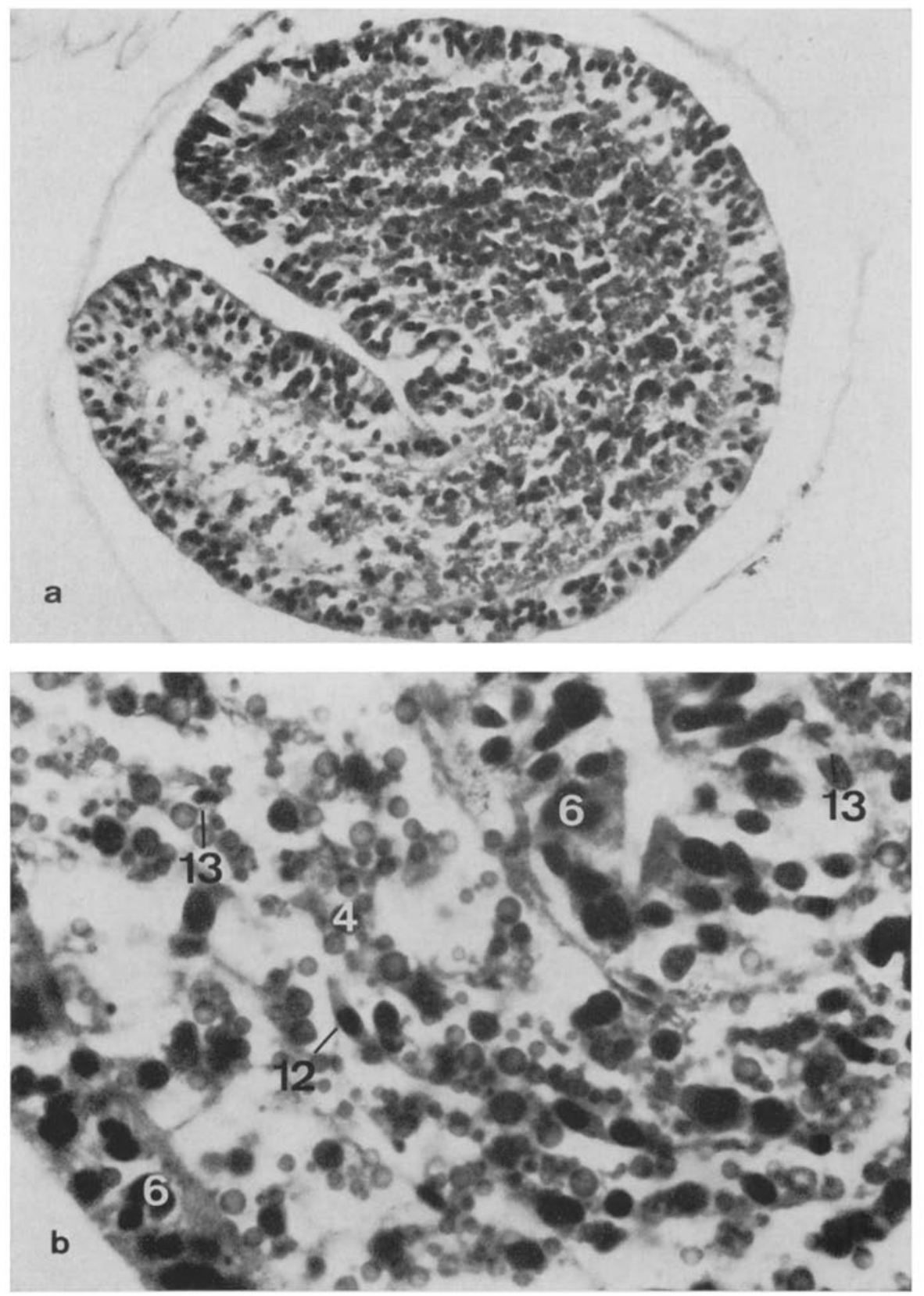

Abb. 28: a Gekrümmte Planula in ihrer Embryonalhülle vor dem Ausschlüpfen. Polare Anordnung der Zellen und des Dotters im Entoderm (460:1). $b$ Ausschnitt aus dem aboralen Ende einer ausschlüpfbereiten Planula (1200:1). 4 Entoderm; 6 Ektoderm; 12 I-Zelle; 13 Cnidoblast 
Seite des Keimes stärker. Die Folge dessen ist eine Einbuchtung in das Entoderm, die $\mathrm{zu}$ einem der Länge nach eingekrümmten Keim führt (Abb. 27b, 28a). Auf Grund der fehlenden Kenntnis über die Ausrichtung der animal-vegetativen Keimachse läßt sich keine Beziehung zwischen dieser und der Einkrümmungsebene finden. Während der Einkrümmung erfolgt eine deutliche Verlagerung des Dotters und vor allem der Cnidoblasten in Richtung auf ein Keimende. Die ausdifferenzierte Gastrula zeigt dadurch eine Körperlängsachse, die vermutlich mit der späteren Planula-Achse identisch ist. Die Gastrula ist nun zur ausschlüpfbereiten Planula geworden.

\section{Auskriechen der Planula und Metamorphose in den Primärpolyp}

Die Embryonalentwicklung ist beendet, wenn die Planula ihre Embryonalhülle verläßt und frei umherschwimmt. Die Hülle wird an einer Stelle von der Planula durchbrochen. $\mathrm{Ob}$ dies ein rein mechanischer Vorgang ist, muß bezweifelt werden, da die Offnung stets auf einen eng umschriebenen Bereich der Perisarc-Hülle begrenzt bleibt. Zu denken wäre an eine lytische Substanz der Ektodermzellen des zuerst austretenden Teils der Planula. Diese könnte das Perisarc lokal ähnlich auflösen, wie es junge, durchbrechende Knospen bei Eudendrium racemosum vollzichen (MerGNER 1957). Die Planula schiebt sich durch die entstandene Offnung, indem sie sich abwechselnd streckt und kontrahiert. Im gestreckten Zustand vollführt dabei der bereits ins freie Wasser ragende Teil langsame, pendelnde Bewegungen. Nach etwa zwei Stunden ist die Planula frei und fällt, zumindest bei Zuchtversuchen, nahezu kugelförmig kontrahiert, zu Boden. Erst nach 1 bis 2 Stunden der Bewegungslosigkeit streckt sie sich und schwimmt mit schraubiger Drehung um ihre Längsachse davon. Die schwimmende Planula ist etwa 1,4 $\mathrm{mm}$ lang und 0,1 mm dick. Bei chemischen Reizen, wie etwa bei Zugabe von $\mathrm{MgCl}_{2}$ zur Betäubung, kann sie sich stark zusammenziehen und ähnelt dann einem Regentropfen, rotiert aber weiter.

Schon nach 24 Stunden können sich die Planulae festsetzen, um in die Metamorphose zum Primärpolypen einzutreten, wie es ähnlich schon Neprr (1917) beobachtet und gezeichnet hat. Meist dauert das freie Leben der Planulae in den Zuchtgefäßen jedoch länger und beträgt zwischen 3 und 5 Tagen. Besonders in Seewasser, das zur Vermeidung von Bakterienwuchs $0,03 \%$ Kanamycin enthält, beginnt die Metamorphose oft erst nach 12 Tagen (vgl, p. 273).

Mehrfach wurde beobachtet, wie sich die positiv phototaktischen Planulae in größeren Mengen an einem Punkt des Zuchtschalenbodens sammeln und hier auch gleichzeitig in Primärpolypen umwandeln. Im Freien würde ein solches Verhalten sofort zu einer faszikulierten Primärkolonie aus zunächst einzelnen Individuen führen. In jeden Fall aber ist eine ausgewachsene Kolonie ein geeignetes Substrat zum Ansetzen der Planulae.

Da die Präparation der Planulae in Neapel für eine ausführliche histologische Untersuchung aus unbekannten Gründen mißlang, muß auf eine eingehende Beschreibung verzichtet werden. Soweit der histologische Bau der Planulae aber untersucht werden konnte, entspricht er weitgehend dem anderer Planulae (KORN 1966, VAN DE VYver 1964, 1967, MergNer 1970). Während der Schwimmphase differenzieren sich 
nun auch im Entoderm Desmonemen, die später ins Ektoderm wandern und dort bald die Stenotelen zahlenmäßig übertreffen. Das Entoderm ist bis zur Metamorphose der Planula solid und vollzieht seine epitheliale Anordnung erst in der PrimärpolypenKnospe und zwar zunächst in der Anlage des Hydranthen.

\section{DISKUSSION}

Nach dem derzeitigen Stand unserer Kenntnis über die Hydroiden ist die Frage nach der Herkunft der Keimzellen, ob aus dem Ekto- oder dem Entoderm, von untergeordneter Bedeutung. Die Auseinandersetzungen hierüber in früheren Arbeiten waren vor allem deshalb von Bedeutung, weil sich hauptsächlich auf die Beantwortung dieser Frage WeIsmanNs Theorie von der Keimbahn bzw. von der Keimstättenverschiebung gründete. Besonders GoetTE (1907) widersprach auf Grund seiner Befunde dieser Theorie, und auch HARGITT (1919) verneinte für die Coelenteraten eine Kontinuität des Keimplasmas. BerRILl \& LiU (1948) weisen darauf hin, daß zur Zeit WeIsManNs ein Verständnis des Zellkerns und seines Inhalts aus genetischer Sicht noch nicht gegeben war. Die Keimzellen wurden nämlich noch als alleinige Träger der Vererbung angesehen. Damit aber erschien eine Kontinuität der Keimbahn in aufeinanderfolgenden Generationen folgerichtig. Die aufsehenerregende Entdeckung der Chromosomendiminuition bei Ascaris durch Boveri führte zudem dazu, die frühzeitige Sonderung der Keimzellen immer mehr unter morphologischen Aspekten zu betrachten. BERRILI \& LIU kommen zu der Ansicht, der Begriff Keimplasma ließe sich nur als reine, philosophisch wertvolle Abstraktion aufrechterhalten. Unabhängig von den großen Verdiensten Weismanns um die Hydroiden-Forschung bliebe aber die Kritik bestehen, "that ideas which WEISMANN arrived at intuitively or by induction from various sources, blinded him in his studies of hydroids and caused him to see imaginiary migrations of visible and invisible germ cells" (BERRILL \& Liv 1948, p. 131).

Heute sind die I-Zellen allgemein als Mutterzellen der Keimzellen anerkannt. Sie sind also geschlechtlich determiniert (WEILER-STOLT 1960, MülLER 1967) und werden durch einen bestimmten physiologischen Zustand des Polypengewebes zur Keimzellenbildung angeregt (WEIL.ER-STOLT 1960, BRIEN 64). BRIEN ist allerdings der Auffassung, $\mathrm{da} ß$ die I-Zellen indifferent sind und auch ihr Geschlecht durch einen sexualphysiologischen Zustand des Somas geprägt wird.

Zieht man die große Potenz der I-Zellen in Betracht, die alle Differenzierungsmöglichkeiten innerhalb des Hydroiden-Gewebes umfaßt, so werden die Bedenken gegen eine frühe Sonderung der Keimzellen noch unterstützt. Besonders die Zuordnung der I-Zellen und damit auch der Keimzellen zu einem bestimmten Keimblatt kann selbstverständlich nur für einen Abschnitt in der Ontogenese einer Art getroffen werden. Bei Corydendrium wie auch bei allen anderen bisher untersuchten Filifera und Corynoidea entstehen sie während der Embryogenese im Entoderm und wandern erst im Zuge der Metamorphose ins Ektoderm (VAN DE VYver 1967, 1968a, b). Nur die Tubularoidea, deren Jugendstadium eine Actinula ist, bilden die I-Zellen direkt im Ektoderm. Allerdings wurde für Tubularia radiata und $T$. venusta eine entodermale Entstehung während der Gastrulation beobachtet (NAGAO 1965). 
WeISManNs Annahme von einer zweimaligen Wanderung der zukünftigen Keimzellen durch die Mittellamelle erscheint zunächst wenig glaubhaft. Sie hat aber letztlich doch, wie am Beispiel von Corydendrium parasiticum nachgewiesen wurde, eine gewisse Bestätigung gefunden; wenn auch nicht im ursprünglichen Sinn seiner Theorie. Potentielle Keimzellen wandern einmal während der Gastrulation aus dem Ento- in das Ektoderm und später zur Zeit der Koloniereifung aus dem Ekto- wieder in das Entoderm. Der Vorwurf gegen WeISMANN (vgl. p. 271) ist daher nur zum Teil berechtigt.

Da die I-Zellen der adulten Hydroidpolypen im allyemeinen nur im Ektoderm vorkommen, erfolgt die Bereitstellung von Embryonalzellen zur Gametenbildung ebenfalls im Ektoderm. Damit ist es durchaus statthaft, wie folgt zu verallgemeinern: Die Keimzellen der Fydroiden sind ektodermaler Herkunft.

Uber die Embryonalentwicklung von Corydendrium parasiticum gibt es, neben wenigen Angaben über den äußeren Verlauf der Metamorphose (NEPPI 1917), nur einige histologische Details von HargitT (1904). Seine Befunde weichen von den in der vorliegenden Arbeit erhobenen darin ab, daß er an der Morula einen syncytialen Aufbau zu erkennen glaubt und später auch keine Differenzierungen des prospektiven Entoderms, z. B. Cnidoblasten findet. Genau das gleiche Versäumnis unterlief HargitT (1904) bei Eudendrium racemosum. Eine Kernvermehrung ohne Herstellung von Zellgrenzen („independent nuclear proliferation") findet mit Sicherheit nicht statt, wenn auch diese im Ento- wie im Ektoderm in der späten Gastrulationsphase kaum noch wahrnehmbar sind. Es ist daher unrichtig, Corydendrium parasiticum als Beispiel dafür anzuführen, daß innerhalb einer Art mehrere Furchungstypen vorkommen können (SIEwINg 1969).

Eine gewisse Beachtung während des Furchungsverlaufes fand immer die Kreuzstellung der ersten vier bzw. acht Blastomeren bei den Coelenteraten (ME'TSCHNrKoff 1886, Morgenstern 1901, Nyholm 1943, Mergner 1957, Bérnard-Boirard 1962, VAN DE Vyver 1964). Die Entstehung dieser Kreuzstellung, wie sie auch bei Corydendrium zustande kommt, beschreibt schon Metschniкoff (1886, p. 38) wie folgt: „Im Allgemeinen läßt sich bemerken, daß je tiefer die Furche zwei brüderliche Blastomeren theilt, diese sich desto intimer mit den benachbarten, also so $\mathrm{zu}$ sagen vetterlichen Blastomeren vereinigen. So entstehen im vierzelligen Furchungsstadium zwei Paar Blastomeren, welche sich zusammen, d. h. paarweise verschieben, wobei ein Paar sich oft um einen rechten Winkel über dem anderen dreht. " Morgenstern beobachtet diese „eigenthümliche kreuzartige Stellung“ auch bei Cordylophora lacustris. Er stellt aber fest, daß diese Stellung nicht durch eine Lageverschiebung nach der Bildung von vier Blastomeren zustande kommt, sondern bereits auf dem 2-Zellenstadium ihre Anlage finden kann. Dies schließt er aus der Spindelstellung in beobachteten 2-Zellenstadien. Ahnlich verhält es sich bei Podocoryne carnea, deren eine Modifikation des Furchungsablaufes („type oblique“) direkt $\mathrm{zu}$ einer Kreuzstellung führt (BÉRnARD-BoIRARD 1962). Daneben kommt als andere Modifikation eine einfache Verlagerung der Blastomeren vor, wie bei Corydendrium oder Hydractinia echinata (VAN DE VYVER 1964). Letztlich ist das Ergebnis der Kreuzstellung doch wohl eine Folge der Verschiebbarkeit der Blastomeren und damit ihre Anpassung an die räumlichen Gegebenheiten.

Eine Bedeutung könnte die Drehung nur dann besitzen, wenn ein animąl-vegetati- 
ver Gradient an eine unverrückbare Struktur des Eies, wie die Kortikalschicht (VAN DE VYver 1964), gebunden ist. Eine derartige Kreuz-(Lücken-)Stellung der Blastomeren in einigen frühen Furchungsstadien (Ratbkea fasciculata, Gonionemus murbachi, weitere Beispiele siehe MERGNER 1970) wird allgemein als „Pseudospiralfurchung“ bezeichnet (Nyноцм 1943), ohne daß durch diesen Terminus eine immerhin mögliche phyletische Beziehung zur echten Spiralfurchung behauptet werden soll. Pseudospiralfurchung kennzeichnet nur die morphologische, dem Beginn einer Spiralfurchung ähnelnde Anordnung der ersten Blastomeren. Allerdings fällt die eigenartige Kreuzstellung der Tochterkerne in der frühen Furchung von Eudendrium racemosum dabei aus dem Rahmen des üblichen, was sicherlich auf die syncytiale Furchungsart zurückzuführen ist (MERGNer 1957).

Eine Gegenüberstellung der Embryonalentwicklung von Corydendrium parasiticum mit den vergleichend-embryologischen Untersuchungen an Hydroiden aus neuerer Zeit (van de Vyver 1964, 1967, 1968a, b, Bérnard-Boirard 1962, Nagao 1965, Bodo \& Boutllon 1968) zeigt keine besonderen Unterschiede. Aus einer soliden Morula, die zu keiner Zeit eine Furchungshöhle aufweist, entsteht durch Morula-Delamination eine typische Sterrogastrula, die bis zur Metamorphose der Planula beibehalten wird. Eine polare Differenzierung des Keimes wird erst kurz vor dem Schlüpfen der Planula durch die unterschiedliche Verteilung des Dotters, der I-Zellen und der Cnidoblasten sichtbar. Im aboralen Pol der Corydendrium-Planula sind ähnlich wie bei Cordylophora lacustris (VAN DE VYVER 1967) nur wenige dieser Zellelemente zu finden. Der aborale (animale?) Pol ist außerdem, wie bei den bisher untersuchten Planulae, durch ektodermale Drüsenzellen, die der späteren Anheftung dienen, gekennzeichnet (KORN 1966). Er entspricht dem Vorderpol der schwimmenden Planula, genau wie bei allen andern beweglichen Cnidarier-Stadien (außer Planula auch: Frustel, Saccula, Actinula und Meduse) (ReIsinger 1957).

Für die Anheftung und damit für die Auslösung und Beginn der Planula-Metamorphose scheinen Bakterien ein entscheidender Faktor zu sein (MüLLER 1969). 98 \% der Planula von Hydractinia echinata treten in die Metamorphose ein, wenn sie in direkten Kontakt mit bestimmten marinen Bakterien kommen. Das auslösende Agens scheint eine hitzelabile Oberflächenstruktur der Bakterien zu sein, die gegen Ende der Log.-Phase auftritt. MüLler hält es für wahrscheinlich, daß die Bakterien den Planulae ein geeignetes Substrat zur Ansiedlung anzeigen. Daß daneben noch eine Thigmotaxis eine Rolle spielen könnte, zeigen die Untersuchungen von WILLIAMS (1965) und KorN (1966). Doch ist zu vermuten, daß auch in diesen Fällen Bakterien eine Primärfunktion besitzen. So haben sich KorN zufolge Planulae von Clava squamata erst nach 13 Tagen vollzählig festgesetzt (erste Anheftung nach 8 Tagen). VAN DE VYVER (1967) gibt für dieselbe Art einen Zeitpunkt von etwa 6 Tagen an. Dieser Unterschied könnte eine Erklärung darin finden, daß KoRN die Aufzucht in bei $80^{\circ} \mathrm{C}$ sterilisiertem Seewasser vornahm.

Eine zunächst nicht erklärbare Metamorphose-Verzögerung wurde auch bei Corydendrium beobachtet. In Schalen mit fertilen Kolonien, die nicht speziell zur PlanulaZucht dienten, metamorphosierten die Planulae schon nach einem Tag. Wurden Planulae zur Weiterzucht isoliert gehalten, verlängerte sich der Zeitraum auf 3 bis 5 Tage. In Schalen, die zur Vermeidung von Bakterienwuchs $0,03 \%$ des Antibiotikums Kana- 
mycin enthielten, begann die Anheftung dagegen erst nach etwa 12 Tagen. Es ist daher anzunehmen, daß die aus den Zuchtversuchen erhaltenen Zeiten (3-5 Tage) ebenfalls nicht den natürlichen Verhältnissen entsprechen, da in Gegenwart von Kolonien, die mit Detritus und damit von Bakterien bedeckt waren, die Metamorphose bedeutend früher beginnt. Zeitangaben über Entwicklungsphasen, die unter Laboratoriumsbedingungen erhalten werden, sind aus diesem Grunde mit Vorbehalt zu werten.

Eine besondere Mikrovilli-Struktur des Planula-Ektoderms, die vermutich auf der Kanamycin-Zugabe zum Seewasser beruht, wird an anderer Stelle beschrieben (GLÄTZER 1970).

\section{ZUSAMMENFASSUNG}

1. Die Ei- und Embryonalentwicklung des Hydroiden Corydendrium parasiticum (L.) wurde unter besonderer Berücksichtigung der feinstrukturellen Veränderungen der Oocyten während der Vitellogenese untersucht.

2. Corydendrium bildet als Stockform Monopodien mit Endpolypen und subterminaler Knospung. Das Perisarc beziehungsweise Periderm der Kolonie wird durch mit Toluidinblau metachromatisch anfärbbare Tröpfchen des Ektoderms gebildet; sie zeigen eine parakristalline Binnenstruktur und entsprechen den unter dem Lichtmikroskop sichtbaren, stark acidophilen Grana. In die Grundsubstanz der Mittellamelle sind Fibrillen mit periodischer Anordnung von Untereinheiten eingelagert. Perforationen in der Mittellamelle sind ein Ergebnis durchtretender Zellausläufer, die vermutlich eine Funktion beim Nahrungsaustausch besitzen.

3. Die Eizellen entstehen diffus in der Keimzone unterhalb eines Hydranthen. Ektodermale I-Zellen wandern nachweislich durch die Mittellamelle und differenzieren sich im Entoderm zu Keimzellen. Nur in diesem sind Prophase-Stadien der Meiose $\mathrm{zu}$ finden. Mit Berechtigung kann jedoch, trotz unterschiedlicher Herkunft der I-Zellen in der Frühentwicklung, von einer ektodermalen Abstammung der HydroidenKeimzellen gesprochen werden.

4. Die Eizellen wandern während der Wachstumsphase auf der Mittellamelle zur Gonophoren-Bildungszone. Die Gonophoren sind Hydranthen-Knospen homolog und vermutlich phyletisch umgewandelte Hydranthen. Frühzeitig in eine Knospenausstülpung einwandernde Oocyten legen deren Entwicklung zum Gonophor fest oder werden durch dessen morphologisch noch nicht sichtbares Blastem angelockt. Die Oocyten werden im Gonophor durch dessen Wachstum passiv mitgenommen und von einem allseitig geschlossenen Follikel-Epithel umgeben. Nach der Endphase ihres Wachstums vollziehen sie im Gonophor ihre beiden Reifeteilungen, wobei sie vorher ihr Follikel-Epithel durchbrochen haben. Die Befruchtung erfolgt entweder im Gonophor noch während des Auskriechens oder kurz danach an dessen Spitze im Freien.

5. Die feinstrukturellen Veränderungen während der Vitellogenese werden entsprechend den Entwicklungsstadien der Eizelle beschrieben. Komplexdotter, Lipidtropfen und Glykogen stehen am Ende der Vitellogenese. Zur Bildung des mengenmäßig überwiegenden Reservematerials der befruchtungsfähigen Eizelle, des Komplexdot- 
ters, werden zahlreiche Zwischenstufen geformt. Von besonderem Interesse sind dabei die Cytosomen, die auf Grund ihrer engen Beziehung zum granulären endoplasmatischen Retikulum und wegen ihrer parakristallinen Innenstruktur den „microbodies“ der Leber und Niere ähneln. In dem aus vier unterscheidbaren Komponenten bestehenden Komplexdotter sind vergleichbare parakristalline Strukturen nachweisbar, die den histochemisch im Dotter anderer Tierarten schon nachgewiesenen Enzymen entsprechen könnten. Neben einem Versuch, den Ablauf der Vitellogenese zu rekonstruieren, wird auf den Bau der Kernmembran und des Nucleolus näher eingegangen.

6. Die Furchung beginnt schon während des Ausstoßens der Eier aus dem Gonophor, an das sich diese unter Abscheidung einer Embryonalhülle festkleben. Die Furchung ist total und äqual. Die Kreuzstellung der vier ersten Blastomeren ist die Folge ihrer Verschiebbarkeit gegeneinander. Eine Furchungshöhle tritt nicht auf. Die Keimblätterbildung erfolgt als Morula-Delamination. I-Zellen und Cnidoblasten werden im prospektiven Entoderm gebildet und wandern frühzeitig in das durch eine besondere Rindenzone gekennzeichnete Ektoderm. Eine polare Differenzierung tritt erst kurz vor dem Ausschlïpfen der Planula hervor.

7. Die Planulae behalten bis zu ihrer Umwandlung in Primärpolypen ein solides Entoderm, wie es einem Sterrogastrula-Stadium entspricht. Schon nach einem Tag können sie metamorphosieren. Der bis zu 12 Tagen verzögerte Beginn der Metamorphose in Laborversuchen beruht wahrscheinlich auf der Abwesenheit bestimmter Bakterien.

Danksagungen. Herrn Prof. Dr. H. Mergner, Bochum, bin ich für die Anregung zu dieser Untersuchung, den Herren Prof, Dr. K.-J. Götrrng, Gießen, und Dr. D. ZissLeR, Freiburg, für die Einführung in die elektronenmikroskopischen Arbeitsweisen zu Dank verpflichtet. Großen Dank für stete Förderung und wertvolle Ratschläge schulde ich zudem Herrn Prof. Dr. Dr. h. c. W. E. Ankex, Gießen. Ferner danke ich dem Deutschen Akademischen Austauschdienst für die Ermöglichung eines dreimonatigen Studienaufenthaltes an der Stazione Zoologica Napoli und meiner Frau für die umfangreichen Fotoarbeiten. Die Arbeiten wurden am I. Zoologischen Institut der Justus-Liebig-Universität Gießen mit Geräten durchgeführt, die die Deutsche Forschungsgemeinschaft zur Verfügung gestellt hat.

\section{ZITIERTE LITERATUR}

Abeison, H. T. \& SMIth, G. H., 1970. Nuclear pores: the pore-annulus relationship in thin section. J. Ultrastruct. Res. 31, 558-588.

Agrawal, H. O., KenT, J. W. \& Mackay, D. M., 1965. Rotation technique in electron microscopy of viruses. Science, N. Y. 148, 638-640.

Aliman, G. J., 1871. A monograph of the gymnoblastic or tubularian hydroids. Hardwicke, London, $474 \mathrm{pp}$.

Anderson, E., 1968. Oocyte differentiation in the sea urchin, Arbacia punctulata, with particular reference to the origin of cortical granules and their participation in the cortical reaction. J. Cell Biol. 37, 514-539.

Balinski, B. I. \& Devis, R. J., 1963. Origin and differentiation of cytoplasmic structures in the oocyte of Xenopus laevis. Acta Embryol. Morph. exp. 6, 55-108. 
Beams, H. W., 1964. Cellular membranes in oogenesis. In: Cellular membranes in development. Ed. by M. Locke. Academic Press, New York, 382 pp.

- \& KesseL, R. G., 1962. Intracisternal granules of the endoplasmic reticulum in the crayfish oocyte. J. Cell Biol. 13, 158-162.

- - 1963. Electron microscope studies on developing crayfish oocytes with special reference to the origin of york. J. Cell Biol. 18, 621-649.

- - 1968. The Golgi apparatus: structure and function. Int. Rev. Cytol. 23, 209-276.

- \& SEKHON, S. S., 1966. Electron microscope studies on the oocyte of the fresh-water mussel (Anodonta) with special reference to the stalk and mechanism of yolk deposition. J. Morph. $119,477-502$.

BÉNARd-Botrard, J., 1962. Développement embryonnaire de Podocoryne carnea SARs de Roscoff. Cah. Biol, mar. 3, 137-155.

Berrill, N. J. \& Liu, C. K., 1948. Germplasm, Weismann, and Hydrozoa. Q. Rev. Biol. 23, $124-132$.

BrER, K., 1967. Oogenese, das Wachstum von Riesenzellen. Narurwissenschaften 54, 189-195.

Bodo, F. \& Boulnton, J., 1968. Étude histologique du développement embryonnaire de quelques hydroméduses de Roscoff: Phialidium hemisphaericum (L.), Obelia sp. Peron \& Lesueur, Sarsia eximia (Allman), Podocoryne carnea (Sars), Gonionemus vertens Agassiz. Cah. Biol. mar. 9, 69-104.

BONNER, J. T., 1955. A note concerning the distribution of polysaccharides in the early development of the hydromedusa Pbialidium gregarium. Biol. Bull. mar. biol. Lab., Woods Hole 108, 18-20.

Bouillon, J., 1963. Les cellules glandulaires des Hydroides. C. r. hebd. Séanc. Acad. Sci., Paris 256, $1617-1620$.

- 1966. Les cellules glandulaires des Hydroides et Hydroméduses. Leur structure et la nature de leurs sécrétions. Cah. Biol. mar. 7, 157-205.

- 1968. Introduction to coelenterates. In: Chemical Zoology. Ed. by M. Florkin \& B. T. SCHEER. Academic Press, New York 2, 1-639.

Brien, P., 1964. Substance gamétiques. Substance sexuelle chez les hydres d'eau douce. Annls Endocr. 25, 30-35.

Burnett, A. L., Davis, L. E. \& Ruffing, F. E., 1966. A histological and ultrastructural study of germinal differentiation of interstitial cells arising from gland cells in Hydra viridis. J. Morph. 120, 1-8.

Callahan, W. P. \& Horner, J. A., 1964. The use of vanadium as a stain for electron microscopy. J. Cell Biol. 20, 350-356.

Callan, H. G. \& Tomlin, S. G., 1950. Experimental studies on amphibian oocyte nuclei. I. Investigation of the structure of the nuclear membrane by means of the electron microscope. Proc. R. Soc. (B) 137, 367-378.

Cavolini, F., 1785. Memorie per servire alla storia de'Polipi marini. Napoli, 279 pp.

Dalton, A. J. \& Haguenau, F. (Ed.), 1968. The nucleus. Academic Press, New York, 244 pp.

Daniels, E. W., MCNiff, J. M. \& Ekberg, D. R., 1969. Nucleopores of the giant amoeba, Pelomyxa carolinensis. Z. Zellforsch. mikrosk. Anat. 98, 357-363.

Dapples, C. C. \& King, R. C., 1970. The development of the ovarian nurse cell of Drosophila melanogaster. Z. Zellforsch. mikrosk. Anat. 103, 34-47.

Davis, L. E. \& Haynes, J. F., 1968. An ultrastructural examination of the mesogloea of Hydra. Z. Zellforsch. mikrosk. Anat. 92, 149-158.

Driesch, H., 1890. Tektonische Studien an Hydroidpolypen II. Plumularia und Aglaophenia. Die Tubulariiden. Nebst allgemeine Erörterungen über die Natur tierischer Stöcke. Jena. Z. Naturw. 24;657-688.

DrolleR, M. J. \& Roth, T. F., 1966. An electron microscope study of yolk formation during oogenesis in Lebistes reticulatus guppyi. J. Cell Biol. 28, 209-232.

Duspiva, F., 1969. Molekularbiologische Aspekte der Entwicklungsphysiologie. Naturw. Rdsch., Stuttg. 22, 191-202.

Emanuelsson, H., 1969. Electronmicroscopical observations on yolk and yolk formation in Ophryotrocha labronica LA GRECA \& BACCI. Z. Zellforsch. mikrosk. Anat. 95, 19-36. 
Essner, E. \& Novikoff, A. B., 1962. Cytological studies on two functional hepatomonas. Interrelations of endoplasmatic reticulum, Golgi-apparatus and lysosomes. J. Cell Biol. 15, 289-312.

FAwCETT, D. W., 1966. An atlas of fine structure: the cell. Saunders Company, Philadelphia, $448 \mathrm{pp}$.

FeLdiferR, C. M., 1962. The nuclear annuli as pathways for nucleo-cytoplasmic exchanges. J. Cell Biol. 14, 65-72.

Florendo, N. T., 1969. Ribosome substructure in intact mouse liver cells. J. Cell Biol, 44, 335-339.

Franke, W. W., 1970. On the university of nuclear pore complex structure. Z. Zellforsch. mikrosk. Anat. 105, 405-429.

- \& SCHeER, U., 1970a. The ultrastructure of the nuclear envelope of amphibian oocytes: a reinvestigation. I. The mature oocyte. J. Ultrastruct. Res. 30, 288-316.

- - 1970b. The ultrastructure of the nuclear envelope of amphibian oocytes: a reinvestigation. II. The immature oocyte and dynamic aspects. J. Ultrastruct. Res. 30, 317-327.

Ghosh, S., Letrré, R. \& GHOSH, I., 1969. On the composition of the nucleolus with special reference to its filamentous structure. Z. Zellforsch. mikrosk. Anat. 101, 254-265.

Glätzer, K. H., 1970. Der Membranbesatz der Mikrovilli einer Planula von Corydendrium parasiticum (L.) (Hydrozoa, Athecata). Cytobiologie 2, 408-412.

Godman, G. C. \& Porter, K. R., 1960. Chondriogenesis, studies with the electron microscope. J. biophys. biochem. Cytol. 8, 719-760.

Goette, A., 1907. Vergleichende Entwicklungsgeschichte der Geschlechtsindividuen der Hydropolypen. Z. wiss. Zool. 87, 1-836.

GöTtING, K.-J., 1966. Zur Feinstruktur der Oocyten mariner Teleosteer. Helgoländer wiss. Meeresunters. 13, 118-170.

Grimstone, A. V., 1959. Cytoplasmic membranes and the nuclear membrane in the flagellate Trichonympha. J. biophys. biochem. Cytol. 6, 369-378.

HamanN, O., 1882. Der Organismus der Hydroidpolypen. Jena. Z. Naturw. 15, 437-544.

Hanisch, J., 1970. Die Blastostyl- und Spermienentwicklung von Eudendrium racemosum Cavolini. Zool. Jb. (Anat. Ontogenie Tiere) 87, 1-62.

HargitT, C. W., 1904. Notes on some Hydromedusae from the Bay of Naples. Mitt. zool. Stn Neapel 16, 553-585.

HargitT, G. T., 1919. The germ cells of Coelenterates. VI. General considerations, discussion, conclusions. J. Morph. 33, 1-59.

$\mathrm{H}_{\mathrm{AY}}$, E. D., 1968. Structure and function of the nucleolus in developing cells. In: The nucleus. Ed. by A. Dalton \& F. Haguenau. Academic Press, New York, 244 pp.

Hess, A., 1961. The fine structure of cells in hydra. In: The biology of Hydra and some other coelenterates. Ed. by H, M. Lenhoff \& W. F. Loomis. Univ. Miami Press, Coral Gables, Florida, $467 \mathrm{pp}$.

Hinsch, G. W. \& Cone, M. V., 1969. Ultrastructural observations of vitellogenesis in the spider crab, Libinia emarginata L. J. Cell Biol. 40, 336-342.

Horstmann, E. \& KNoop, A., 1957. Zur Struktur des Nukleolus und des Kerns. Z. Zellforsch. mikrosk. Anat. 46, 100-107.

Hruban, Z. \& Rechcigl, M., 1969. Microbodies and related particles. Morphology, Biochemistry, and Physiology. Academic Press, New York, 296 pp.

Hst, W. W., 1962. An electron microscopic study on the origin of yolk in the oocytes of the ascidian Boltenia villosa Stimpson. Cellule 62, 147-155.

HumphreYs, W. J., 1967. The fine structure of cortical granules in eggs and gastrulae of Mytilus edulis. J. Ultrastruct. Res. 17, 314-326.

JoNes, K. W., 1965. The role of the nucleolus in the formation of ribosomes. J. Ultrastruct. Res. 13, 257-262.

Kawaguti, S. \& Ogasawara, Y., 1967. Electron microscopy on the ovary of an anthomedusa, Spirocodon saltatrix. Biol. J. Okayama Univ. 13, 115-129.

KesseL, R. G., 1966. An electron microscope study of nuclear-cytoplasmic exchange in oocytes of Ciona intestinalis. J. Ultrastruct. Res. 15, 181-196. 
- 1968a. Electron microscope studies on developing oocytes of a coelenterate medusa with special reference to vitellogenesis. J. Morph. 126, 211-248.

- 1968b. An electron microscope study of differentiation and growth in oocytes of Ophioderma panamensis. J. Ultrastruct. Res. 22, 63-89.

- 1968c. Mechanisms of protein yolk synthesis and deposition in crustacean oocytes. Z. Zellforsch. mikrosk. Anat. 89, 17-38.

- 1969. Fine structure of the pore-annulus complex in the nuclear envelope and annulate lamellae of germ cells. Z. Zellforsch. mikrosk. Anat. 94, 441-453.

- \& BeAms, H. W., 1968. Intranucleolar membranes and nuclear-cytoplasmic exchange in young crayfish oocytes. J. Cell Biol. 39, 735-741.

KIrChNER, H. A., 1935. Die Bedeutung der interstitiellen Zellen für den Aufbau von Cordylophora caspia. Z. Zellforsch. mikrosk. Anat. 22, 1-19.

KORN, H., 1966. Zur ontogenetischen Differenzierung der Coelenteratengewebe (Polyp-Stadium) unter besonderer Berücksichtigung des Nervensystems. Z. Morph. OKol. Tiere 57, 1-118.

KüHN, A., 1910. Die Entwricklung der Geschlechtsindividuen der Hydromedusen. Studien zur Ontogenese und Phylogenese der Hydroiden. II. Zool. Jb. (Anat. Ontogenie Tiere) 30, 43-147.

- 1914. Entwicklungsgeschichte und Verwandtschaftsbeziehungen der Hydrozoen. 1. Teil: Die Hydroiden. Ergebn. Fortschr. Zool. 4, 1-284.

Markham, R., FreY, S. \& Hilis, B. J., 1963. Methods for the enhancement of image detail and accentuation of structure in electron microscopy. Virology 20, 88-102.

Mepham, R. H. \& Lane, G. R., 1969. Nucleopores and polyribosome formation. Nature, Lond. 221, 288-289.

Mergner, H., 1957. Die Ei- und Embryonalentwicklung von Eudendrium racemosum CavoLINI. Zool. Jb. (Anat. Ontogenie Tiere) 76, 63-164.

-- 1970. The egg of Cnidaria. In: Textbook of the experimental embryology of marine and freshwater invertebrates. Ed. by G. Reverberi. North-Holland Pubi. Comp., Amsterdam.

Merriam, R. W., 1969. Movement of cytoplasmic proteins into nuclei induced to enlarge and intiate DNA or RNA synthesis. J. Cell Sci. 5, 333-349.

Metschnikoff, E., 1886. Embryologische Studien an Medusen. Hölder, Wien, 159 pp.

Millard, N. A. H., 1959. Hydrozoa from the coasts of Natal and Portugues East Africa. Part II: Gymnoblastea. Ann. S. Afr. Mus. 44, 297-313.

Millonig, G., Bosco, M. \& Giambertone, L., 1968. Fine structure analysis of oogenesis in sea urchins. J. exp. Zool. 169, 293-314.

Morns, P. B., 1968. The structure and function of the synaptinemal complex in Lilium longiflorum sporocytes. Chromosoma 23, 418-451.

MonNERon, A. \& BERNAARD, W., 1969. Fine structural organization of the interphase nucleus in some mammalian cells. J. Ultrastruct. Res. 27, 266-288.

Morgenstern, P., 1901. Untersuchungen iiber die Entwicklung von Cordylophora lacustris All. Z. wiss. Zool. 70, 567-591.

MüLLER, W., 1964. Experimentelle Untersuchungen über Stockentwicklung, Polypendifferenzierung und Sexualchimären bei Hydractinia echinata. Wilhelm Roux Arch. EntwMech. Org. $155,181-268$.

- 1967. Differenzierungspotenzen und Geschlechtsstabilität der I-Zellen von Hydractinia echinata. Wilhelm Roux Arch. EntwMech. Org. 159, 412-432.

- 1969. Auslösung der Metamorphose durch Bakterien bei den Larven von Hydractinia echinata. Zool. Jb. (Anat. Ontogenie Tiere) 86, 84-95.

NAGAO, Z., 1965. Studies on the development of Tubularia radiata and Tubularia venusta (Hydrozoa). Publs Akkeshi mar. biol. Stn 15, 9-35.

Nepri, V., 1917. Osservazioni sui polipi idroidi del golfo di Napoli. Pubbl. Staz. zool. Napoli $2,42-48$.

Nørrevang, A., 1965. Oogenesis in Priapulpus caudatus Lamarck. An electron microscopical study correlated with light microscopical and histochemical findings. Vidensk. Meddr dansk naturh. Foren. 128, 1-83.

- 1968. Electron microscopic morphology of oogenesis. Int. Rev. Cytol. 23, 113-186. 
Nyноц, K.-G., 1943. Zur Entwicklung und Entwicklungsbiologie der Ceriantharien und Aktinien. Zool. Bidr. Upps. 22, 89-248.

Palade, G. A., 1952. A study of fixation for electron microscopy. J. exp. Med. 95, 285-297.

PARKs, H. F., 1962. Unusual formation of ergastoplasm in parotid acinous cell of mice. J. Cell Biol. 14, 221-235.

Pasteel.s, J. J., 1969. L'activité phosphatasique acide, étudiée au microscope électronique dans des oeufs de Barnea candida (Mollusque, Bivalve). Archs Biol., Paris 80, 1-17.

- \& Harven, E. DE, 1963. Etude au microscope électronique du cytoplasme de l'oeuf vierge et fécondé de Barnea candida (Mollusque bivalve). Archs Biol, Paris 74, 415-437.

Patrizi, G. \& Poger, M., 1967. The ultrastructure of the nuclear periphery. The Zonula Nucleum Limitans. J. Ultrastruct. Res. 17, 127-136.

Raven, C. P., 1961. Oogenesis: The storage of developmental information. Pergamon Press, London, $274 \mathrm{pp}$.

Rebrun, L. I., 1963. Induced amoeboid movement in eggs of the surf-clam Spisula solidissima. Expl Cell Res. 29, 593-602.

REISINGER, E., 1957. Zur Entwicklungsgeschichte und Entwicklungsmechanik von Craspedacusta (Hydrozoa, Limnotrachylina). Z. Morph. Okol. Tiere 45, 656-698.

Romers, B., 1948. Mikroskopische Technik. 15. Aufl. Leibnitz, München, 695 pp.

Sabatini, D. D., Bensch, K. \& Barrnett, R. J., 1963. Cytochemistry and electron microscopy. The preservation of cellular ultrastructure and enzymatic activity by aldehyd fixation. J. Cell Biol. 17, 19-58.

SCHARRER, B. \& WURZELMANN, S., 1969. Ultrastructural study on nuclear-cytoplasmic relationships in oocytes of the african lungfish, Protopterus aethiopicus. I. Nucleolo-Cytoplasmic pathways. Z. Zellforsch. mikrosk. Anat. 96, 325-343.

SснміDт, W., 1962. Licht- und elektronenmikroskopische Untersuchungen über die intrazelluläre Verarbeitung von Vitalfarbstoffen. Z. Zellforsch. mikrosk. Anat. 58, 573-637.

SHERIDAN, W. F. \& BARRNETT, R. J., 1969. Cytochemical studies on chromosome ultrastructure. J. Ultrastruct. Res. 27, 216-229.

Shostax, S., Patel, N. G. \& Burnett, A. L., 1965. The role of mesoglea in mass cell movement in Hydra. Devl Biol. 12, 434-450.

- \& Globus, M., 1966. Migration of epithelio-muscular cells in Hydra. Nature, Lond. 210, 218-219.

SiEwING, R., 1969. Lehrbuch der vergleichenden Entwicklungsgeschichte der Tiere. Parey, Hamburg, $531 \mathrm{pp}$.

Sotelo, J. R. \& Wettstein, R., 1964. Electron microscope study on meiosis. The sex chromosome in spermatocytes, spermatids and oocytes of Gryllus argentinus. Chromosoma 15, $389-415$.

STAGNI, A. \& Lucci, M. L., 1964. Ulteriori osservazioni al microscopio elettronico sulla ovogenesi di Chlorohydra viridissima. Rc. Ist. Sci. Univ. Camerino 5, 290-297.

Tessenow, W., 1960. Untersuchungen an den interstitiellen Zellen von Pelmatobydra oligactis Pallas und Cordylophora caspia Pallas unter besonderer Berücksichtigung spezifischer Färbemethoden. Protoplasma 51, 563-594.

Thomas, C., 1969. Etude cytodhimique, au microscope électronique, des structures à ARN et du glycogen dans le cytoplasma des oocytes de Xenopus laevis. J. Embryol. exp. Morph. 21, 165-176.

TrINCr, G., 1907. Studii sull'oocite dei Celenterati durante il periodo di crescita. Archo ital. Anat. Embriol. 5, 533-666.

Venable, J. H. \& Coggeshalr, R., 1965. A simplified lead citrate stain for use in electron microscopy. J. Cell Biol. 25, 407-408.

VYver, G. VAN DE, 1964. Etude du développement d'Hydractinia echinata (Flem.). Cah. Biol. mar. 5, 295-310.

- 1967. Etude du développement embryonnaire des hydraires athécates (gymnoblastiques) à gonophores. I. Formes à planula. Archs Biol., Paris 78, 451-518.

- 1968a. Etude du développement embryonnaire des hydraires athécates (gymnoblastiques) à gonophores. II. Formes à actinulas. Archs Biol., Paris 79, 327-363. 
- 1968b. Etude du développement embryonnaire des hydraires athécates (gymnoblastiques) à gonophores. III. Discussion et conclusions générales. Archs Biol., Paris 79, 365-379.

WARTENBERG, H., 1962. Elektronenmikroskopische und histochemische Studien über die Oogenese der Amphibieneizelle. Z. Zellforsch. mikrosk. Anat. 58, 427-486.

Watson, M. L., 1959. Further observations on the nuclear envelope of the animal cell. J. biophys. biochem. Cytol. 6, 147-156.

WEAKLEY, B. S., 1969. Granular cytoplasmic bodies in oocytes of the golden Hamster during the post-natal period. Z. Zellforsch. mikrosk. Anat. 101, 394-400.

WeIter-Stolt, B., 1960. Uber die Bedeutung der interstitiellen Zellen für die Entwicklung und Fortpflanzung mariner Hydroiden. Wilhelm Roux Arch. EntwMech. Org. 152, 398-454.

WeIsmann, A, 1883. Die Entstehung der Sexualzellen bei den Fydromedusen. Fischer, Jena, $308 \mathrm{pp}$.

WeRNER, B., 1965. Die Nesselkapseln der Cnidaria, mit besonderer Berücksichtigung der Hydroida. I. Klassifikation und Bedeutung für die Systematik und Evolution. Helgoländer wiss. Meeresunters. 12, 1-39.

Wessing, A., 1965. Der Nucleolus und seine Beziehungen zu den Ribosomen des Cytoplasmas. Eine Untersuchung an den Malpighischen Gefäßen von Drosopbila melanogaster. Z. Zellforsch. mikrosk. Anat. 65, 445-480.

WIENER, J., SPIRO, D. \& LOEWENSTEIN, W. R., 1965. Ultrastructure and permeability of nuclear membranes. J. Cell Biol. 27, 107-117.

WILLIAMs, G. B., 1965. Observations on the behaviour of the planulae larvae of Clava squamata. J. mar. biol. Ass. U.K. 45, 257-273.

Wohlfarth-Bottermann, K. E, 1957. Die Kontrastierung tierischer Zellen und Gewebe im Rahmen ihrer elektronenmikroskopischen Untersuchung an ultradünnen Schnitten. Naturwissenschaften 44, 287-288.

WORLEY, L. G. \& MORIbER, L. G., 1961. The origin of protein yolk from the Golgi apparatus in gastropods. Ann. N. Y. Acad. Sci. 23, 352-356.

Anschrift des Autors: Dr. K. H. GläTZER

Institut für Allgemeine Biologie

4 Düsseldorf

Mettmanner Straße 16-18

Bundesrepublik Deutschland 